University of Rhode Island

DigitalCommons@URI

Open Access Master's Theses

1991

\title{
DEVELOPMENT OF A NEW NON-SURGICAL PERFUSION TECHNIQUE TO EVALUATE NASAL DRUG DELIVERY
}

Polireddy Dondeti

University of Rhode Island

Follow this and additional works at: https://digitalcommons.uri.edu/theses

\section{Recommended Citation}

Dondeti, Polireddy, "DEVELOPMENT OF A NEW NON-SURGICAL PERFUSION TECHNIQUE TO EVALUATE NASAL DRUG DELIVERY" (1991). Open Access Master's Theses. Paper 244.

https://digitalcommons.uri.edu/theses/244

This Thesis is brought to you for free and open access by DigitalCommons@URI. It has been accepted for inclusion in Open Access Master's Theses by an authorized administrator of DigitalCommons@URI. For more information, please contact digitalcommons-group@uri.edu. 
DEVELOPMENT OF A NEW NON-SURGICAL PERFUSION TECHNIQUE TO EVALUATE NASAL DRUG DELIVERY

BY

POLIREDDY DONDETI

A THESIS SUBMITTED IN PARTIAL FULFILLMENT OF THE

REQUIREMENTS FOR THE DEGREE OF

MASTER OF SCIENCE

IN

PHARMACEUTICAL SCIENCES

UNIVERSITY OF RHODE ISLAND

1991 


\section{MASTER OF SCIENCE THESIS \\ $\mathrm{OF}$}

POLIREDDY DONDETI

\section{APPROVED:}

Thesis Committee Major Professor
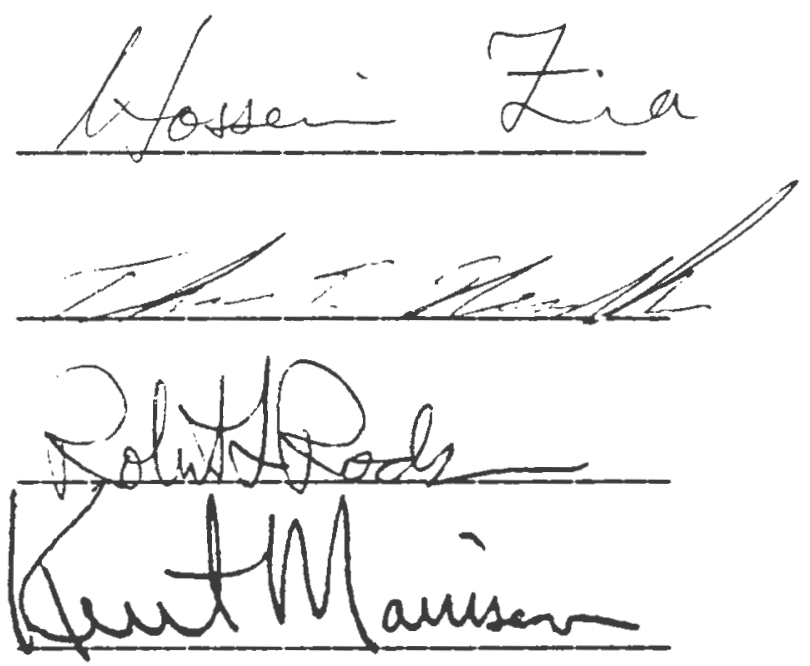

DEAN OF THE GRADUATE SCHOOL

UNIVERSITY OF RHODE ISLAND

1991 


\begin{abstract}
Peptide and protein drugs are increasingly becoming popular with the advances in biotechnology. Although these compounds are highly potent and display superior pharmacological profiles, there are various barriers to their systemic delivery. Most of these barriers are related to the properties of the proteins and peptides which include high large molecular size, susceptibility to proteolytic breakdown, tendency to undergo aggregation, adsorption, and denaturation.

Most of these molecules are delivered by parenteral administration due to the low bioavailability obtained by the oral route. Among the noninvasive routes of drug administration, the nasal route seems to be a potential alternative to parenteral administration of peptides and proteins.

When compared to other noninvasive routes of administration, the nasal route offers some advantages; including avoidance of the first pass effect and enzymatic degradation in the gastrointestinal tract; and a relatively large surface area and adequate blood flow, resulting in rapid absorption of drugs through the nasal mucosa and providing high patient compliance. However, there are certain factors which could interfere with the nasal absorption of drugs such as the method and technique of administration, and pathological conditions of the nasal cavity.
\end{abstract}

Surprisingly few animal models have been developed and characterized to study the basic physicochemical nature of the nasal mucosal absorption processes, in spite of the great potential offered 
by the intranasal route for systemic drug administration. Most of the mechanistic and absorption screening studies have been performed using the in situ rat nasal recirculation technique. The small nasal cavity and nostrils of the rat restrict the evaluation of nasal formulations such as metered sprays, powders and microspheres. The acute nature of the perfusion technique limits its application to small laboratory animals for economic reasons. Hence there is a need to develop chronic perfusion techniques in large laboratory animals which can give better representation of the nasal mucosal absorption processes in human beings.

The objectives of this study were: (I) to develop and establish a non-surgical perfusion technique for use with large laboratory animals, (2) to compare the new technique with the existing techniques, (3) to identify the study conditions to establish and validate the animal model, (4) to evaluate various nasal formulations and/or modes of administration such as sprays, microparticles using the same animal model and compare with the results obtained from perfusion studies.

Insulin was chosen as model polypeptide and the rabbit was selected as an animal model. A randomized crossover study design was used for evaluating the insulin effect in five rabbits. The absorption of insulin was measured by determining blood glucose levels using Accu chek II and ChemStrip bG strips.

A new non-surgical perfusion technique was developed and established using the rabbit. The study conditions identified in establishing the animal model include: the angle at which the rabbit head is placed, the perfusion rate, the volume of the perfusate, the 
amount of the enhancer present in the perfusate and the $\mathrm{pH}$ of the solution. Spray formulations containing different levels of insulin $(1.25,2.5,5$ and $10 \mathrm{U} / \mathrm{kg})$ and sodium taurocholate $(1 \%)$ were evaluated in the same animal model. The nasal sprays resulted in an immediate reduction of glucose levels. A maximum hypoglycemic effect was observed approximately 60 minutes after administration. As the insulin dose was increased, there was an increase in glucose reduction. A polyacrylic acid gel formulation containing insulin loaded microparticles $(10 \mathrm{U} / \mathrm{kg})$ resulted in a hypoglycemic effect, but the overall effect was less when compared to the spray formulations and s.c injection.

The apparent bioavailability was determined relative to subcutaneously injected insulin $(0.25 \mathrm{U} / \mathrm{kg})$. This bioavailability increased for spray formulations as the dose of insulin was decreased. A maximum bioavailability of $18.8 \%$ was observed for the $1.25 \mathrm{U} / \mathrm{kg}$ spray and the minimum bioavailability (1.58\%) was observed for the perfusion study carried out using the new technique. 


\section{ACKNOWLEDGMENT}

I would like to express my sincere thanks to my major professor, Dr. H. Zia, for his constant support, encouragement and guidance provided to me throughout this project.

I am grateful to Dr. T. E. Needham for his scientific guidance and financial support, without which this project wouldn't have been a success. I also would like to express my sincere appreciation to Dr. Lawing for his kind help and patience in analyzing the data. I am also grateful to Dean Luzzi for providing me the financial support during the initial stage of my graduate study at U. R. I. I would like to thank Dr. Rodgers and Dr. Kislalioglu for their kind support. I also would like to express my appreciation to the other faculty members and fellow graduate students of pharmaceutics department for their assistance provided to me during my graduate study.

Finally, I want to dedicate this work to my parents and brother for being a constant source of encouragement and inspiration to achieve my goals in life. 


\section{TABLE OF CONTENTS}

ABSTRACT

ACKNOWLEDGMENT V V

TABLE OF CONTENTS vi

LIST OF TABLES viii

LIST OF FIGURES $\quad$ x

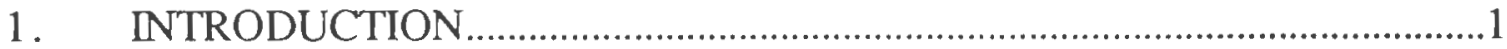

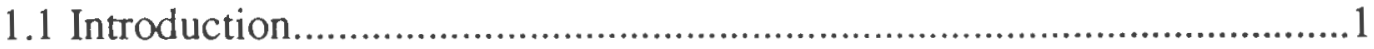

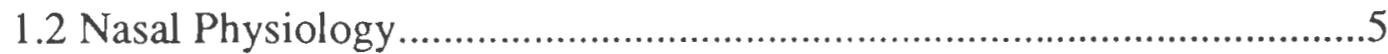

1.3 Deposition and Clearance of Drugs from the Nasal Cavity.....9

1.4 Nasal Absorption of Peptides and Proteins : Physicochemical

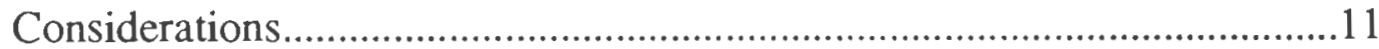

1.4.1 Effect of Molecular Weight............................................11

1.4.2 Effect of Drug Concentration...........................................13

1.4.3 Effect of Dose Volume..........................................................14

1.5 Pharmacokinetics of Nasal Absorption.......................................14

1.5.1 Factors Affecting Nasal Absorption.............................15

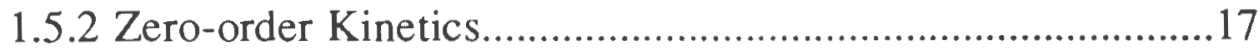

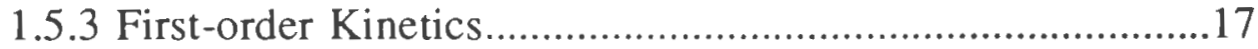

1.6 Enhancement of Nasal Absorption of Peptides and

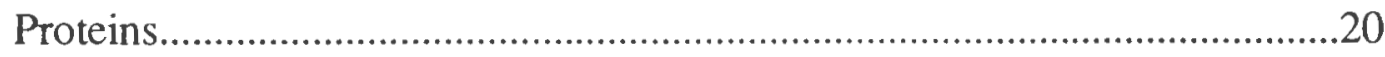

1.6.1 Structural Modifications....................................................20

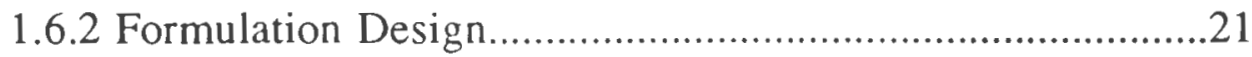

1.6.3 Membrane Permeation Enhancers..............................22

1.6.3.1 Surface Active Agents.....................................22

1.6.3.2 Bioadhesive Agents.............................................30 
1.6.3.3 Vasoactive Agents.

1.7 Animal Models Used in Evaluation of Absorption Studies

1.7.1 In Situ Absorption Models................................................33

1.7.2 In vivo Absorption Models.............................................35

1.7.3 Physical and Chemical Parameters to be Considered in Evaluation of Absorption Models........................................38

1.7.3.1 Effect of Perfusion Rate......................................38

1.7.3.2 Effect of Perfusate Volume..............................38

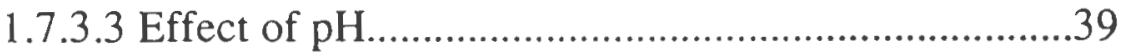

1.7.3.4 Effect of Partition Coefficient...........................39

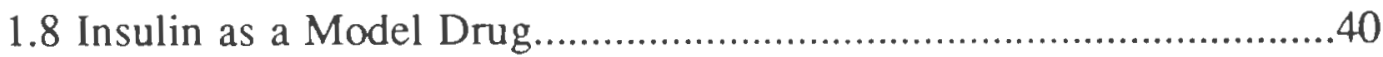

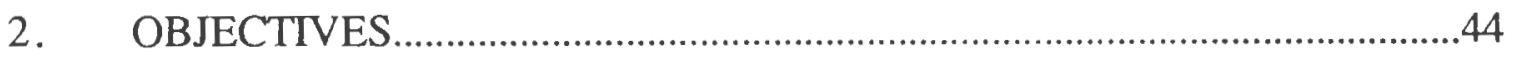

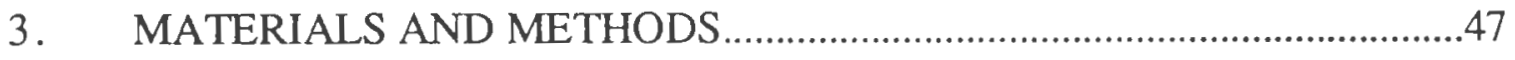

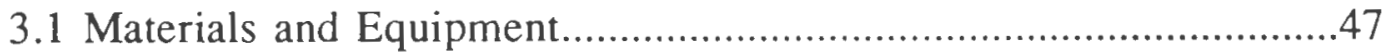

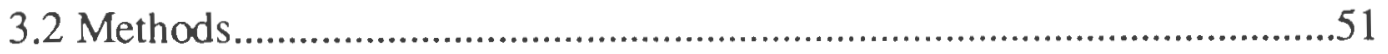

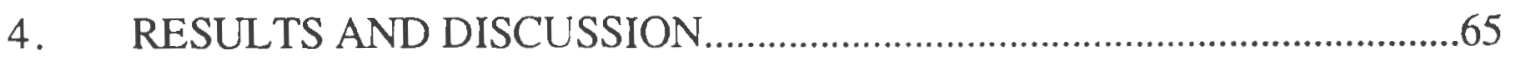

4.1 Perfusion by Old Non-Surgical Technique.................................65

4.2 Perfusion by New Non-Surgical technique...............................66

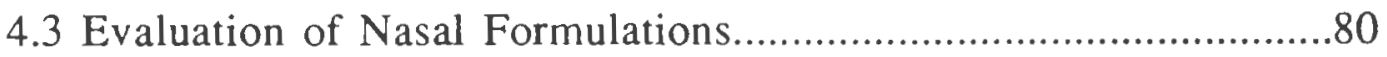

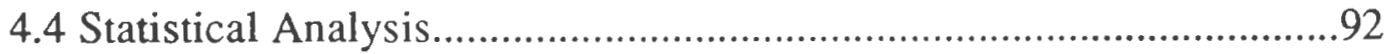

4.5 Comparison of Apparent Pharmacokinetic Parameters.......95

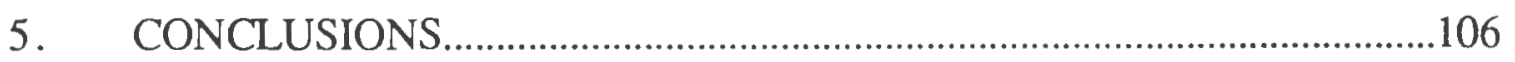

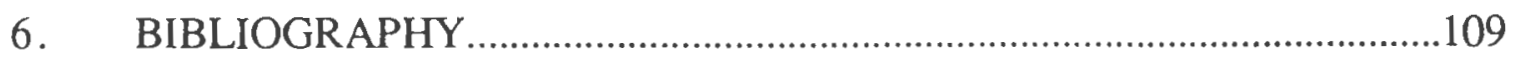




\section{LIST OF TABLES}

Table 1. Intranasal Bioavailabilities of Peptides and Proteins.....12

Table 2. Blood Glucose Assay using Accu chek II to Determine Accuracy and Precision

Table 3. Reproducibility of The Blood Glucose Assay using Accu Chek II.

Table 4. Glucose Concentration as a Function of Time During Perfusion of Insulin and Buffer Solutions Using The Old Non-Surgical Perfusion Technique

Table 5. Glucose Concentration as a Function of Time During Perfusion of Insulin and Buffer Solutions Using The New Non-Surgical Perfusion Technique. .71

Table 6. Effect of Anesthetics on Blood Glucose Levels in

Rabbits .76

Table 7. Effect of Spray Formulations on Rabbit Blood Glucose Levels

Table 8. Observed Blood Glucose Levels After Administration of Insulin by Subcutaneous Route .88

Table 9. Observed Blood Glucose Levels After Administration of Insulin by Nasal Route

Table 10. Comparison of Mean Deviations in Blood Glucose Levels Compared to Controls After Administration of Insulin Spray Formulations

Table 11. Comparison of Mean Deviations in Blood Glucose Levels Compared to Controls After Administration of Insulin....99 
Table 12. Comparison of Apparent Pharmacokinetic Parameters After Intranasal Administration of Various Insulin

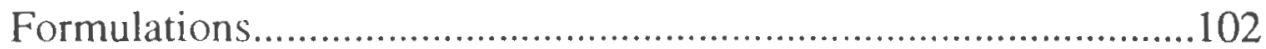




\section{LIST OF FIGURES}

Figure 1. Transmission Electron Microscopic View of Various Cell Types in the Nasal Epithelium..................................................

Figure 2. The Experimental Setup for In Situ Perfusion Technique in Rat Model

Figure 3. The Top and Side Views of the Cannulation Arrangement for In Vivo Studies in Rat Model..............................................36

Figure 4. The Structure of Insulin Molecule.

Figure 5. Schematic Diagram of the Rabbit Non-Surgical Perfusion Technique (old).

Figure 6. The Experimental Setup for New Non-Surgical Perfusion Technique in Rabbits

Figure 7. Correlation of Accuracy and Precision of the Accu Chek Glucose Assay. .60

Figure 8. Blood Glucose as a Function of Time During Perfusion of Insulin and Buffer Solutions Using The Old Non-Surgical Technique.

Figure 9. Blood Glucose as a Function of Time During Perfusion of Insulin and Buffer Solutions Using The New Non-Surgical Technique.

Figure 10. Comparison of the Reduction in Blood Glucose Using The Two Non-Surgical Perfusion Techniques.

Figure 11. Effect of Anesthetics on Rabbit Blood Glucose Levels.......78

Figure 12. Blood Glucose Concentration as a Function of Time After Administration of Insulin Nasal Spray 
Figure 13. Comparison of Blood Glucose Levels After Administration of Insulin by Nasal Spray and Perfusion Methods.............86

Figure 14. Comparison of Blood Glucose Reduction After Administration of Insulin by Nasal and S.C. Routes.........89

Figure 15. Comparison of Blood Glucose Reduction After Administration of Insulin by Spray and Gel Formulation.

Figure 16. Comparison of Mean Deviations in Glucose Levels From Controls After Administration of Insulin Nasal Spray......98

Figure 17. Comparison of Mean Deviations in Glucose Levels From Controls After Administration of Insulin...........................101

Figure 18. Dose vs AUC for Insulin Spray Formulations in Rabbits 


\section{INTRODUCTION}

\subsection{Introduction}

With the advance of biotechnology, peptide and protein drugs are increasingly becoming popular. However, the technology for the manufacture of proteins and peptides has advanced far more rapidly than our ability to deliver these molecules in appropriate and convenient dosage forms (Sandow et al., 1987; Davis, 1989). Although these types of compounds are highly potent and display superior pharmacological profiles, there are a number of barriers to their systemic delivery. Most of these barriers are related to the properties that set proteins and peptides apart from the vast majority of drug substances in use today. These properties include molecular size, susceptibility to proteolytic break down, rapid plasma clearance, peculiar dose response curves, immunogenicity, biocompatibility and the tendency to undergo aggregation, adsorption, and denaturation (Lee, 1988; Borchardt et al., 1989).

The oral route is the most popular means of delivering drug molecules as it provides many advantages. However, proteins and peptides when given orally produce very poor bioavailability, because these molecules are easily degraded by proteolytic enzymes in the gastrointestinal tract and are generally not well absorbed. Currently, they are mostly delivered by parenteral administration. However, they often have an extremely short biological half-life when administered parenterally and repeated injections are needed. This type of therapeutic regimen is highly risky to administer without close medical supervision. It is often difficult for most 
patients to accept and this leads to reduced usage and a low rate of compliance. The commercial success of protein and peptide drugs will depend on the development of either non-parenteral routes of administration such as nasal, rectal, buccal, pulmonary, vaginal, ophthalmic and transdermal or on the successful development of other novel parenteral approaches such as implantable delivery systems (Banga et al., 1988; Lee, 1988).

Compared to other routes, the buccal mucosa offers a large and easily accessible area for placement of delivery systems such as adhesive tablets, gels, and patches. However, the low bioavailability observed for various proteins and peptides indicate that the buccal mucosa is not very permeable to macromolecules (Lee, 1988). Consequently, further work is required to determine whether he bioavailability of these molecules can be improved through the manipulation of delivery systems.

Solutions, gels, and suppositories are conventional dosage forms for rectal and vaginal delivery of peptides and proteins (De Boer et al., 1990). Gel formulations seem to be the most efficient because they offer a proper balance between retention at the site of administration and the rate of peptide release. Though these routes offer a promising potential for delivery of peptides and proteins, low patient compliance is the major hurdle.

The ocular membrane can also be used for the systemic delivery of therapeutic peptides and proteins (Banga et al., 1988). Systemic delivery via the ocular route relies on overflow of the instilled eye drops and nasolacrimal duct absorption. Some of the approaches which have been found useful in enhancing the ocular 
absorption of peptides and proteins include use of nanoparticles, liposomes, gels, inserts, latex systems, bioadhesives and surfactants (Chiou et al., 1989). In addition to the permeation barrier, the presence of peptidases in ocular tissues limit the absorption of intact peptide and protein drugs. This route of administration is not likely to become popular for systemic delivery since the bioavailability is extremely low. Also, ocular tissues are extremely sensitive to foreign substances and patient compliance could be rather low.

Compared to mucosal routes, the transdermal route shows greater resistance to peptide and protein absorption, primarily because of the impermeability of the stratum corneum. Iontophoresis is now being actively investigated to overcome this deficiency. Results indicate limited success with significant inter-animal variation (Lee, 1991). These contradicting results coupled with the uncertain long-term effect of applied current on the well-being of the skin, cast doubt on the viability of iontophoresis as a noninvasive technique to improve transdermal peptide and protein delivery. Among the non-invasive routes of drug administration, the nasal route seems to be a potential alternative to parenteral administration of peptides and proteins (Lee et al., 1988; Lee, 1988; Chien et al., 1989; Harris, 1989).

Historically, use of nasal route for drug delivery has received the attention of mankind since ancient times. Nasal therapy, also called " Nasaya Karma" has been a recognized form of treatment in the Ayurvedic system of Indian medicine for many centuries. Psychotropic drugs and hallucinogens have been used as a nose snuff by the Indians of South America (Chien et al,,1985). Use of the nasal 
route to deliver peptides systemically dates back to 1922 (Chien et al., 1985). Since then, many attempts have been made to deliver peptides and proteins nasally. In recent years, the nasal route has received a great deal of attention as a viable alternative to the parenteral route for delivering proteins and peptides (Lee et al.,1988).

When compared to other routes of administration, the nasal route offers many advantages. In addition to its accessibility for systemic drug delivery, the nasal cavity offers both pharmacokinetic and pharmaceutical advantages. It offers the advantage of bypassing the metabolic elimination pathways of gastrointestinal tract and liver and thereby significantly reducing first pass metabolism. The nasal mucosa offers a large surface area and relatively low enzymatic degradation resulting in the rapid absorption of drug molecules. Thus the pharmacokinetics of intranasal administration are characterized by rapid absorption into the systemic circulation producing high plasma levels similar to those witnessed after i.v. administration. Intranasal administration is a convenient and easy form of self-administered non-invasive therapy and should enjoy a high level of patient compliance.

However, there are certain factors that limit the exploitation of nasal route for systemic absorption of peptide and protein drugs (Chien et al., 1989; Pontiroli et al., 1990). Rapid clearance of the surface mucous coat in the nose shortens the time available for drug absorption. The permeability of the nasal membrane is dependent on the size of drug molecules. Due to their high molecular size, peptides and proteins often need permeation enhancers to increase their 
bioavailability. These enhancers may destroy the mucous membrane and disrupt the nasal functions. Nasal preparations are not amenable to formulation manipulation. Other factors that should be considered in optimizing dosage regimens for nasal administration are, the methods and techniques of administration and the existence of any pathological conditions which may affect nasal function significantly.

\subsection{Nasal Physiology}

The nasal passage has three physiological functions (Geurkink, 1983). It serves as (a) particle barrier to and a collector of inspired dust, allergens, and microorganisms; (b) as a heat exchanger and humidifier of air on its way to the lungs; and (c) as an organ of olfaction.

The nasal passage which runs from the nasal vestibule to the nasopharynx has a depth of approximately $12-14 \mathrm{~cm}$. There are three distinct functional zones in the nasal cavity: namely, vestibular, respiratory, and olfactory areas (Jafek, 1983; Geurkink, 1983; Chien et al., 1989). The vestibular area serves as a baffle system, and its surface is covered by a common pseudostratified epithelium whose long hairs provide the function of filtering airborne particles. The respiratory area has a surface lined by a pseudostratified columnar epithelium, and is normally covered by a dense layer of mucus that is constantly moving towards the posterior apertures of the nasal cavity by a powerful system of motile cilia. The olfactory region is about $10 \mathrm{~cm}^{2}$. The olfactory airway lies between the nasal septum and the lateral wall of the main passage. 
The anterior nares mark the beginning of the double nasal airway, which extends from the entrance at the nostrils to the beginning of ciliated mucosa at the anterior ends of the nasal septum and turbanates. The main nasal passage extends backward by approximately 6 to $8 \mathrm{~cm}$ to the posterior ends of the turbanates and the arch of the septum.

The nasal mucous membrane, lining the entire nasal cavity, can be divided into olfactory and nonolfactory epithelia. The nonolfactory epithelium is a highly vascular tissue that is covered by pseudostratified columnar, ciliated epithelium. The olfactory epithelium is a pseudostratified columnar in type, and consists of specialized olfactory cells, supporting cells, and both serous and mucous glands.

There are two types of mucus covering the surface of the mucous membrane: one adheres to the tips of cilia, and the other fills the space among the cilia. Three cell types- columnar, goblet, and basal - make up the mucous membrane, as shown in the Figurel. Columnar cells, either ciliated or nonciliated are covered with microvilli on their apical surfaces. Goblet cells secret the mucin used in coating the epithelial layer with a protective mucus layer. Basal cells are developing, undifferentiated columnar or goblet cells and do not extend into the nasal cavity.

Nasal mucociliary activity is one of the most important physiological defense mechanisms of the respiratory tract used to protect the body against any inhaled noxious materials (Geurkink, 1983). The mucous blanket consists of two layers. The outer layer is 


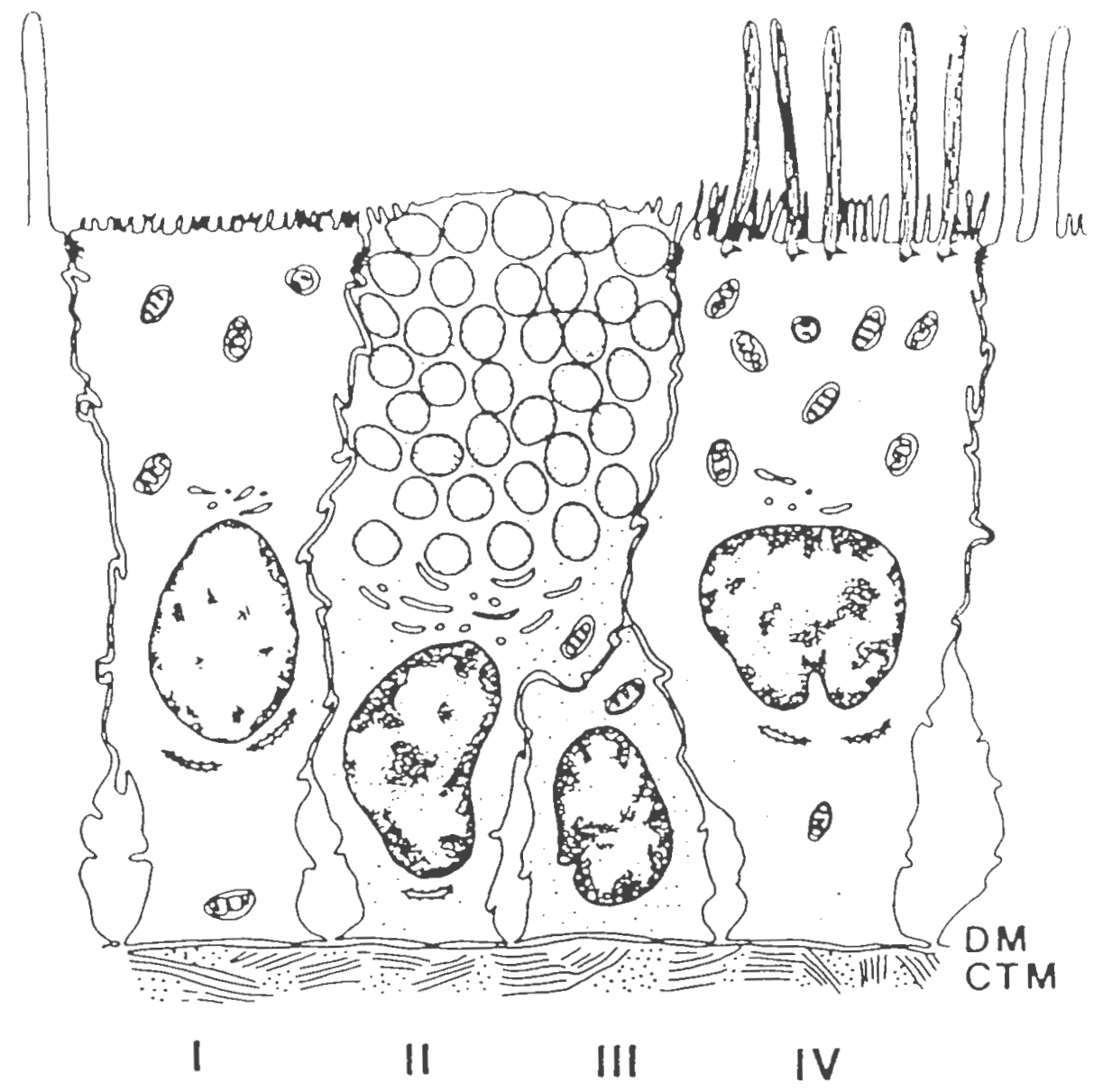

Figure 1. Microscopic view of various cell types in the nasal epithelium. I-nonciliated columnar cell with microvilli, II-goblet cell with mucous granules and Golgi apparatus, III-basal cell, IV-ciliated columnar cell with mitochondria in the apical part, DM-double membrane, CTM-convective tissue membrane.

Source: Chien et al., 1989. 
relatively viscous and rests on a thin layer of serous fluid that tends to facilitate the action of the underlying cilia. The fine particulate matter that enters the inspired air is filtered by the process of adhering to the mucous film.

In general, nasal mucociliary clearance carries airway secretions backward to the nasopharynx. This material is dispatched by a wiping action of the palate to the stomach periodically through swallowing. However, there is an area in the anterior nares of the inferior turbinate from which mucociliary clearance moves material forward, and this provides a clearance of deposited foreign materials from the body by nose blowing and wiping. Nasal clearance proceeds at an average rate of about $1 \mathrm{~cm} / \mathrm{min}$. Thus the mucous blanket is replaced every 10 to 15 minutes. A total of approximately 1500 $2000 \mathrm{ml}$ of mucous is produced daily, and contains 90-95\% water, 1 $2 \%$ salt, and $2-3 \%$ mucin. The functions of mucus include : (a) acts as a retainer for substances in the nasal duct; (b) behaves as an adhesive; (c) has water-holding capacity; (d) transports particulate matter; (e) exhibits surface electrical activity; (f) protects the mucosa; (g) acts as a mesh with specific permeability; and (h) allows heat transfer. It has been reported that the nasal epithelium may be altered to produce excess mucus by a variety of agents, including gases, viruses, bacteria and certain diseases such as allergic rhinitis (Chien et al., 1989).

Pathological conditions may impair mucociliary function. Drying of the nasal mucous membrane will cause cessation of ciliary activity while prompt moistening will restore its normal activity. The optimum temperature range for ciliary activity is $28-30{ }^{\circ} \mathrm{C}$. 
Hypotonic saline solutions will inhibit ciliary activity; hypertonic saline solutions will cause it to stop. It has also been reported that certain drugs such as adrenaline, cocaine and a number of other drugs or chemicals will interfere with ciliary activity (Chien et al., 1989).

Nasal secretions contain certain enzymes which cause degradation of drugs especially peptides and proteins. These are cytochrome P-450- dependent monooxygenase, lactate dehydrogenase, oxidoreductase, leucine aminopeptidase and phosphoglucomutase (Chien et al., 1989).

\subsection{Deposition and Clearance of Drugs From the Nasal Cavity}

The site of deposition within the nasal cavity depends upon the delivery system used and the technique of administration applied. The standard method of administration has been in the form of sprays or drops being delivered using rhinyl catheters, single dose pipettes and metered dose spray pumps (Su, 1989). The rhinyl catheter was the first system to be introduced and has the advantage that the catheter is graduated for different doses as required by the patient. The advantage of the disposable pipette is that it is suitable for single dose administration and therefore does not require addition of a preservative which is one of the most singular cause of nasal irritation and allergic rhinitis in patients on long term nasal therapy. The spray pump is simple to use and allows multiple dosing of any given dose. The site of deposition and the rate of clearance of the drug from nasal cavity will influence the efficacy of the dose received by the patient. 
A study by Aoki \& Crawley (1976) compared the deposition and clearance of relatively large volumes of solution (0.1-0.75 ml) applied as nasal sprays and drops. It was found that greater coverage of the walls of the nasal cavity was achieved following administration of drops. It was also observed that the clearance rates were similar following both methods of administration and for all dosing volumes.

The clearance of drug from the nasal cavity is a biphasic phenomenon; a rapid initial clearance followed by slow clearance. In another study (Hardy et al., 1984) Technetium -99m labeled human serum albumin was administered into the human nose by a nasal spray or nose drops. Forty percent of the dose was cleared rapidly with average half times for clearance ranging from 6 to 9 minutes. Following this rapid phase, clearance of the spray was much slower than drops, because most of the spray was deposited on the nonciliated regions, whereas the solution from the nose drops spread more extensively over the ciliated areas of the nose.

Harris (1989) reported that the deposition pattern in nasal cavity is dependent of the mode of administration. Desmopressin solution was administered as sprays using two types of metered spray pumps or as drops using a rhinyle catheter or a pipette. The pipette and rhinyle catheter deposited solution towards the rear of the nasal cavity at the site of the nasopharynx and sprays deposited droplets on the anterior side of the nasal cavity. Fifty percent of the drops from the pipette and rhinyle catheter were cleared in 14 and 20 minutes whereas the $200 \mu 1$ and $100 \mu \mathrm{l}$ sprays were cleared in 120 and 240 minutes. 
Environmental conditions such as the relative humidity and temperature, may also influence nasal clearance (Aoki et al., 1976; Hardy et al, 1985).

It is well established that pathological conditions involving mucociliary dysfunction can greatly affect the clearance rates. For example, Kartagener's syndrome, Sjogren's syndrome, cystic fibrosis, and nasal polyposis have been shown to slow down the clearance rates (Hardy et al., 1985). The common cold can cause either rapid or slow clearance, depending on whether the subject has a 'runny nose' or nasal congestion (Bond et al., 1984). However, Phillpotts et al., (1984) reported that the rate at which human interferon- $\alpha$ was cleared from the nose was not substantially altered during a cold. Therefore, it seems likely that high concentration of interferon could be maintained in the nose during rhinovirus infection by means of an intranasal spray.

\subsection{Nasal Absorption of Peptides and Proteins -}

\section{Physicochemical Considerations}

There are various factors associated with peptide and proteins which affect their transport through the biological membranes. These include high molecular weight, concentration, volume of the dose administered to the nasal cavity and formulation composition.

\subsubsection{Effect of Molecular Weight:}

Proteins and peptides have poor bioavailability after intranasal administration because of their high molecular weight. Table 1 lists, in order of increasing molecular weight, the bioavailabilities of a 
Table 1. Intranasal bioavailabilities of proteins and peptidesa

\begin{tabular}{lll}
\hline Compound & $\begin{array}{l}\text { Amino Acids } \\
\text { (No.) }\end{array}$ & $\begin{array}{l}\text { Bioavailability } \\
(\%)\end{array}$ \\
\hline TRH & 3 & 45 \\
Metkephamid & 5 & 100 \\
Somatostatin analog & 6 & 75 \\
0rytocin & 9 & 1 \\
Desmopressin & 9 & 10 \\
Buserelin & 9 & 2.5 \\
LH-RH & 10 & 1.5 \\
Nafarelin & 10 & 2 \\
ACrH analog & 17 & 12 \\
Secretin & 27 & 10 \\
Glucagon & 29 & $<1$ \\
Calcitonin & 32 & $<1$ \\
GH-RH & 40 & $<1$ \\
Insulin & 51 & $<1$ \\
Beta-Interferon & 165 & $<1$ \\
Growth hormone & 191 & \\
\hline
\end{tabular}

a Source: Lee, 1990. 
series of peptides and proteins after intranasal administration (Lee 1990). Data indicates that, for low molecular weight peptides such as thyroid-releasing hormone and metkephamid, bioavailability can be quite high after intranasal administration; but for larger peptides and proteins, the nasal mucosa is relatively impermeable. Very poor bioavailability was observed for drugs of molecular weight greater than 1000 daltons (McMartin et al., 1987).

Maitani et al., (1989) investigated the nasal absorption of two dextran derivatives, fluorescein isothiocyanate - dextran (DT) and fluorescein isothiocyanate diethylamino ethyl dextran (DE) in the presence of sodium glycocholate to study the influence of molecular weight and charge using a rabbit model. The concentration of DT in plasma decreased as the molecular weight of DT was increased. The concentration of $\mathrm{DE}$ in plasma increased conversely with molecular weight of DE (<10000). When DE \& DT of same molecular weight were given nasally, DE which carries a positively charged substituent showed higher plasma levels when compared to DT.

\subsubsection{Effect of Drug Concentration:}

It was observed that the nasal absorption of L-tyrosyl-Ltyrosine was concentration dependent in the range of $2.8 \times 10^{-4}$ to $2.2 \times 10^{-3} \mathrm{M}$ (Huang et al., 1985). Harris (1989) reported that a greater response for desmopressin was observed after the $100 \mu \mathrm{l}$ dose than with the $200 \mu 1$ dose given in the spray form. Su et al. (1985) reported that the area under the curve of serum metkephamid levels versus time increased linearly with concentration. However, Aoki et al. (1976) reported that there was no significant effect on 
distribution and clearance from the nasal cavity when the concentration of human serum albumin was changed from 3 to $30 \%$.

\subsubsection{Effect of Dose Volume:}

The volume that can be administered nasally is limited. If large volumes are administered, much of the preparation is likely to be swallowed at the time of dosing. Harris et al. (1988) studied the effect of dose volume on the nasal bioavailability of desmopressin. It was found that the bioavailability of intranasal desmopressin from $2 \times 50 \mu \mathrm{L}$ dose $(20 \%)$ compared with $1 \times 50 \mu \mathrm{L}(11 \%)$ and $1 \times 100 \mu \mathrm{L}$ (9\%) spray doses. This finding suggests that an optimal dosage is obtained by delivering drug once into each nostril. In another study (Harris, 1989), the same group reported that greater absorption of desmopressin was observed from $100 \mu \mathrm{l}$ than from $200 \mu \mathrm{l} .200 \mu \mathrm{l}$ spray was cleared in $120 \mathrm{~min}$ compared to $240 \mathrm{~min}$ of clearance time

for $100 \mu \mathrm{l}$ spray. However, Aoki et al. (1976) reported that no significant difference was found when the volume was varied from 0.1 to $0.75 \mathrm{ml}$.

\subsection{Pharmacokinetics of Nasal Absorption}

Pharmacokinetics may be simply described as the mathematical relationship that exists between the dose of a drug and the measurable concentration in a readily accessible site in the body (e.g., plasma or blood). The fundamental pharmacokinetic parameters of interest are clearance, volume of distribution, half-life and bioavailability. 
The principal pharmacokinetic rationale for employing the nasal route is to accommodate drugs that are extensively metabolized in the gut wall or that are subjected to extensive firstpass elimination in the liver when administered orally. Another important reason is to provide a suitable route of administration for drugs such as peptides or proteins, which are destroyed by the gastrointestinal fluids, and not capable of adequate absorption into the systemic circulation following oral administration.

\subsubsection{Factors Affecting Nasal Absorption:}

Factors that could affect the pharmacokinetic parameters following intranasal administration are (Colaizzi, 1985):

1. Physiology-related factors, such as
a. Vascularity
b. Speed of mucous flow
c. Presence of infection
d. Prevalent atmospheric conditions

2. Dosage form-related factors, such as
a. Concentration of drug
b. Physicochemical properties of drug
c. Density/viscosity of the formulation
d. $\mathrm{pH}$ of the medium
e. Pharmaceutical excipients used
f. Biocompatibility: irritancy, toxicity, etc.

3. Administration-related factors, such as
a. Volume
b. Droplet size 
c. Spray characteristics

d. Site of deposition

e. Rate and extent of loss from the site of application

Bioavailability is defined as the fraction of the unchanged drug reaching the site of drug action, or more usually the systemic circulation following administration by any route. The bioavailability of a drug after intranasal administration may be expressed in terms of absolute absorption, Ae, determined from the area under the curve (AUC) following the intravenous (i.v.) and intranasal (i.n.) dose (Colaizzi, 1985).

$$
A e=\frac{(\text { AUC }) \text { i.n. } \cdot(\text { Dose }) \text { i.v. }}{\text { (AUC)i.v.(Dose)i.n. }}
$$$$
\text { -...- eq (1) }
$$

where the AUC was extrapolated to an infinite time following the administration of a single intravenous or intranasal dose.

Ae can also be calculated from the urinary excretion data following intravenous and intranasal administration of a single dose of drug. It is determined from the total amount of drug excreted in the urine in the unmetabolized form $\left(\mathrm{Au}^{\infty}\right)$ :

$$
\mathrm{Ae}=\frac{\left(\mathrm{AU}^{\infty}\right) \text { i.n. }(\text { Dose }) \text { i.v. }}{\left(\mathrm{AU}^{\infty}\right) \text { i.v.(Dose)i.n. }}
$$

This equation is valid only when the fraction of drug dose absorbed and excreted in the urine is the same for both intravenous and intranasal routes.

If the body is considered to act as a single compartment, the pharmacokinetic behavior of a drug administered by the intranasal route may be calculated according to the following model (Colaizzi, 1985):

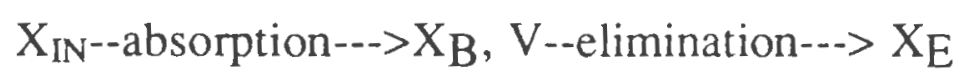


where $X_{\text {IN }}$ represents the amount of drug administered to the nasal site, $\mathrm{X}_{\mathrm{B}}$ represents the amount of drug in the central compartment, $\mathrm{V}$ is the apparent volume of distribution, and $\mathrm{X}_{E}$ is the amount of drug eliminated.

\subsubsection{Zero-order Kinetics:}

In cases where the absorption of drugs from the nasal site of administration follows zero-order kinetics, e.g., controlled delivery, the plasma profile of the drug may be described by(Colaizzi, 1985)

$$
\frac{\mathrm{dX}_{\mathrm{B}}}{\mathrm{dt}}=\mathrm{K}_{0}-\mathrm{K}_{\mathrm{e}} \mathrm{X}_{\mathrm{B}}
$$

in which $\mathrm{K}_{0}$ is the zero-order absorption rate constant, and $\mathrm{K}_{\mathrm{e}}$ is the overall elimination rate constant. Then, the plasma concentration of drug may be expressed as

$$
\mathrm{C}_{\mathrm{p}}=\frac{\mathrm{K}_{0}}{\mathrm{Cl}}\left(1-\mathrm{e}^{-\mathrm{K}_{\mathrm{e}} t}\right)
$$

where $\mathrm{Cl}$ is the total body clearance, and $\mathrm{t}$ represents any specified time interval following the drug administration. The plasma drug level following zero-order transnasal permeation of the drug would increase to a steady-state plateau level $\left(\mathrm{CP}_{\mathrm{P}} \mathrm{SS}\right)$ and then begin to decline exponentially after time tP, which is the time when there is no more absorption of the drug from the nasal cavity.

\subsubsection{First-order Kinetics:}

In cases where the absorption of drugs from the nasal site of administration follows first-order kinetics, the plasma profile of the drug can be described by (Colaizzi, 1985) 


$$
\frac{\mathrm{dX}_{\mathrm{B}}}{\mathrm{dt}}=\mathrm{FX}_{\mathrm{IN}} \mathrm{K}_{\mathrm{a}}-\mathrm{K}_{\mathrm{e}} \mathrm{X}_{\mathrm{B}}
$$

where $\mathrm{K}_{\mathrm{a}}$ is the first-order absorption rate constant, $\mathrm{F}$ is the fraction of applied dose absorbed, $X_{I N}$ is the amount of drug administered to the absorption site, $X_{B}$ is the amount of drug in the central compartment, $\mathrm{K}_{\mathrm{e}}$ is the overall elimination rate constant. Then, the plasma concentration of drug can be expressed as

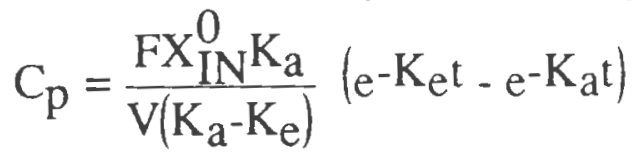

where $\mathrm{X}^{0} \mathrm{IN}$ is the initial drug dose applied to the site of absorption at the time zero.

The nose is an interesting organ from kinetic point of view because, in addition to the process of drug release, absorption, and metabolism, it also has a carrier- and drug-translocating mechanism, namely mucociliary clearance. A mathematical model was developed by Gonda et al. (1990) to describe the rate processes involved in the deposition of drugs placed in their delivery systems into the human nasal cavity. The model contained first-order parallel and sequential irreversible rate processes representing the convective drug and carrier transport by fluid flow, mucociliary clearance and peristalsis, drug release and absorption, and decomposition of the drug prior to its appearance in the systemic circulation. The numerical values of the parameters used were based on literature data from clearance studies of nonabsorbable markers deposited in the human nasal cavity. Data obtained under a variety of experimental conditions were consistent with the model. The fitted values for DTPA (Diethylene Triamine Penta Acetic acid) powder formulation (Gonda 
et al., 1990) were not consistent with the observed values. The effect of bioadhesive carriers was successfully simulated by reducing the mucociliary clearance rate constants for the transport from the the posterior part of the nose into the gastrointestinal tract. The simulation showed that bioadhesion improved bioavailability and reduced the variability in absorption which might be caused by a variable pattern of deposition in the nose. Variable bioavailability could result from removal of the drug from the nasal cavity by sniffing, blowing, or wiping the nose, leading to different drug residence times in the nose. The model simulations further suggested that drug decomposition in the nose, while lowering bioavailability, also reduced variable absorption due to variable residence times of the drug in the nose.

The plasma concentration following intranasal administration shows a concentration profile that is similar to an intravenous bolus injection (Lau et al., 1989). The rate of nasal permeation is very rapid and it takes a very short period of time to reach the peak plasma level. Drugs with poor oral absorption (e.g. insulin, sulbenicillin, cephacetrile, phenol red and disodium cromoglycate) and drugs with extensive hepatic first-pass metabolism (e.g. progesterone, estradiol, testosterone, hydralazine, propranolol, cocaine and nitroglycerin) can be rapidly and completely absorbed through the nasal mucosa into the blood circulation (Chien et al., 1989). 


\subsection{Enhancement of Nasal Absorption of Peptides and Proteins}

Peptides and proteins usually result in poor bioavailability when administered nasally. The obvious reason is their relatively large size and the impermeability of nasal membrane to these high molecular weight compounds. Other possible reasons for low bioavailability may be : (a) the high polarity of peptides and proteins, (b) absorption by a carrier-mediated mechanism, (c) hydrolysis in the nasal cavity, or (d) combinations of the above factors.

Various approaches have been used to enhance the nasal absorption and systemic bioavailability for peptides and proteins as well as other drug molecules.

\subsubsection{Structural Modifications:}

The physicochemical properties of drugs can be altered by chemical modification. When administered nasally, the modified drugs may provide improved bioavailability.

Huang et al. (1985a), using L-tyrosine as a model amino acid, studied the effect of structural modification on its absorption. Acylation of the amino group on the L-tyrosine molecule had no effect on the lipophilicity or rate of nasal absorption of the amino acid. On the other hand, esterification of the phenolic and carboxyl groups resulted in derivatives which are more lipophilic than Ltyrosine. The in-situ rates of nasal absorption of the carboxylic acid esters were significantly greater than that of L-tyrosine, whereas the $\mathrm{O}$-acyl esters were absorbed with rates similar to that of the original 
amino acid. It was suggested that the enhancement in the nasal absorption of the carboxylic acid esters of L-tyrosine might be the result of the masking of the negative charge that was on the carboxylate moiety.

\subsubsection{Formulation Design:}

The proper selection of pharmaceutical excipients in the development of nasal formulations could enhance the formulation stability and/or the nasal bioavailability of a drug.

Harris et al. (1989) reported that the addition of methyl cellulose as a viscosity enhancing agent changed the pattern of deposition and clearance of intranasal desmopressin when administered by nasal spray and drops. The results showed that the addition of $0.25 \% \mathrm{w} / \mathrm{v}$ of methyl cellulose produced a more sustained and slower absorption. However, there was no increase in the total bioavailability. These results were consistent with the findings of Hussain et al. (1980) who, in a dog study, found that the addition of methyl cellulose to a nasal solution of propranolol produced a more sustained blood drug profile, but that the bioavailability was equal to a solution without the viscosity enhancer. Maitani et al. (1989) examined the effect of Avicel on the nasal absorption of Human interferon- $B$ in rabbits from a powder dosage form. Avicel did not produce any significant effect on nasal absorption of Human interferon- $B$ from this type of product.

Nagai et al. (1984) studied the effect of lactose, microcrystalline cellulose, hydroxypropyl cellulose and carbopol-sodium in powder dosage forms for delivering insulin to the nasal cavity. The 
absorption of insulin was fastest with microcrystalline cellulose and was sustained when carbopol-sodium was used in the preparation. High enhancement was observed when insulin and carbopol were freeze-dried together prior to administration. The final powder dosage form produced a hypoglycemia of one third of that observed by intravenous injection assuming that the same dose of insulin was administered.

\subsubsection{Membrane Permeation Enhancers:}

The concept of adding a component to a therapeutic drug formulation to increase absorption and the possible mechanisms involved has been explored extensively for transdermal delivery. Little information is known of the physico-biochemical nature of the

nasal mucosal membrane and its influence on peptide transport. The extent of systemic transport for a given peptide that results from energy dependent active transport processes, versus passive transport, is unknown and may vary given the size of the molecule, its partition coefficient, charge characteristics and its susceptibility to proteolysis by mucosal membranes. Various chemical components have been used in an attempt to increase the uptake of proteins and peptides through the nasal mucosa (Chien et al., 1989; Lee 1990). These include the use of surfactants, bioadhesive agents and vasoactive agents to promote nasal absorption.

\subsubsection{Surface Active Agents:}

The effect of surfactants on drug absorption has been the objective of many studies. A number of these were reviewed by 
Gibaldi (1970), Gibaldi and Feldman (1970) and Lee (1990). A wide variety of ionic and nonionic surfactants such as hydrophobic bile salt derivatives (deoxycholate, cholate, chenodeoxycholate, glycocholate), fusidic acid derivatives, sodium lauryl sulfate, potassium laurate, saponin and various ether and ester derivatives of polyoxyethylene have been shown to increase the nasal absorption of macromolecules such as insulin (Hirai et al., 1978, 1981a, 81b, 81c; Pontiroli et al., 1982), calcitonin (Sandow et al., 1985), thymopentin (Audhya et al., 1983), vasopressin (Harris et al., 1989), leutinizing hormone releasing hormone (Fink et al., 1974), enkephalins (Su et al., 1985) and human growth hormone (Baldwin et al., 1990).

Hirai et al. (1978) studied the effect of surfactants such as saponin, sodium glycocholate and polyoxyethylene-9-lauryl ether on nasal absorption of insulin in dogs. Insulin in the absence of the surfactant produced slight hypoglycemia whereas the presence of only $1 \%$ surfactant enhanced uptake of insulin. The blood glucose level in dogs was reduced by $25-100 \%$ within 1-2 hours after intranasal administration. Sodium glycocholate produced the maximum effect followed by polyoxyethylene-9-1auryl ether and saponin. The results indicated that the alteration of the nasal mucosa by surfactants increases the permeability of mucous membrane, which leads to enhancement in the nasal absorption of insulin. Coadministration of insulin with $1 \%$ surfactant (such as the surfactant of nonionic ether type, anionic or amphoteric-type, bile sats, saponin, and surfactin) in rats was noted to produce a reduction in blood glucose levels (Hirai et al., 1981a). The results suggested that surfactants with an HLB value of 8-14 yield a greater reduction of 
blood glucose levels. It was hypothesized that the surfactant molecule increases nasal permeability or reduces the proteolytic enzyme activity in the nasal mucosa, and therefore promotes the nasal absorption of insulin. It was noted that polyoxyethylene-9lauryl ether produced a maximum hemolytic and protein-releasing effect on the biomembrane, whereas it yielded only a slight inhibition of the enzymatic degradation of insulin (Hirai et al., 1981b). On the contrary, sodium glycocholate produced a lesser extent of both hemolytic and protein-releasing effects, but it showed a significant inhibition of the leucine aminopeptidase activity.

Moses et al. (1983) studied the efficacy and reproducibility of insulin given nasally to normal and diabetic subjects from an insulindeoxycholate $(1 \% \mathrm{w} / \mathrm{v})$ aerosol. The formulation resulted in peak serum insulin concentrations within 10 minutes after nasal administration. The blood glucose level began to fall within 10 minutes and reached the nadir level of $54 \%$ after 30 minutes. The nasal absorption of insulin was approximated to be $10-20 \%$ as efficient as intravenous administration. When compared to normals, the insulin effect was prolonged for 5 hours in both type I and type II diabetics although the mechanism was not clear.

In an extensive study, Gordon et al. (1985), using 40 healthy volunteers, compared the ability of eight different bile salts (ursodeoxycholate, chenodeoxycholate, cholate, taurocholate, glycocholate, deoxycholate, taurodeoxycholate and glycodeoxycholate) to enhance insulin absorption after nasal administration. The effectiveness of the individual bile salt was positively correlated to the hydrophobicity of the steroid nucleus, as 
homogenates was maximally enhanced by sodium glycocholate. However, the observed bioavailability was only $3 \%$ of as that of an i.v. administered dose.

Mishima et al. (1987) investigated the inhibitory action of various enhancers such as sodium caprylate, sodium caprate, sodium laurate, sodium glycocholate on aminopeptidase activity in rats and rabbits. It was found that sodium laurate (98\%) showed the highest inhibition of aminopeptidase activity in rat homogenate, followed by sodium glycocholate $(79 \%)$, sodium caprate $(74 \%)$ and sodium caprylate $(70 \%)$. In a rabbit homogenate, sodium caprate showed $89 \%$ inhibitory action followed by sodium caprylate (88\%), sodium laurate $(87 \%)$ and sodium glycocholate $(86 \%)$.

Aungst et al. (1988) compared the efficiency of the nasal, rectal, and buccal routes for delivering insulin to rats using sodium glycocholate as an enhancer. A five percent concentration of sodium glycocholate was found to significantly increase insulin efficacy by each route. The rank order was nasal $>$ rectal $>$ buccal $>$ sublingual. Nasal and rectal insulin were roughly half as effective as intramuscular insulin.

Tengamnuay and Mitra (1990) used mixed micelles of fatty acids and bile salt to optimize the penetration efficacy while minimizing any changes in membrane integrity caused by permeation enhancers. Using in situ nasal perfusion technique, they found that mixed micelles of sodium glycocholate and various fatty acids in a 15:5 $\mathrm{mM}$ ratio were much more effective in enhancing the nasal absorption of dipeptide [D-Arg${ }^{2}$ Kyotorphin than the individual adjuvants. The adjuvant activity of the mixed micelles was increased 
by increasing the ionic strength of the perfusate and affected by the structure of the lipid component. Oleic acid, a cis-unsaturated fatty acid, was more effective than elaidic acid, the trans-isomer, whereas cis-linoleic acid and trans-linolelaidic acid were equally effective. Mixed micelles appeared to cause transient changes in the integrity of the nasal mucosa that were fully reversible within $20-40 \mathrm{~min}$ after a 60 minute exposure as judged by return of the mucosa to its original impermeable state.

A fusidic acid derivative, sodium tauro-24,25-dihydrofusidate (STDHF) seems to be the most promising enhancer for use in increasing the absorption of nasally administered peptides and proteins (Lee, 1990). Longenecker et al. (1987) reported that STDHF enhanced insulin absorption in the sheep model when insulin was delivered as nasal drops. The observed bioavailability after nasal delivery was $16.4 \%$ relative to i.v. administration. The concentration of STDHF and the ratio of STDHF to insulin were critical parameters in increasing the absorption of insulin. These observations were consistent with Hirai et al. (1981), who reported that enhanced serum insulin values can be observed only when bile salts exceed the CMC. The optimum ratio of STDHF to insulin was found to be between 5 and 10 at STDHF concentrations greater than its CMC $(0.16 \%)$. Optimum absorption was observed at a concentration of $0.3 \%(\mathrm{w} / \mathrm{v})$ of STDHF.

In another study, Verhoef et al (1989) reported the promoting ability of STDHF on nasal absorption of insulin in rats and rabbits. The identical fusidate formulations enhanced insulin bioavailability from $0.9 \%$ to $5.2 \%$ in rabbits and from $0.3 \%$ to $18 \%$ in rats. Co- 
administration of STDHF with the trypsin inhibitor aprotinin resulted in an increase in insulin bioavailability in rats and a decrease in case of rabbits. These results indicate that there seems to be significant interspecies differences which can not be overlooked. Baldwin et al. (1990) reported the nasal absorption of human growth hormone in three animal models. Formulations were nasally administered using a Hamilton syringe with a polyethylene tubing (PE10) attached. In rats, when hGH with $0.5 \%$ STDHF was administered in an $80-\mu l$ dose volume via the nasopharyngeal route, the bioavailability was $32 \%$. Administration of same formulation directly into the nasal cavity through the nares in a volume of $20 \mu \mathrm{I}$ resulted in bioavailability of $17.2 \%$ (relative to i.v.). The presence of $0.5 \%$ STDHF caused an 11fold increase in bioavailability of hGH in rats and in rabbits and a 21fold increase in sheep. In all three species, the pharmacokinetic profile observed, following nasal administration, was a pulsatile profile. That is, the absorption of hGH was rapid followed by rapid clearance of hGH. Glycocholate or taurocholate at $0.5 \%$ was 3 to 5 times less effective than STDHF in enhancing $h \mathrm{GH}$ absorption in rats. The nasal absorption of hGH decreased as the concentration of STDHF was reduced from 0.3 to $1.0 \% \mathrm{w} / \mathrm{v}$.

Hermen et al. (1989) investigated the utility of dimethyl-betacyclodextrin in enhancing the nasal absorption of 17 beta-estradiol in rabbits and rats. High bioavailabilities of estradiol were observed both in rabbits $(95 \%)$ and rats $(67 \%)$ when complexed with cyclodextrin. In another study (Pontiroli et al., 1990), glucagon was complexed with cyclodextrin to increase solubility and delivered 
nasally to normal volunteers. Results showed that there was no significant in plasma glucagon levels.

A number of mechanisms have been hypothesized to explain the activity of nasal membrane permeation enhancers (Lee et al., 1988). For peptides and proteins that tend to aggregate in solution (for example, insulin), solubilization of the monomeric species will increase the molecule's thermodynamic activity and therefore its transport across the membrane. Bile salts and STDHF have been shown to inhibit protease activity and enhance the absorption of drug molecules. Formation of transient hydrophillic pores in the membrane bilayer by the bile salts also has been proposed as a potential mechanism for enhanced protein absorption (Gordon et al., 1985). This mechanism, however, does not explain how, once in the cytoplasm of the epithelial cell, the protein or peptide would be transported out the basal side of the cell and into the capillary bed. Surfactants such as polyoxyethylene-9-lauryl ether have been observed to enhance nasal absorption by eroding the nasal mucous membrane. Specific enhancers such as STDHF seem to loosen the tight cellular junctions and promote the nasal absorption of proteins and peptides.

Though the presence of an enhancer usually improves the uptake of peptides and proteins by the nasal membrane, major concerns regarding the toxic effects and nasal membrane irritation upon administration for long periods remain unaddressed (Martin et al., 1978, 1981). Duchateau et al. (1986) reported that the ciliotoxicity of the bile salts increased with increasing hydrophobicity. Dihydroxy bile salts are more toxic than trihydroxy 
bile salts. Deoxycholate was found to be extremely ciliotoxic at a concentration of $5 \mathrm{mM} / \mathrm{l}$. STDHF seems to be less toxic and less irritating than bile salts (Lee et al., 1988). An ideal enhancer which does not disrupt normal nasal functions and can enhance the uptake of peptides and proteins through the nasal membrane has yet to be found.

\subsubsection{Bioadhesive Agents:}

In addition to the penetration and enzymatic barriers, rapid clearance of the administered dose from the site of administration is another hurdle limiting the absorption of peptide and protein drugs from the nasal cavity. Nasally administered drugs are usually cleared from from the site of deposition within 30 minutes. It is postulated that by increasing the residence time of drug in the nasal cavity, absorption would be increased since more time will be available for drug to be absorbed. Residence time can be increased by coadministering or formulating a number of different agents into the nasal products.

Morimoto et al. (1985) demonstrated the nasal absorption promoting activity for the bioadhesive agent, polyacrylic acid. Using a rat model, polyacrylic acid gel was shown to enhance the biological actions of insulin and calcitonin, both of which were inactive when administered alone. Formulation $\mathrm{pH}$ (4.5-7.5) did not appear to affect insulin absorption from the gel formulation, however low viscosity gels demonstrated a more rapid onset of insulin activity, as measured by hypoglycemic response. However, the nasal administration of insulin in $1 \% \mathrm{w} / \mathrm{v}$ carboxymethyl cellulose solution 
had no hypoglycemic effect. Harris et al. (1989) reported that the addition of $0.25 \% \mathrm{w} / \mathrm{v}$ of methyl cellulose produced a more sustained and slower absorption of desmopressin. However, there was no increase in the total bioavailability which was consistent with the findings of Hussain et al. (1980) who, in a dog study, found that the addition of methyl cellulose to a nasal solution of propranolol produced a more sustained blood levels of drug. Thus, these results suggest that addition of a viscosity builder may sustain drug absorption rather than increasing the bioavailability.

A similar approach involves the delivery of solid peptide formulations designed to absorb water and to gel upon contact with the mucosa. Good bioavailability of insulin (30\%) was observed when insulin was freeze dried together with carbopol 934 prior to nasal administration to dogs (Nagai et al., 1984, 86). Illum et al. (1987) studied three bioadhesive microsphere systems (albumin, starchspherex and DEAE-dextran) for nasal administration. The half life of clearance for starch microspheres was found to be in the order of 240 minutes as compared to 15 minutes for the liquid and powder formulations. In another study, the same group (Illum et al., 1988) reported that incorporation of an absorption enhancer, lysolecithin into the starch microspheres resulted in increased uptake of gentamicin in rats and sheep. The observed bioavailability was 50\% of the i.v. dose as compared to less than $1 \%$ for a simple nasal solution of gentamicin. Bjork et al. (1988) investigated degradable starch microspheres as a nasal delivery system for insulin in rats. Insulin $(0.75 \mathrm{U} / \mathrm{kg}$ and $1.7 \mathrm{U} / \mathrm{kg})$ - starch microspheres administered as a dry powder resulted in a dose-dependent decrease in blood 
glucose and a concomitant increase in serum insulin. Blood glucose was reduced within $30-40 \mathrm{~min}$ by $40 \%$ and $64 \%$ respectively using the two aforementioned doses. The insulin peak was reached 8 minutes after dosing and the observed bioavailability was $30 \%$.

\subsubsection{Vasoactive Drugs:}

Olanoff and co-workers (1987) investigated a third approach to enhance peptide delivery using what they term 'physiological modifying agents'. These agents have vasoactive properties and exert their action by increasing nasal mucosal blood flow. In theory, by increasing nasal blood flow, concentrations of drug on basal side of the nasal mucosal membrane would remain low, increasing the effective concentration gradient, thereby augmenting peptide permeation across the mucosal membrane by passive diffusion. Agents capable of increasing nasal blood flow include histamine, leukotriene $D_{4}$, prostaglandin $E_{1}$ and the beta adrenergic agonists, isoprenaline and terbutaline. Also included in this group are agents which promote the release of endogenous vasoactive substances such as histamine, kinins, prostaglandins, and the vasoactive peptides. In a clinical trial with eight normal subjects, the intranasal administration of histamine immediately prior to desmopressin administration increased the antidiuretic response. These results and additional data showing an increase in nasal blood flow in the presence of histamine suggest that peptide absorption is in part limited by blood flow. 


\subsection{Animal Models Used in Evaluation of Nasal Absorption}

Studies

Review of literature has shown that there are two types of models which are used for evaluation of nasal absorption.

\subsubsection{In Situ Absorption Models:}

In-situ nasal perfusion studies can be used to evaluate the nasal absorption potential of a drug and to predict the in vivo rate of absorption. The surgical perfusion procedure was originally developed by Hirai et al. (1981a) using the rat as animal model. The experimental set up is given in Figure 2.

In this model the rat is anesthetized and an incision is made in the neck. The trachea is then cannulated with a polyethylene tube and another tube is inserted through the esophagus towards the posterior part of the nasal cavity. The nasopalatine tract which connects the nasal cavity with the mouth is sealed with an adhesive to prevent the drainage of the drug solution from the nasal cavity into the mouth. The drug solution is placed in a reservoir vessel and circulated through the nasal cavity via a peristalic pump. After flowing through the nasal cavity, the perfusion solution passes out of the nostrils, flows through the funnel, and returns to the reservoir again. The extent and the rate of nasal absorption are determined, over a period of time, by analyzing the drug concentration remaining in the perfusing solution. 


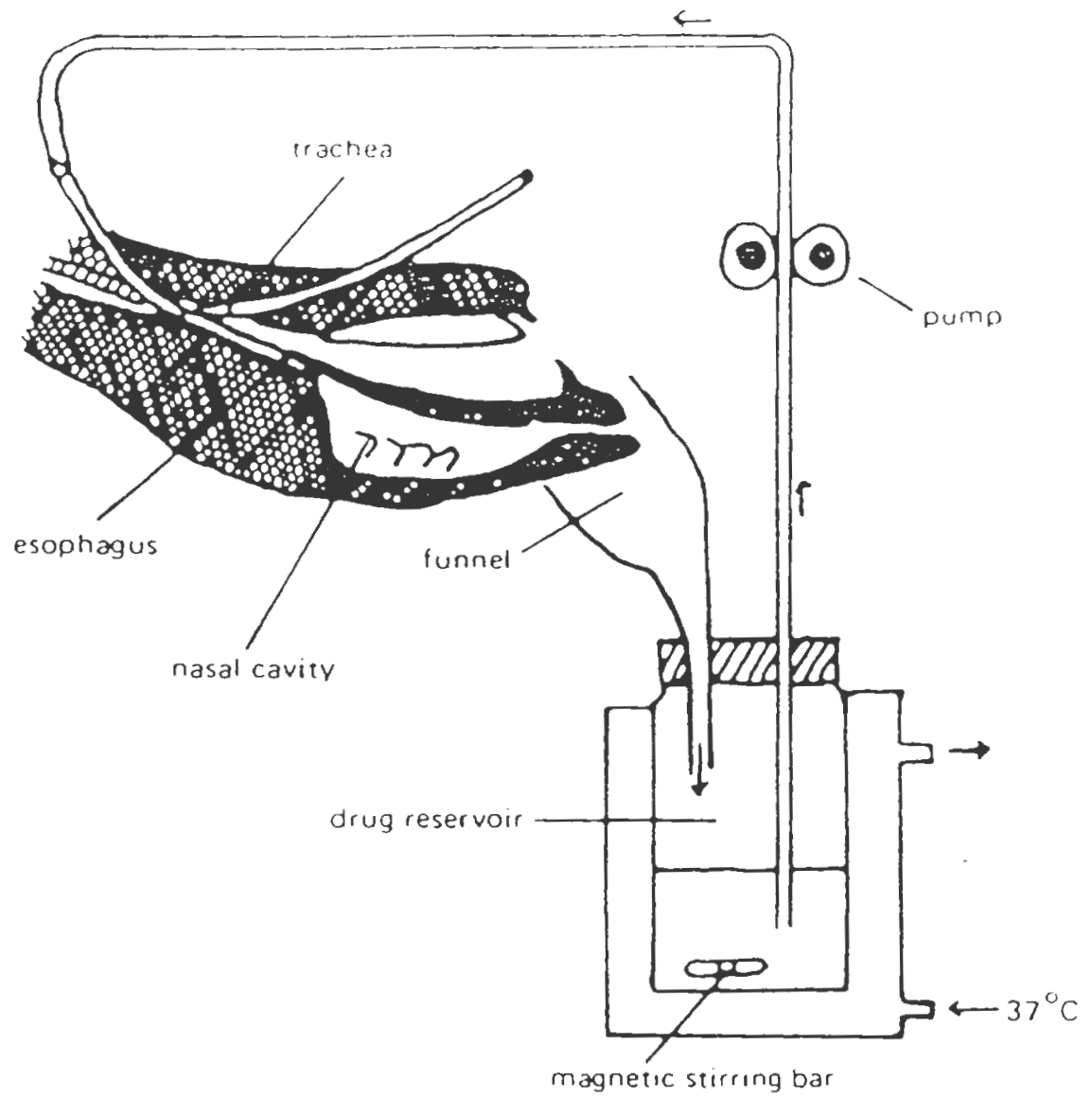

Figure 2. The experimental setup for in situ perfusion technique in rat model.

Source: Chien et al., 1989. 


\subsubsection{In Vivo Absorption Models:}

As shown in Figure 3, the surgical procedure for in vivo studies in rats is similar to that described for the in-situ nasal perfusion studies. The drug solution is administered to the nasal cavity through the esophageal cannulation tubing or into the nostril with a syringe. The extent and the rate of nasal absorption are determined by analyzing drug concentrations in the plasma or in the urine over a period of time. Since all the possible outlets in the in vivo rat model are blocked after surgical preparation, the only possible passage for the absorption of a drug into the systemic circulation is penetration through the nasal mucosa. This approach is considered to provide a well controlled animal model for screening the nasal absorption potential of drug candidates.

A number of different animal species have been studied to evaluate nasal absorption. These include the rat, guinea pig, rabbit, dog, sheep, and monkey. Among these animal models, the rat model has been used extensively for evaluation of the nasal absorption of various drugs such as propranolol (Hussain et al., 1979; 1980); naloxone and buprenorphine (Hussain et al., 1984); sulbenicillin, cefazolin, cephacetrile, phenol red, salicylic acid, aminopyrin, and bucolome (Hirai et al., 1981a); insulin (Hirai et al.,1981b,1981c; Morimoto et al., 1985; Deurloo et al., 1989); enkephalins (Su et al., 1985); cyclo-(-Pro-Phe-D-Trp-Lys-Thr-Phe); horseradish peroxidase (McMartin et al., 1987) and calcitonin (Morimoto et al., 1985). Drugs studied nasally using the rabbit as an animal model include progesterone and its hydroxy derivatives (Corbo et al., 1988), insulin (Zia et al., 1989; Deurloo et al., 1989) and human interferon-beta 


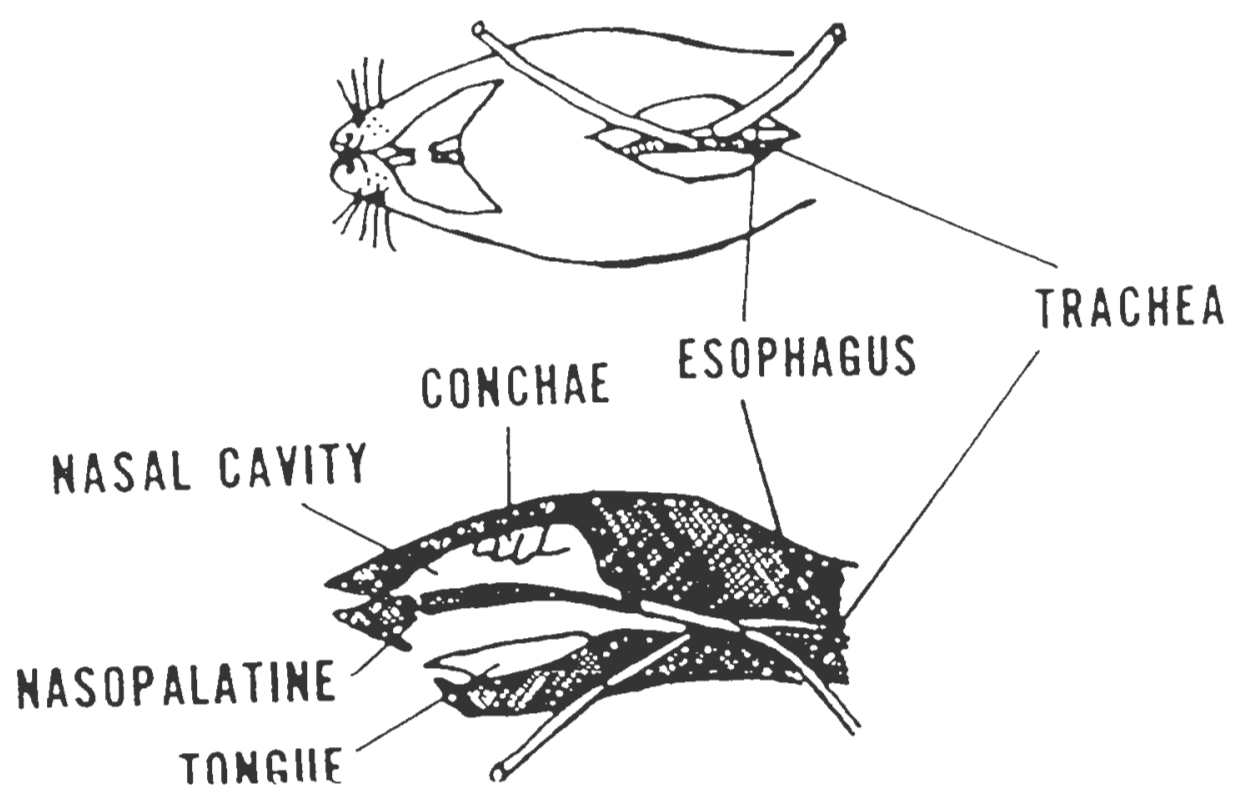

Figure 3. The top and side views of the cannulation arrangement for in vivo studies in rats.

Source: Chien et al., 1989. 
(Maitani et al., 1989). Audhya et al. (1983) used the guinea pig as an animal model to determine the efficacy of thymopentin following administration by various routes. The in vivo dog model was used to evaluate nasal absorption of propranolol (Hussain et al., 1980) and insulin (Hirai et al., 1978; Nagai et al., 1984; Longnecker et al., 1987; Farraj et al., 1990). Sheep were used as an animal model for various drugs such as insulin (Longenecker et al., 1987). The monkey has been used to evaluate the nasal absorption of progesterone (Anand Kumar et al., 1982), B-Endorphin (Jagannadha Rao et al., 186), insulin (Anik et al., 1984), nafarelin acetate (Anik et al., 1984) etc.

The rat model is the most widely used model for evaluation of the nasal absorption potential of different drug molecules because the rat is a small animal with low cost, is easy to handle and is inexpensive to maintain. However, the small nasal cavity and nostrils of the rat restrict the evaluation of formulations such as metered sprays, powders and microspheres. Because of their larger nostrils and body size as compared to rat model; the dog, sheep and monkey models are more suitable and practical for evaluating wider variety of formulations and modes of administration. These animals are larger in size, more difficult to handle, and more expensive to maintain in the laboratory. The rabbit offers certain advantages as an animal model. It is a laboratory animal as commonly accessible as the rat, and provides large nostrils and increased nasal surface area that is comparable to that of human beings. The rabbit is relatively inexpensive, readily available, and easily maintained in the laboratory setting. However, the nonsurvival and surgical nature of 
the perfusion technique (Hirai et al., 1981a) restrict the use of this approach in these species.

Mehta et al. (1990) developed a nonsurgical perfusion technique and presented preliminary data using rabbit as animal model. However more studies are necessary to establish and validate this technique.

\subsubsection{Physical and Chemical Parameters to be Considered in} Evaluation of Absorption Models

\subsubsection{Effect of Perfusion Rate:}

Huang et al. (1985) examined the effect of perfusion rate on nasal absorption using the in situ nasal perfusion technique in rats. As the perfusion rate was increased from 1.0 to $2.5 \mathrm{ml} / \mathrm{min}$, the rate of nasal absorption of phenobarbital increased initially and then reached a plateau at $2 \mathrm{ml} / \mathrm{min}$ and was independent of the rate of perfusion when pumped faster than $2 \mathrm{ml} / \mathrm{min}$.

\subsubsection{Effect of Perfusate Volume:}

The effect of varying the volume of the perfusion solution on the apparent rate of absorption was studied using phenobarbital, Ltyrosine, propranolol and phenol red (Huang et al., 1985). The apparent absorption rate constants were increased when the volume of perfusate was increased from 3 to $20 \mathrm{ml}$. The dependency of absorption rate constants on volume can be mathematically described in accordance with Fick's law of diffusion:

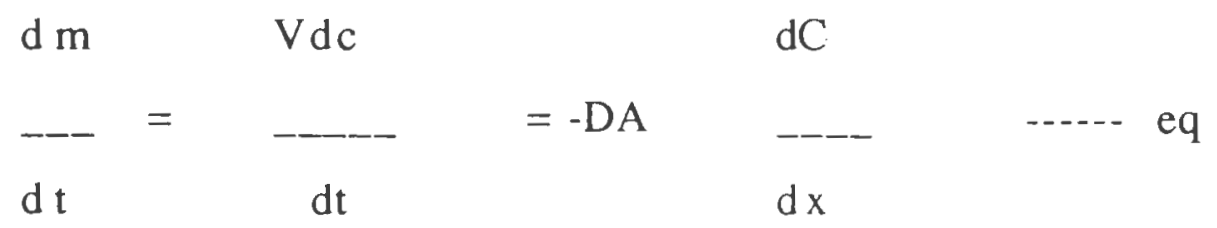


where $m=$ amount of the drug in the perfusion solution

$v=$ volume of the solution

$\mathrm{dC} / \mathrm{dx}=$ Concentration gradient across the nasal

membrane with a thickness of $h$

$\mathrm{D}=$ diffusion coefficient

$A=$ surface area of the nasal mucosa.

\subsubsection{Effect of $\mathrm{pH}$ :}

Hirai et al. (1978) reported that the extent and duration of hypoglycemia induced by the nasal application of insulin depended on the $\mathrm{pH}$ of the preparation. Absorption of insulin from the nasal mucosa was enhanced significantly when it was dissolved in an acid medium ( $\mathrm{pH}$ 3.1) than in a neutral one. Similarly, the effect of $\mathrm{pH}$ on the nasal absorption of benzoic acid $(\mathrm{pKa}=4.19)$ was studied by Huang et al. (1985). As the $\mathrm{pH}$ of the solution was increased from 2 to 7.19 , the amount absorbed was decreased from $44 \%$ to $13 \%$ (Hirai et al., 1981). But Hussain et al. (1989) reported that the absorption of L-tyrosine was $\mathrm{pH}$ independent in the range of 4-7.4.

\subsubsection{Effect of Partition Coefficient:}

The rate and extent of absorption of a drug through a biological membrane is influenced by its lipophilicity. Hussein et al. (1985) studied the effect of lipophilicity on the extent of nasal absorption of a series of barbiturates at $\mathrm{pH} 6.0$, where the barbiturates $(\mathrm{pKa}=7.6)$ exist entirely in their unionized form. A forty-fold difference in the partition coefficient of pentobarbital and barbital resulted only in a four-fold increase in the extent of absorption. Further more, it was also observed that the nasal absorption of L-tyrosine (Hussein., 
1989) was not significantly changed when the partition coefficient was increased 50 times. Corbo et al. (1988) studied the nasal delivery of progestational steroids in overiectomized rabbits. It was found that octanol/water partition coefficient does not reflect the partition behavior of progesterone and its derivatives in the nasal mucosa. The systemic bioavailability was correlated well with the nasal mucosa/buffer partition coefficient. In another study (Corbo et al., 1990), the same group reported that nasal membrane permeability decreased as the order of hydrophilicity of the progestins increased.

\subsection{Insulin as Model Drug}

The first known description of diabetes is in the Ebers Papyrus of $1500 \mathrm{BC}$. An effective treatment for diabetic patients came much later after insulin was discovered in 1921 by Banting and Best (Chien et al., 1989a).

Diabetes is an enormous health and economic burden in the United States and the developed countries. As of 1985, the NIH estimated that more than six million residents of the United States had been diagnosed with diabetes, and an additional four million were thought to be undiagnosed. By the end of this century, the disease could affect 20 million people in the United States alone, where it is now responsible for about 40,000 deaths per year (Tzagournis et al., 1989).

Insulin is a proteinous macromolecule composed of 51 amino acids with a molecular weight of 5,808 daltons (Figure 4). Though insulin was discovered in 1921, it is still routinely administered in the form of an injection. However, the use of injections throughout 
the life of a diabetic patient presents various problems including physical and psychic pain, hypertrophy or atrophy of the subcutaneous fat at an injection site and occasionally an allergic reaction throughout the whole body. A tremendous amount of effort has been directed towards developing new means of insulin delivery, including the recent efforts to develop self-regulating insulin delivery systems (Touitou et al., 1980; Ishida et al., 1981; Nagai et al., 1986; Bjork et al., 1988; Farraj et al., 1990; Damge et al., 1990). Several of these attempts were started and have either ended or are continuing as laboratory research, with no products reaching the market. In a recent review, Chien et al. (1989a) discussed the various approaches that have been developed for achieving systemic delivery of insulin.

The choice of delivery routes is restricted by the molecular dimensions of insulin and its inherent instability as a protein molecule. Among the noninvasive routes, the nasal route seems to be a promising alternative to injection. Attempts to deliver insulin nasally dates back to 1922 when Woodyatt attempted to administer insulin unsuccessfully (Chien et al., 1989a). Since then many attempts have been made to deliver insulin nasally using a variety of animal models. When administered alone, the bioavailability of insulin has been found to be less than one percent because of its high molecular weight and its susceptibility to proteolytic degradation. When given with an enhancer or using the approaches described above, the observed bioavailability has been increased to as high as $10-30 \%$. 


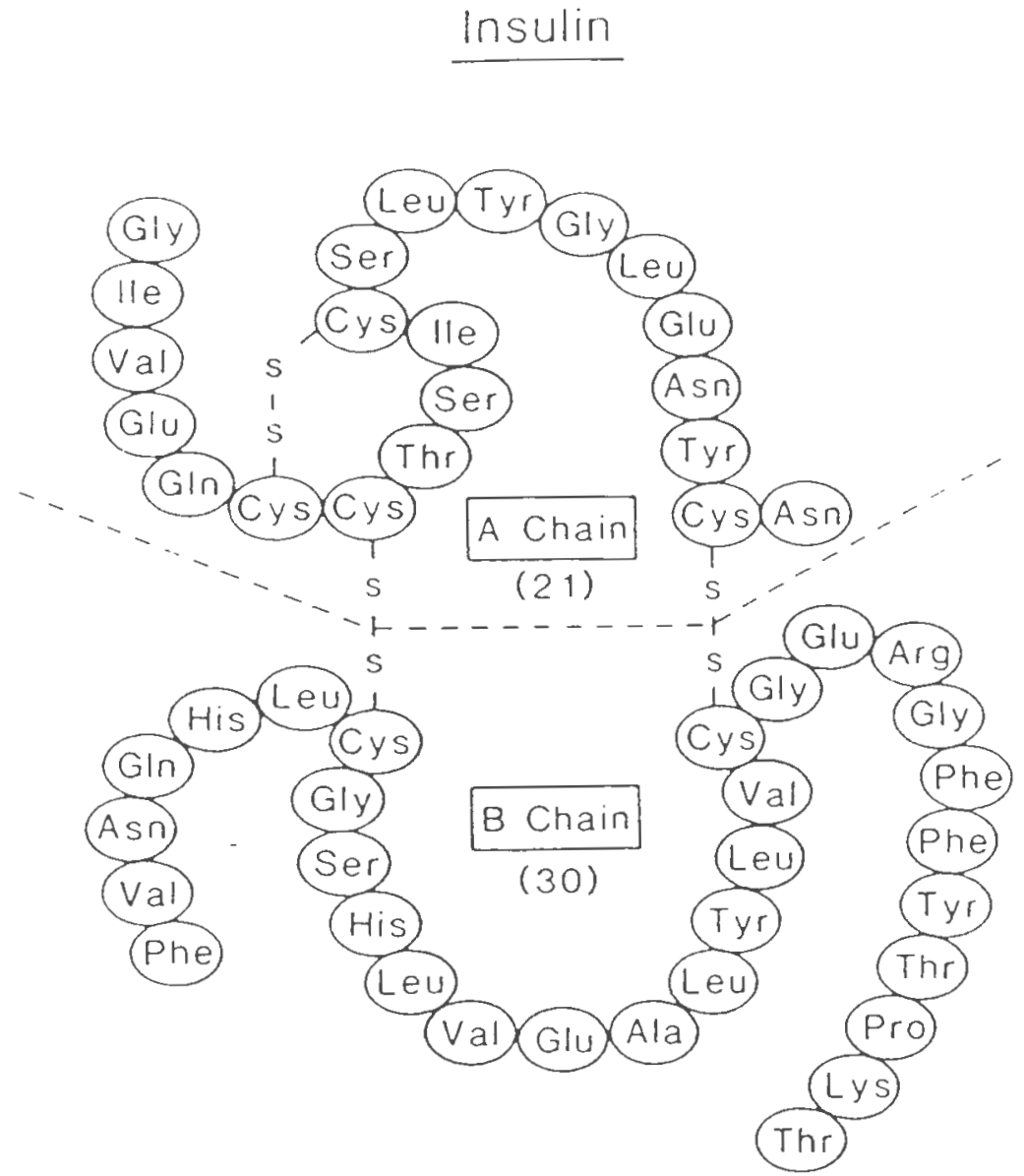

Figure 4. The structure of insulin molecule. Source: Chien et al., 1989a. 
Insulin was chosen as model drug for this work because it is a well researched polypeptide, a lot of data is available in the literature which can be served as a comparative data base for these efforts. 


\section{OBJECTIVES}

The rich vascularity and location of the nose make it an attractive site for the systemic absorption of drugs. Lipophilic drugs such as propranolol (Hussain et al.,1979), progesterone (Ananda Kumar et al., 1982), 17 \$-estradiol (Hermens et al., 1990) etc, result in rapid and complete absorption after intranasal administration. Peptides and proteins, on the other hand are poorly absorbed nasally. The bioavailability of insulin in the absence of an enhancer was reported to be less than 1\% (Hirai et al., 1978, 1981b, 1981c). Similarly, the nasal bioavailability of nafarelin acetate in monkeys was found to be only $1 \%$ of that from the intravenous administration. While the tripeptide, L-pyro-2-2aminodipyl-L-histidyl-Lthiazolidine-4-carboxamide, although possessing fewer amino acids than insulin and nafarelin acetate, has a poor bioavailability of $7 \%$ (Hussain, 1985). It appears that the mechanism for nasal absorption of drugs, especially peptides and proteins, is not fully understood. In order to gain insight into the mechanism of nasal absorption, only few animal models have been developed and characterized, in spite of the great potential offered by the nasal route for systemic drug administration. Most of the mechanistic and absorption screening studies have been performed using the in-situ rat nasal recirculation technique (Hirai et al., 1981a). While this technique is convenient and reliable for in-situ studies for some drugs, it is not suitable for in-vivo screening of formulations intended for administration by spray devices which is the most popular means of nasal administration. The small nasal cavity and nostrils of the rat restrict 
the evaluation of nasal formulations such as metered sprays, powders and microspheres in this model.

Deurloo et al. (1989) observed significant interspecies differences in rats and rabbits using identical nasal formulations. STDHF at $1 \%(\mathrm{w} / \mathrm{v})$ enhanced nasal insulin bioavailability from 0.9 to $5.2 \%$ and from 0.3 to $18.0 \%$ in rabbits and rats respectively. Coadministration with the trypsin inhibitor aprotinin increased insulin bioavailability in rats and decreased bioavailability in rabbits. In sheep model, the observed insulin bioavailability was $16.4 \%$ (Longenecker et al., 1987) . Baldwin et al. (1990), reported that the presence of $0.5 \%$ STDHF enhanced nasal absorption of hGH by 11 -fold in rats and in rabbits and by 21 -fold in sheep. Similarly, nasal administration of leuprolide acetate in rats resulted in a bioavailability of 6.0 to $40.0 \%$ when compared to i.v. administration (Adjei, 1990). Intra-animal coefficient of variation of the data was 30 to $60 \%$. The same drug when administered nasally by spray to humans resulted in a mere $2 \%$ bioavailability. Hirai et al. $(1981,81 \mathrm{a}$, 81 b) reported that in a dog study, the nasal absorption of insulin was enhanced when it was dissolved in acid medium resulting in a bioavailability of $25 \%$ compared with the hypoglycemic effect following i.v. injection. However, in a human clinical study, the same insulin solution did not produce any hypoglycemic effect and similar results were observed with the rat model. These studies indicate that the absorption process of macromolecules through the biological membranes is not fully understood. Significant interspecies differences seem to exist and no suitable perfusion technique is available to evaluate these differences. The surgical, nonsurvival 
nature of the rat recirculation technique limits its application only to rats due to economic reasons and thus these animals can not act as their own controls. Hence there is a need to develop perfusion techniques in large laboratory animals which can give better representation of the nasal mucosal absorption processes in human beings. Evaluation and validation of the non-surgical perfusion technique may address these problems.

The objectives of this study were:

(1) to develop and establish a non-surgical perfusion technique for use with large laboratory animals

(2) to compare the new technique with the existing perfusion techniques

(3) to identify the study conditions to establish and validate animal model

(4) to evaluate various nasal formulations and/or modes of administration such as sprays, microparticles using the same model and compare with the perfusion studies. 


\section{MATERIALS AND METHODS}

\subsection{Materials and Equipment:}

\subsubsection{Materials:}

Acepromazine maleate, lot\#3890769

Aveco Co., Inc., Fort Dodge, Iowa 50501

Acetone, lot\# 881807

Fisher Scientific, Fair Lawn, NJ 07410

Bovine insulin (25.7 I.U./mg) lot\# 79F-0092

Sigma Chemical Company, St. Louis, MO 63178

Chemstrip bG test strips lot\# 252169,

Boehringer Mannheim Diagnostics, Indianapolis, IN

Cotton balls, lot\# 021399,

Consumer Value stores, Woonsocket, RI 02895

Dextrose injection $(5 \% \mathrm{w} / \mathrm{v})$, USP, lot\# 33864JT

Abbott laboratories, North Chicago, IL 60064

Ethyl alcohol-200 proof, lot\# 1094,

U.S. Industrial Chemicals, Tuscola, IL 61953

Fusidic acid sodium salt, lot\# 48F-0204

Sigma Chemical Company, St. Louis, MO 63178

Glucose controls lot\# 30843

Boehringer Mannheim Diagnostics, Indianapolis, IN Hydrochloric acid, lot\# 026490

E.I. Dupont de Nemours \& Co. (Inc.), Delaware

Ketamine hydrochloride, lot\# 440105

Aveco Co., Inc., Fort Dodge, Iowa 50501

Lancets, lot\# 226396,

Ulster Scientific, Inc., Highland, NY 12528 
Maltose, lot\# 19F-0531

Sigma Chemical Company, St. Louis, MO 63178 Needles, lot\# W11587

Becton Dickinson \& Co., Rutherford, NJ 07070 Olive oil, lot\# 40H-01232

Sigma Diagnostics, St. Louis, MO 63178

Palmitic acid, lot\# 59F-5601

Sigma Chemical Company, St. Louis, MO 63178

Poly(acrylic acid), lot\# B570080

BFGoodrich Company, Brecksville, OH 44141

Polyethylene tubing, Intramedic, PE 240, PE 260

Fisher Scientific, Fair Lawn, NJ 07410

Potassium phosphate monobasic, lot\# KHTC

Mallinckrodt, Inc., Paris, Kentucky 40361

Silicone ear plug, lot\# SB-30100

Santa Barbara Medco, Inc., Santa Barbara, CA 93160

Skin gel, lot\# 5K142B,

Hollister Inc., Libertyville, IL 600048

Sodium chloride, lot\# 891067

Fisher Scientific, Fair Lawn, NJ 07410

Sodium hydroxide, lot\# 880519

Fisher Scientific, Fair Lawn, NJ 07410

Sodium pentobarbital, lot\# 26807 AF

Abbott Laboratories, North Chicago, IL 60064

Sodium phosphate dibasic, lot\# 871003,

Fisher Scientific, Fair Lawn, NJ 07410

Sodium taurocholate, lot\# 118F-5008 
Sigma Chemical Company, St. Louis, MO 63178

\subsubsection{Animals used:}

New Zealand White male rabbits, $3-5.5 \mathrm{~kg}$

Millbrook farm, Amherst, MA 01004

\subsubsection{Equipment:}

Accu-Chek II blood glucose monitor, Model 792

Boehringer Mannheim Diagnostics, Indianapolis, IN Autoclix TM

Bio-Dynamics, W. Germany

Constant speed and torque control unit

Cole-parmer Instrument Company, Chicago, IL

Duo Seal Vacuum pump

The Welch Scientific Company, Skokie, IL

Freeze dryer, Model 77500

Labconco Corporation, Kansas City, MO 64132

Heating mantle

Glas-Col Apparatus Co., Terre haute, IN 47802

Infusion pump, model 352

Orion research Inc.

Magnetic Stirrer, model 417

Electronic Laboratory equipment, Kansas City, MI Mettler analytical balance, AE240 Dual range balance

Mettler Instrument Corporation, Highstown, NJ Motomatic Motor generator

Electro-craft Corporation, Hopkins, Minnesota $\mathrm{pH}$ meter 
Markson Science, Ine., Del Mar CA

POWERSTAT ${ }^{R}$ variable autotransformer,

The Superior Electric Co., Bristol, Con.

Sartorius weighing balance, Model 1601MP8

Sartorius GMBH, Gottingen, Germany

Spray pump, $50 \mu \mathrm{l}$

Pfeiffer metered dosage systems, Princeton, NJ. 


\subsubsection{Methods}

\subsubsection{Original Non-Surgical Perfusion Technique (Old Method):}

Each rabbit was anesthetized using an intramuscular injection of $75 \mathrm{mg} / \mathrm{kg}$ ketamine hydrochloride, $7.5 \mathrm{mg} / \mathrm{kg}$ acepromazine maleate and $12 \mathrm{mg} / \mathrm{kg}$ xylazine hydrochloride. A supplemental dose of $50 \mathrm{mg}$ of ketamine hydrochloride and $5 \mathrm{mg}$ of acepromazine maleate was administered intraperitonially at the 60 minute interval to maintain the anesthesia when the experiment was extended. The original non-surgical perfusion technique was carried out according to the method of Mehta et al. (1990). After placing the animal on its back, a hard polyethylene tube was inserted by mouth into the trachea to allow breathing during perfusion of the nasal cavity with drug solution. A peroral nasal intubation cannula was prepared by connecting two pieces of hard polyethylene tubing with a soft polyethylene tube and folded in a shape suitable for insertion into the nasal cavity from the mouth. Figure 5 shows this cannula and the technique used for peroral nasal cannulation. The cannula was inserted in the mouth and pushed into the esophagus, approximately 6 inches, and then pulled back carefully until the short end of the cannula reached into the nasal cavity. The long end of the cannula coming out of the mouth was connected to a perfusion pump. The placement of the cannula was tested by infusing a small amount of saline solution through the nasal cannula and observing saline flow from the nostrils. Twenty $\mathrm{ml}$ of insulin solution was perfused at a rate of $10 \mathrm{ml} / \mathrm{hr}$ and the collected solution was recirculated for 3.5 hours. At the conclusion of the experiment, the cannula was removed 
a
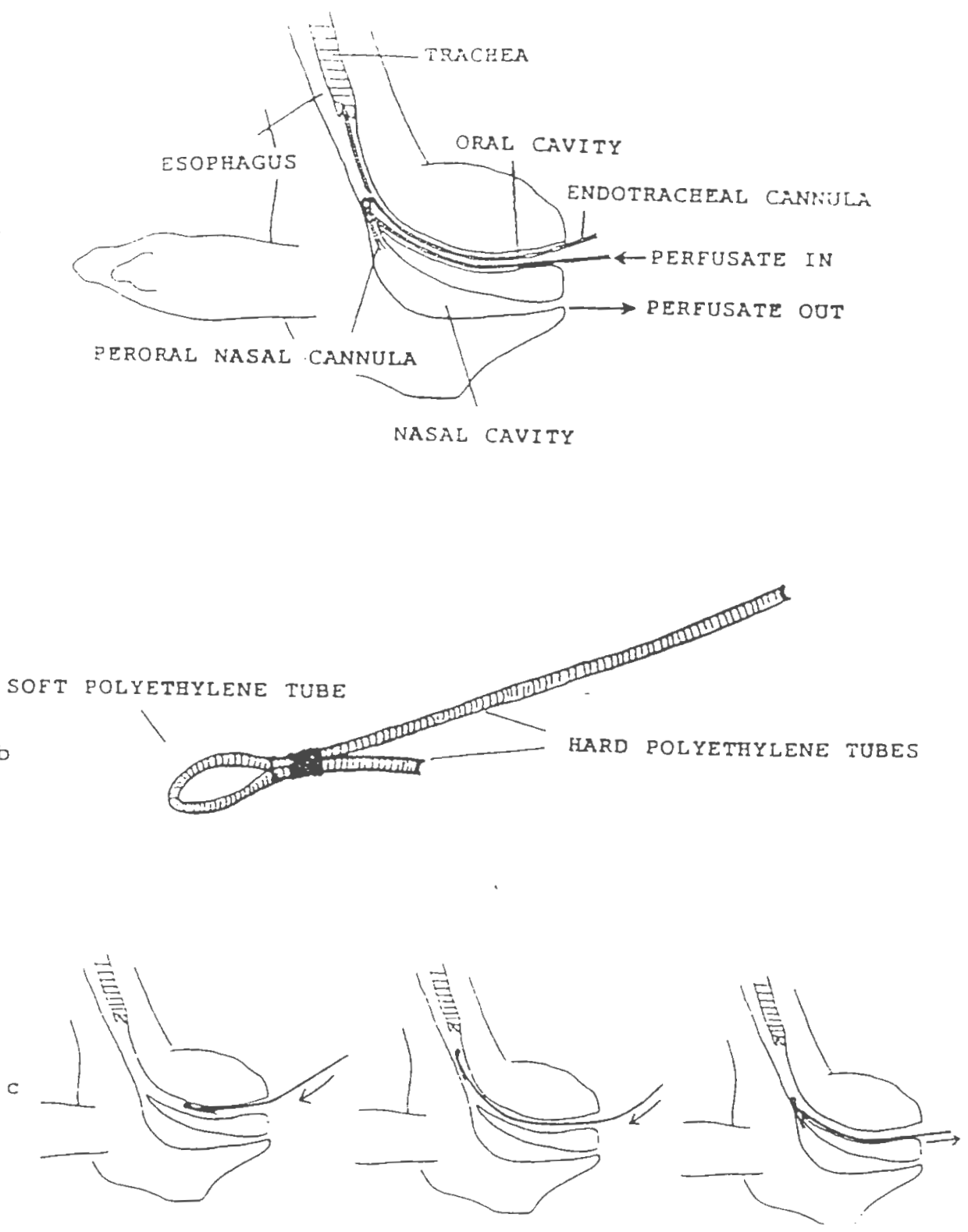

Figure 5. Schematic diagram of the rabbit non-surgical perfusion technique (old).

Source: Mehta et al., 1990. 
from the nasal cavity by pushing the cannula into the esophagus, rotating it $90^{\circ}$, and slowly removing from the mouth. The rabbit was then placed on its side to remove any perfusate remaining in the nasal cavity. Finally, the endotracheal cannula was removed and the animal was returned to the cage after monitoring for short period.

\subsubsection{New non-Surgical Perfusion Technique (New Method):}

The rabbit was anesthetized as described above. After placing the animal on its back, a hard polyethylene tube was inserted by mouth into the trachea in order to allow the rabbit to breathe while the nasal cavity was being perfused by drug solution. A soft polyethylene tube was inserted into right nostril of the rabbit. To prevent leakage of the solution through the same nostril, a combination of a silicone ear plug and a copolymerized polymer was used to plug the nostril. The rabbit head was placed at an angle of $15^{0}$ downwards from the horizontal plane. Figure 6 shows the experimental set up for the new technique. The other end of the cannula coming out of the nostril was connected to a perfusion pump and the placement of the cannula was tested by infusing a small amount of saline solution through the nasal cannula and observing saline flow from the left nostril. $20 \mathrm{ml}$ of insulin solution was perfused at a rate of $10 \mathrm{ml} / \mathrm{hr}$ and the collected solution was recirculated for 3.5 hours. At the conclusion of the experiment, the cannula and sealed plug were removed from the nostril and the rabbit was then placed on its side to allow drainage of any perfusate remaining in the nasal cavity. Finally, the endotracheal cannula was 


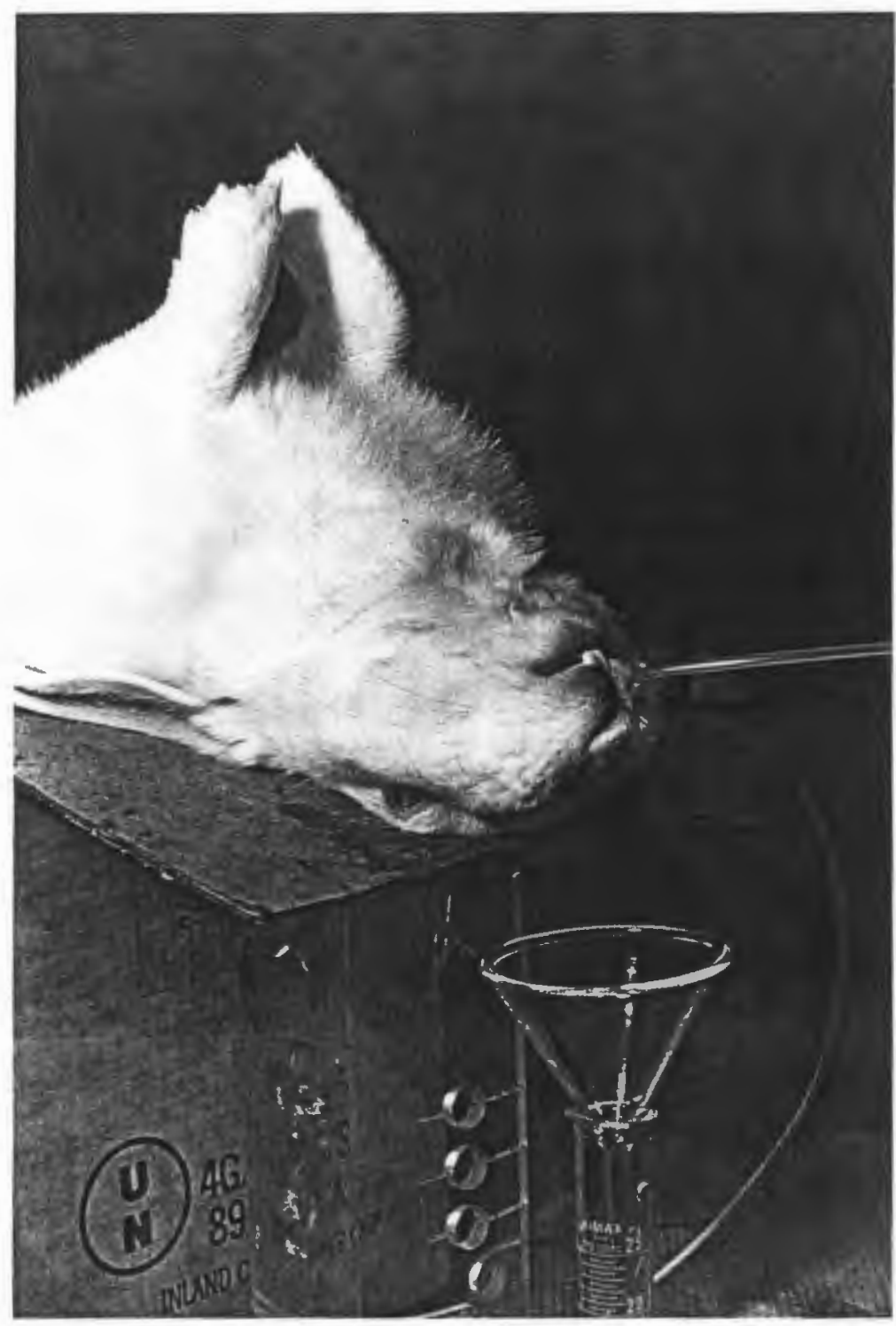

Figure 6. The experimental setup for new non-surgical perfusion technique in rabbits. 
removed and the animal was returned to the cage after monitoring for a short period.

\subsubsection{Study Design:}

Five New Zealand white male rabbits weighing 3.0 to $5.5 \mathrm{~kg}$ were fasted for 14-16 hours prior to the experiment. The study design used in this project was a randomized crossover with a wash out period of at least one week between treatments.

\subsubsection{Preparation of Solutions:}

(a) Perfusion Solution: Perfusion solutions were prepared by dispersing $10 \mathrm{U} / \mathrm{kg}$ of bovine insulin in $0.057 \mathrm{M}$ isotonic phosphate buffer $(\mathrm{pH} 7.4) .0 .05 \% \mathrm{w} / \mathrm{v}$ of sodium taurocholate was dissolved in the perfusion solution as a permeation enhancer. A constant volume of $20 \mathrm{ml}$ solution was used throughout each perfusion study.

(b) Spray Solutions: Solutions for administration by nasal spray were prepared by dispersing various doses of bovine insulin $(10 \mathrm{U} / \mathrm{kg}, 5 \mathrm{U} / \mathrm{kg}, 2.5 \mathrm{U} / \mathrm{kg}$ and $1.25 \mathrm{U} / \mathrm{kg})$ in $0.057 \mathrm{M}$ isotonic phosphate buffer ( $\mathrm{pH} 7.4)$. All the solutions contained $1 \% \mathrm{w} / \mathrm{v}$ of sodium taurocholate as an enhancing agent. Sprays were administered in the nasal cavity using a spray pump that delivers 50 $\mu \mathrm{l}$ after each actuation. A volume of $100 \mu \mathrm{l}$ was delivered during each treatment.

(c) Subcutaneous Injection Solution: Bovine insulin (0.25 U/kg)

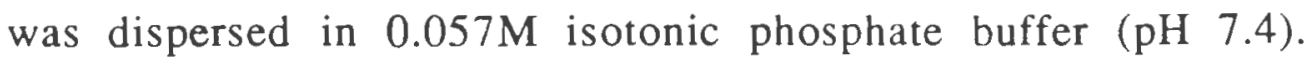




\subsubsection{Preparation of Mucoadhesive Microspheres:}

Carbopol 934, a linear chained carboxylated poly(acrylic acid) polymer was cross-linked with the disaccharide maltose, using a W/O emulsification technique to form mucoadhesive microspheres. The microencapsulation procedure used was same as that described by Lewis et al. (1990). An aqueous phase consisting of $1.0 \mathrm{gm}$ of polyacrylic acid and $0.1 \mathrm{gm}$ of maltose dissolved in $30 \mathrm{ml}$ of purified water was prepared. An organic medium consisting of $100 \mathrm{ml}$ of olive oil containing $0.4 \mathrm{gm}$ of palmitic acid was used. Since palmitic acid is an endogenous lipid, any residual amounts present in the microspheres should be pharmaceutically acceptable. Both the organic and aqueous mediums were placed in a wide mouthed bottle ands stirred at $1600 \mathrm{rpm}$. Within several minutes a fine emulsion was produced. An electrothermal isomantle was then placed under the flask and the emulsion was heated to $90-98{ }^{\circ} \mathrm{C}$ for 4.0 hours until the oil appeared clear and the microspheres were cured. The cooled mixture was poured into a large beaker containing $200 \mathrm{ml}$ acetone. The flask was washed thoroughly with a further $100 \mathrm{ml}$ of acetone. The supernatant was removed from the sedimented particles. The microspheres were washed repeatedly with acetone until no trace of oil could be detected. The microspheres were dried and stored under vacuum.

Due to the high temperature involved in the cross-linking process, insulin had to be incorporated into the synthesized microsphere by swelling the particle in a solution of drug followed by dehydration under vacuum. This was accomplished by placing $500 \mathrm{mg}$ of microspheres into a $20 \mathrm{ml}$ glass vial containing $2.5 \mathrm{ml}$ of 
insulin solution $(1.0 \% \mathrm{w} / \mathrm{v})$. The microspheres were hydrated with insulin solution overnight and subsequently vacuum dried to obtain a free flowing powder. In this way, insulin loaded microparticles were produced which could be solvent activated. That is, the drug was locked into place by the surrounding molecular chains of the polymer, and when exposed to an environmental fluid the polymer would swell, allowing insulin to diffuse outward. Excess drug in the original solution will be associated with the polymer on the surface.

The polyacrylic acid aqueous gel base for insulin microparticles was prepared by presoaking polyacrylic acid $(1 \% \mathrm{w} / \mathrm{v})$ in distilled water for 15 hours at room temperature and adjusting the $\mathrm{pH}$ to 6.0 by adding concentrated solution of sodium hydroxide (Morimoto et al., 1985).

\subsubsection{Administration of Insulin to Rabbits:}

For perfusion studies, a constant volume of $20 \mathrm{ml}$ of insulin solution $(10 \mathrm{U} / \mathrm{kg})$ containing $0.05 \% \mathrm{w} / \mathrm{v}$ sodium taurocholate was used. The perfusion was carried out for 3.5 hours at a rate of 10 $\mathrm{ml} / \mathrm{hr}$.

Spray formulations were delivered into the nasal cavity of rabbits by spray pump. $50 \mu \mathrm{l}$ was delivered in each nostril and an overall volume of $100 \mu \mathrm{l}$ per rabbit was given.

For subcutaneous injection, each rabbit received $0.25 \mathrm{U} / \mathrm{kg}$ through the hind leg.

The insulin microparticles freeze dried together with polyacrylic acid (10U/kg) were suspended in $1 \mathrm{gm}$ of polyacrylic acid 
aqueous gel base $(1 \% \mathrm{~W} / \mathrm{V})$. This formulation was administered to the nasal cavity by means of a syringe.

\subsubsection{Analytical Method:}

The absorption of insulin was measured by monitoring the blood glucose levels in the rabbits. The instrument used was an Accu-chek II blood glucose monitor which is a battery operated reflectance photometer that measures glucose photoelectronically in whole blood when used in conjunction with Chemstrip bG test strips. The determination of glucose in whole blood with Chemstrip bG test strips is based on the glucose oxidase/peroxidase reaction. Each reagent strip has two test pads which contain color indicators, and the enzymes glucose oxidase and glucose peroxidase. When whole blood is placed on the test pads, D-glucose is oxidized to gamma- Dgluconolactone with glucose oxidase acting as a catalyst. The hydrogen peroxide resulting from this reaction oxidizes the indicators in the presence of peroxidase. The intensity of the colors formed is proportional to the glucose concentration in the specimen. When the reacted strip is placed in the instrument, the color intensity of each test pad is evaluated by the double track optical system and converted to a numerical blood glucose value which is displayed on the LCD screen.

The instrument was tested initially using standard control solutions with a concentration of 66 and $312 \mathrm{mg} / \mathrm{dl}$ as provided by the manufacturer (Table 3).

(a) Accuracy: The accuracy of the analytical method was determined using a standard control solution with a glucose 
concentration of $66 \mathrm{mg} / \mathrm{dl}$. The experiment was run six times per day and on each of three different days. The observed mean and standard deviation were calculated using $n=18$ (Table 3 ).

If one considers the random error to be the width of the Gaussian distribution at a specified confidence interval of $99 \%$ (estimated by $\pm 2.58 \times$ S.D), the accuracy of the method can be obtained as the difference between the measured mean $(x)$, and the true value $(\boldsymbol{\mu})$ (Karnes et al., 1991). For this set of samples:

Observed value $(x)=68.3 \mathrm{mg} / \mathrm{dl}, \mathrm{S} . \mathrm{D}=2.7, \mathrm{n}=18$

True value $(\mu)=66.0 \mathrm{mg} / \mathrm{dl}$

Accuracy $=$ absolute value of $(x-\mu)$

$$
=68.3-66.0=2.3 \mathrm{mg} / \mathrm{dl}
$$

Total error (E) can be calculated as:

$$
\begin{aligned}
E & =\text { absolute value of }(x-u) \pm 2.58 \times S . D \\
& =(68.3-66.0) \pm 2.58 \times 2.7=(-4.7 \mathrm{mg} / \mathrm{dl}, 9.3 \mathrm{mg} / \mathrm{dl})
\end{aligned}
$$

(b) Precision: According to the manufacturer, Accu-chek II can be used to reliably measure blood glucose levels accurately in the range of 20 to $500 \mathrm{mg} / \mathrm{dl}$. To determine the accuracy of the instrument within this range, glucose levels in blood were varied and the observed values were compared with the predicted values. Six samples were measured to obtain the mean and standard deviation in each case. Initially, rabbit blood was collected and assayed for glucose levels using Accu-chek II (Table 2). Then the glucose concentration was increased by adding 5\% dextrose solution to a series of different levels: $152.7,168.5,212.0,252.7 \mathrm{mg} / \mathrm{dl}$. The observed mean values $( \pm$ S.D) from these samples were 152.3 \pm 3.4 , $171.7 \pm 2.0,208.2 \pm 1.3$ and $248.3 \pm 4.6 \mathrm{mg} / \mathrm{dl}$ respectively. To check the 


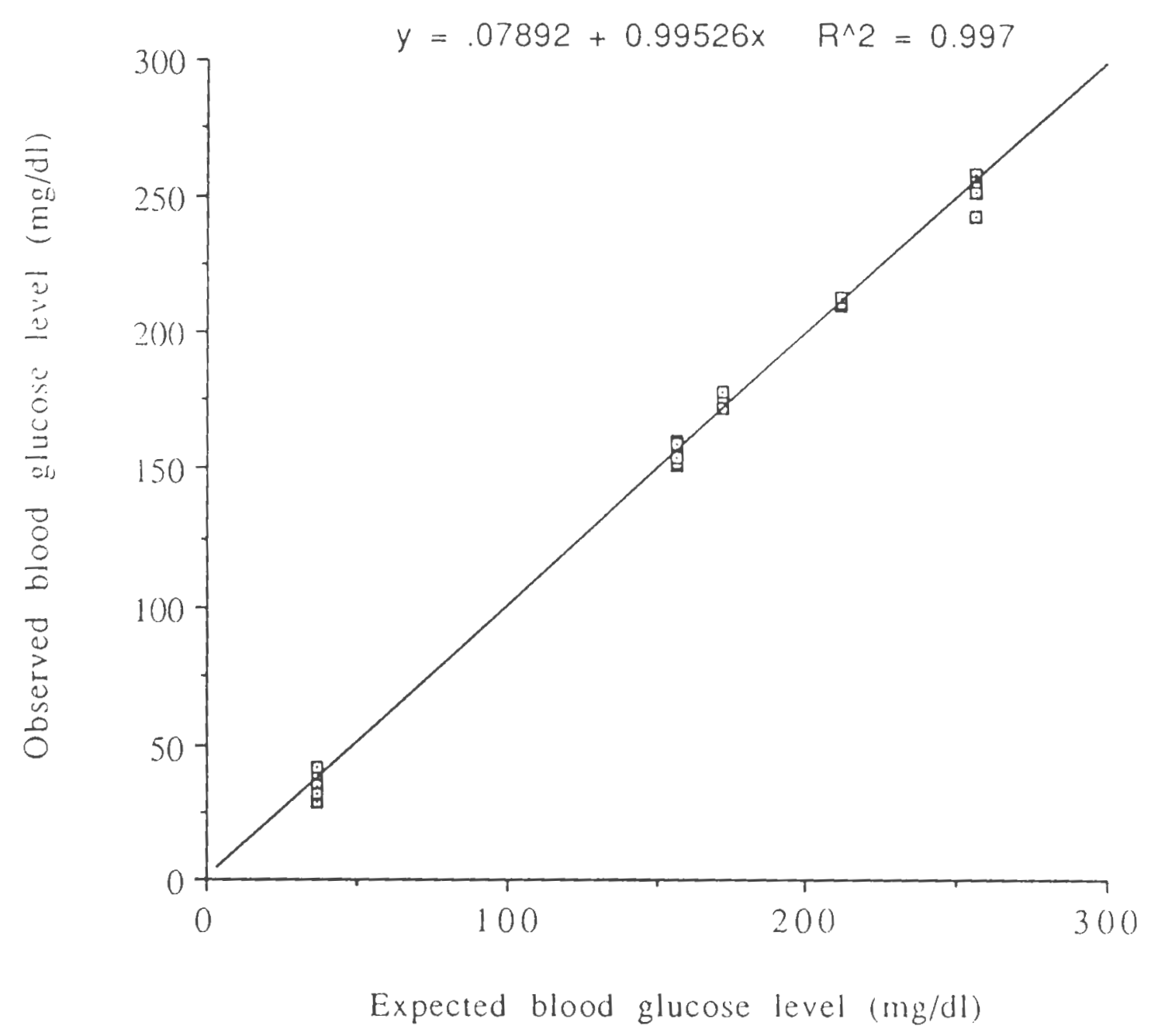

Figure 7. Correlation of Accuracy and Precision of the Accu Chek Glucose assay 
Table 2. Blood Glucose Assay Using Accu Chek II to Determine Accuracy and Precision

\begin{tabular}{|c|c|c|c|c|c|c|c|c|}
\hline \multirow{3}{*}{ no } & \multirow{3}{*}{ Bld' } & \multicolumn{4}{|c|}{ BLOOD GLUCOSE LEVEL (mg/d) } & \multirow{3}{*}{$\begin{array}{l}\text { Bld:P04 } \\
2: 3\end{array}$} & \multirow{3}{*}{$B / d^{1}$} & \multirow{3}{*}{$\begin{array}{l}\text { Bld:P0 } 4^{4} \\
2 \text { dilutions }\end{array}$} \\
\hline & & Bld:solA2 & Bld:sola 2 & Bld:solB ${ }^{3}$ & Bld 1 & & & \\
\hline & & $1: 1$ & $1: 2$ & $1: 1$ & & & & \\
\hline 1 & 106 & 148 & 170 & 254 & 78 & 28 & 120 & 209 \\
\hline 2 & 109 & 155 & 173 & 239 & 81 & 25 & 119 & 206 \\
\hline 3 & 109 & 149 & 172 & 251 & 82 & 31 & 114 & 209 \\
\hline 4 & 106 & 156 & 174 & 250 & 85 & 38 & 114 & 207 \\
\hline 5 & 99 & 156 & 168 & 248 & 82 & 34 & 117 & 209 \\
\hline 6 & 104 & 150 & 173 & 248 & 82 & 29 & 116 & 209 \\
\hline \multicolumn{2}{|c|}{ Mean 105.5} & 152.3 & 171.7 & 248.3 & 81.7 & 30.8 & 116.7 & 208.2 \\
\hline (SD) & $(3.4)$ & $(3.4)$ & $(2.0)$ & $(4.6)$ & $(2.2)$ & $(4.6)$ & $(2.5)$ & $(1.3)$ \\
\hline \multicolumn{2}{|c|}{ Espected } & & & & & & & \\
\hline valu & es - & 152.7 & 168.5 & 252.7 & - & 32.7 & - & 212.0 \\
\hline
\end{tabular}

1. Blood was collected from rabbits

$2.1 \mathrm{ml}$ of $5 \%$ destrose solution was diluted to $25 \mathrm{ml}$ with isotonic phosphate buffer

$3.2 \mathrm{ml}$ of $5 \%$ dextrose solution $w$ as diluted to $25 \mathrm{ml}$ with isotonic phosphate buffer

4. Glucose level was increased to $1038.7 \mathrm{mg} / \mathrm{dl}$ and then diluted with phosphate buffer. 
sensitivity of the method, blood was diluted with phosphate buffer to obtain a minimum glucose level of $32.7 \mathrm{mg} / \mathrm{dl}$ and the observed value was $30.8 \pm 4.6 \mathrm{mg} / \mathrm{dl}$. Blood glucose level was increased to $1038.7 \mathrm{mg} / \mathrm{dl}$ by adding $5 \%$ dextrose solution. Since the glucose levels higher than $500 \mathrm{mg} / \mathrm{dl}$ could not be measured, the test solution containing $1038.7 \mathrm{mg} / \mathrm{dl}$ was diluted with phosphate buffer to bring the glucose level within the measurable range $(346 \mathrm{mg} / \mathrm{dl})$. The observed mean value was found to be $375.2 \pm 6.3 \mathrm{mg} / \mathrm{dl}$. The observed values were plotted against the expected values in Figure 7 and a correlation of 0.997 was seen.

(c) Reproducibility: The standard control solution with a glucose concentration of $66.0 \mathrm{mg} / \mathrm{dl}$ was measured on each three days to determine the reproducibility of the assay. The results as seen in Table 3 show that the mean observed values ( \pm S.D) on these three days were $67.0 \pm 2.1,69.3 \pm 2.6$ and $67.8 \pm 1.7 \mathrm{mg} / \mathrm{dl}$. At a $99 \%$ confidence level, the observed glucose levels were not significantly different from each other.

(d) Sampling: Fresh blood was collected from the ear vein of the rabbit and tested for glucose levels at different times. In all the studies, blood samples taken from the ear vein at $-40,-20,-10,15$, $30,45,60,75,90,105,120,135,150,165,180,210,240,300,360$ and 420 minutes after administration of insulin formulations.

\subsubsection{Data Analysis:}

Quantifying absorption requires either comparing plasma insulin levels after injecting insulin, where absorption is assumed to be complete, or comparing the response caused by the absorbed 
Table 3. Reproducibility of The Blood Glucose Assay Using Accu Chek 11

\begin{tabular}{|c|c|c|c|c|}
\hline \multirow{3}{*}{ no } & \multicolumn{4}{|c|}{ BLOOD GLUCOSE LEUEL $(\mathrm{mg} / \mathrm{dI})$} \\
\hline & \multirow[t]{2}{*}{ CONTROL(high) } & \multicolumn{3}{|c|}{ CONTROL(IOW) } \\
\hline & & day 1 & $\operatorname{day} 2$ & day3 \\
\hline 1 & 309 & 64 & 70 & 66 \\
\hline 2 & 315 & 67 & 74 & $6 ?$ \\
\hline 3 & 320 & 69 & 68 & 66 \\
\hline 4 & 305 & 69 & 69 & 69 \\
\hline 5 & 309 & 68 & 69 & 69 \\
\hline 6 & 303 & 65 & 66 & 70 \\
\hline Mean & 310.2 & 67.0 & 69.3 & 67.8 \\
\hline (SD) & $(5.8)$ & $(2.1)$ & $(2.6)$ & $(1.7)$ \\
\hline $\begin{array}{l}\text { Erpected } \\
\text { Values }\end{array}$ & 312.0 & 66.0 & 66.0 & 66.0 \\
\hline
\end{tabular}


insulin by quantifying the change in plasma glucose concentration. The extent of absorption or efficacy relative to injected insulin is a primary determinant of the feasibility of the noninjectable insulin dosage forms. In this study, the insulin efficacy was compared after nasal administration under uniform experimental conditions. Efficacy was estimated relative to the subcutaneous route. Blood glucose levels were determined as a measure of insulin efficacy. Apparent pharmacokinetic parameters were calculated following nasal and subcutaneous administration of insulin. The area under the curve (AUC) was calculated based on the mean difference in the glucose level from the controls using the trapezoidal rule. The apparent bioavailability was calculated based on a comparison of the effect observed when a subcutaneous injection of $0.25 \mathrm{U} / \mathrm{kg}$ was given.

App. bioavailability $=\left(\right.$ AUC $_{\text {nasal }} \times$ Dose $\left._{\text {s.c }}\right) /\left(\right.$ AUC $_{\text {s.c }} \times$ Dose $\left._{\text {nasal }}\right) \times 100$

The SAS software package was used to analyze data obtained during this srudy. Split-plot design and Least Significant Difference (LSD) were used to analyze whether the drug treatments were significant or not at 95\% confidence interval (Hicks, 1982). 


\section{RESLLTS AND DISCUSSION}

The rabbit was used as an animal model in this study as it offers certain advantages when compared to other animal models. It provides large nostrils and large nasal surface area that is comparable to that of human beings. The rabbit is relatively inexpensive, readily available, and easily maintained in the laboratory setting.

Insulin was used as the model drug as it provides the challenges of a typical polypeptide in delivering through the nasal membrane. An improved means of insulin delivery would also alleviate the difficulties faced by the diabetic patients.

The original objective was to set up and validate an animal model and then to proceed to evaluation of formulation development of inatranasal drug delivery.

\subsection{Perfusion by Old Non-Surgical Technique:}

The animal model developed by Mehta et al. (1990) using a non-surgical perfusion technique was selected for our use since the non-surgical nature of the technique would allow the animal to act as its own control and hence the interanimal variability could be minimized.

Initially, perfusion studies were carried out with the rabbit as the animal model and the performance and reproducibility of this system were determined. The experiments were carried out perfusing $20 \mathrm{ml}$ of insulin solution $(10 \mathrm{U} / \mathrm{kg}$ ) containing $0.05 \% \mathrm{w} / \mathrm{v}$ sodium taurocholate as a permeation enhancer. The control experiment involved perfusion of an $0.057 \mathrm{M}$ isotonic phosphate 
huffer The results obtained during this study are given in Table t. It can be seen that perfusion studies using the isotonic phosphate buffer, resulted in an immediate increase in glucose levels with a maximum of $297.0 \pm 32.5 \mathrm{mg} / \mathrm{dl}$ after 45 minutes of perfusion and then the glucose levels were gradually reduced over a seven hour period. In case of perfusion of insulin solution, the highest blood glucose levels were observed at 15 minutes and then the glucose levels were lowered gradually when compared to controls, presumably due to the absorption of insulin into the systemic circulation. Figure 8 shows that the lowest glucose levels $(69.7 \pm 8.4$ $\mathrm{mg} / \mathrm{dl}$ ) were observed approximately after 165 minutes of perfusion. During this study certain difficulties were encountered. The technique was complex and didn't provide reproducible results. The rabbits could not be reused as the nasal cavity was often damaged during the placement of the cannula. Thus this technique resulted in not only variable results but also a loss of rabbits. Since the same rabbits could not be used for crossover studies, the rabbits could not act as their own controls. All these factors led us to develop an improved non-surgical perfusion technique.

\subsection{Perfusion by New Non-Surgical Technique:}

A new non-surgical technique was developed that can be considered relatively simple when compared to the original 
Table 4. Glucose Concentration as a Function of Time During Perfusion of Insulin and Buffer Solutions Using The 0ld Non-Surgical Perfusion Technique

\begin{tabular}{|c|c|c|}
\hline Time & Blood g & $n g / d l)$ \\
\hline$(\min )$ & Phosphate buffer & in solution \\
\hline & Mean+S.E & Mean+S.E \\
\hline-40 & $128.8 \pm 4.6$ & $117.2 \pm 10.2$ \\
\hline-30 & administrati & ics \\
\hline-20 & - & $151.3 \pm 13.4$ \\
\hline-10 & $170.3 \pm 8.5$ & $197.0 \pm 25.8$ \\
\hline 0 & nasal admini & ulin \\
\hline 15 & $265.7 \pm 6.2$ & $336.0 \pm 43.0$ \\
\hline 30 & $269.0 \pm 19.3$ & $324.7 \pm 45.8$ \\
\hline 45 & $297.0 \pm 32.5$ & $272.5 \pm 26.3$ \\
\hline 60 & $266.7 \pm 11.3$ & $214.0 \pm 9.0$ \\
\hline 75 & $268.3 \pm 18.1$ & $182.7 \pm 16.0$ \\
\hline 90 & $262.7 \pm 9.0$ & $146.2 \pm 18.1$ \\
\hline 105 & $262.0 \pm 6.7$ & $105.2 \pm 12.6$ \\
\hline 120 & $241.3 \pm 14.1$ & $99.0 \pm 8.4$ \\
\hline 135 & $245.3 \pm 15.4$ & $83.5 \pm 3.3$ \\
\hline
\end{tabular}


Table 4. (Continued)

\begin{tabular}{|c|c|c|}
\hline Time & Blood g & vel $(\mathrm{mg} / \mathrm{dl})$ \\
\hline (min) & Phosphate buffer & Insulin solution \\
\hline & Mean+S.E & Mean+S.ED \\
\hline 150 & $245.7 \pm 19.4$ & $74.0 \pm 6.2$ \\
\hline 165 & $245.7 \pm 26.9$ & $69.7 \pm 8.4$ \\
\hline 180 & $227.3 \pm 22.3$ & $70.5 \pm 9.5$ \\
\hline 210 & $213.0 \pm 27.2$ & $85.3 \pm 9.7$ \\
\hline 240 & $227.7 \pm 55.2$ & $74.2 \pm 14.8$ \\
\hline 300 & $219.7 \pm 47.2$ & $88.3 \pm 7.5$ \\
\hline 360 & $232.0 \pm 60.9$ & $93.3 \pm 6.8$ \\
\hline 420 & $213.7 \pm 52.0$ & $98.3 \pm 9.6$ \\
\hline
\end{tabular}

a .05 $M$ isotonic phosphate buffer, $\mathrm{pH}=7.4, \mathrm{n}=3$

b $100 / \mathrm{kg}$ insulin $+0.05 \%$ NaTC solution, $n=4$ S.E-Standard Error 


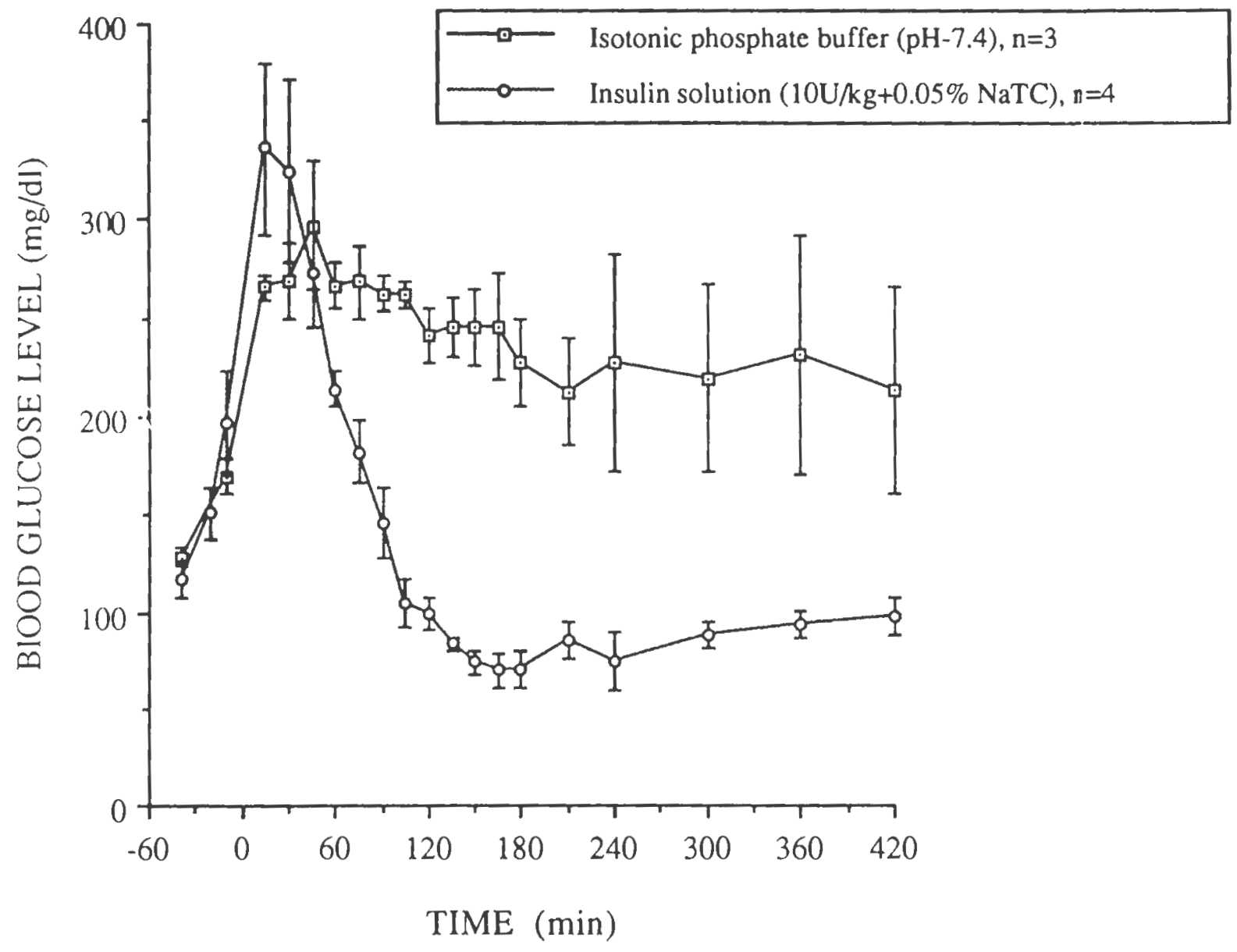

Figure 8. Blood Glucose as a Function of Time During Perfusion of Insulin and Buffer Solutions Using The Old Non-Surgical Technique 
methodology. Table 5 summarizes the results obtained by perfusing insulin solution $(10 \mathrm{U} / \mathrm{kg})$ containing $0.05 \%$ sodium taurocholate. As shown in the Figure 9, when isotonic phosphate buffer $(\mathrm{pH} 7.4)$ was perfused without insulin, there was a rise in blood glucose levels from $117.2 \pm 4.9$ to $265.8 \pm 23.6 \mathrm{mg} / \mathrm{dl}$ after administration of the anesthetics. Maximum blood glucose levels $(265.8 \pm 23.6 \mathrm{mg} / \mathrm{dl})$ were observed after 60 minutes. The blood glucose levels returned to normal after 6.0 hours. When insulin solution was perfused, a similar increase in glucose levels was observed. In this case, the perfusion of insulin solution resulted in a gradual reduction of glucose levels. The lowest average concentration of glucose was $88.8 \pm 5.4 \mathrm{mg} / \mathrm{dl}$ at 240 300 minutes after beginning of the perfusion.

The new technique, when compared to the old non-surgical perfusion technique, offers many advantages. The new technique is very simple and the animals can be reused without causing any damage to the nasal cavity. Placement of the cannula is much easier and requires less skill and/or practice than the old technique. Moreover the results are very reproducible. The results showed that the absorption was less in case of new technique when compared to the old technique. Figure 10 shows that the glucose reduction in case of old technique was higher and occurred in less time as compared to the new technique. The higher absorption of insulin with the old technique could be due to absorption of the drug in the throat. The drug solution might be entering the throat due to improper placement of the cannula. This was confirmed as the experiments progressed by the very variable and reduced quantities of perfusate collected from that originally added with the old technique. 
Table 5. Glucose concentration as a function of Time during Perfusion of Insulin and Buffer solutions Using The New Non-Surgical Perfusion Tecnnique

$\begin{array}{lll}\text { TIME } & \text { BLOOD GLUCOSE LEUEL }(\mathrm{mg} / \mathrm{d} I) \\ \text { (min) } & \text { Phosphate buffer } & \text { Insulin solution } \\ & \text { Mean+S.Ea } & \text { Mean+S.E }\end{array}$

\begin{tabular}{llc}
\hline-40 & $117.2 \pm 4.9$ & $113.3 \pm 5.8$ \\
-30 & administration of anesthetics \\
-20 & $151.0 \pm 12.3$ & $143.3 \pm 2.8$ \\
-10 & $189.0 \pm 12.3$ & $188.8 \pm 13.9$ \\
0 & nasal administration of insulin \\
15 & $238.6 \pm 23.7$ & $239.5 \pm 12.8$ \\
30 & $260.8 \pm 27.6$ & $253.7 \pm 16.2$ \\
45 & $252.4 \pm 21.3$ & $249.2 \pm 18.0$ \\
60 & $265.8 \pm 23.6$ & $230.7 \pm 20.3$ \\
75 & $258.4 \pm 23.7$ & $213.3 \pm 18.4$ \\
90 & $259.8 \pm 22.0$ & $193.3 \pm 25.2$ \\
105 & $255.6 \pm 20.9$ & $180.5 \pm 25.4$ \\
120 & $240.6 \pm 15.6$ & $153.7 \pm 24.3$ \\
135 & $225.6 \pm 14.7$ & $143.3 \pm 18.4$ \\
\hline
\end{tabular}


Table 5. (Continued)

\begin{tabular}{|c|c|c|}
\hline \multirow{3}{*}{$\begin{array}{l}\text { Time } \\
(\text { min })\end{array}$} & \multicolumn{2}{|c|}{ Blood glucose level (mg/dl) } \\
\hline & Phosphate buffer & Insulin solution \\
\hline & Mean+S.E & Mean+S.Eb \\
\hline 150 & $220.6 \pm 11.8$ & $126.0 \pm 19.2$ \\
\hline 165 & $211.8 \pm 15.7$ & $119.2 \pm 16.8$ \\
\hline 180 & $199.2 \pm 14.1$ & $108.8 \pm 11.3$ \\
\hline 210 & $176.2 \pm 14.0$ & $100.5 \pm 12.8$ \\
\hline 240 & $158.4 \pm 14.5$ & $92.0 \pm 10.2$ \\
\hline 300 & $132.0 \pm 4.8$ & $88.8 \pm 5.4$ \\
\hline 360 & $117.8 \pm 1.8$ & $107.8 \pm 9.2$ \\
\hline 420 & $107.8 \pm 3.7$ & $116.2 \pm 9.0$ \\
\hline
\end{tabular}

a $0.05 \mathrm{M}$ isotonic phosphate buffer, $\mathrm{pH}=7.4, \mathrm{n}=5$

b $100 / \mathrm{kg}$ insulin $+0.05 \%$ NaTC solution, $n=6$, S.E-Standard Error 


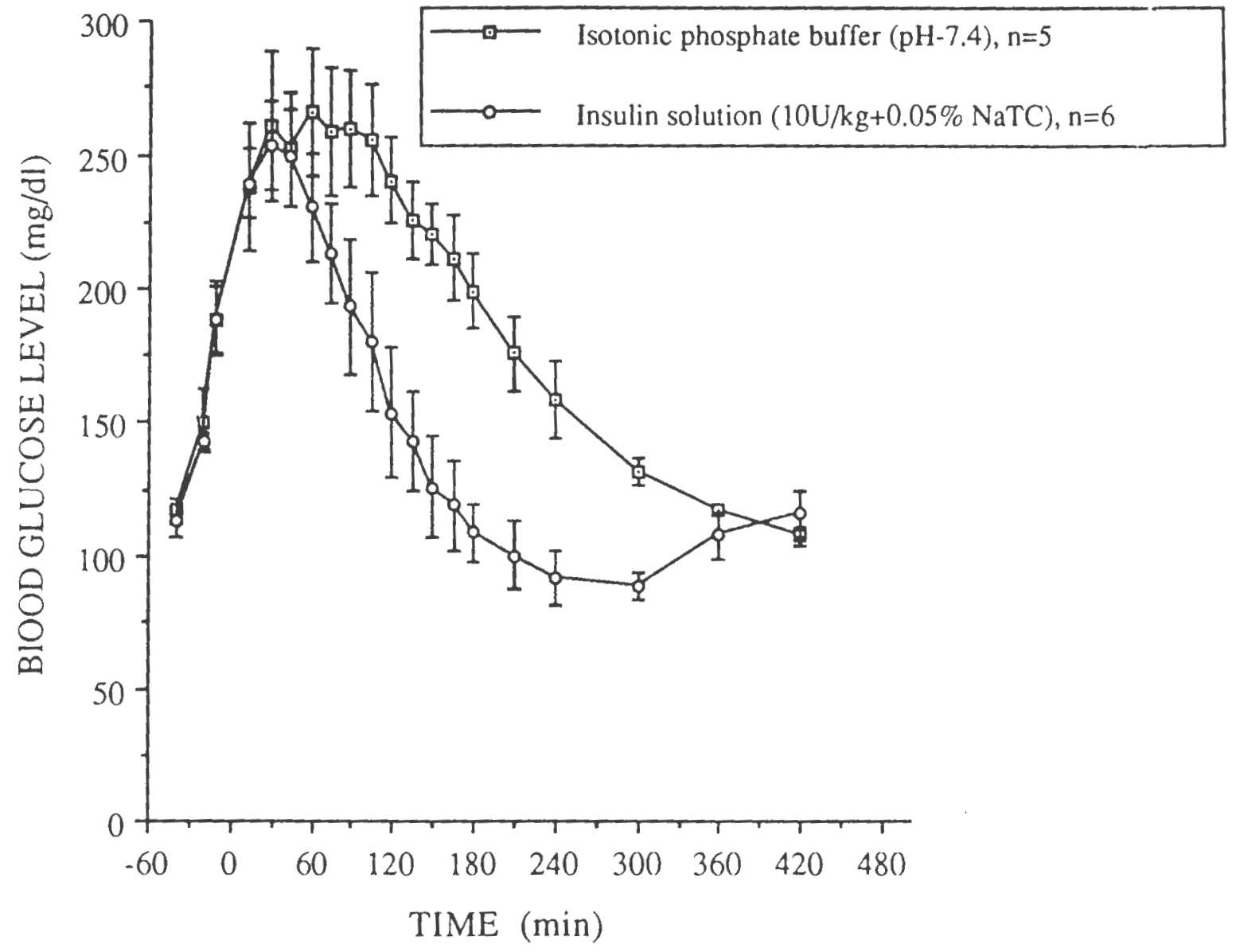

Figure 9. Blood Glucose as a Function of Time During Perfusion of Insulin and Buffer Solutions Using The New Non-Surgical Technique 


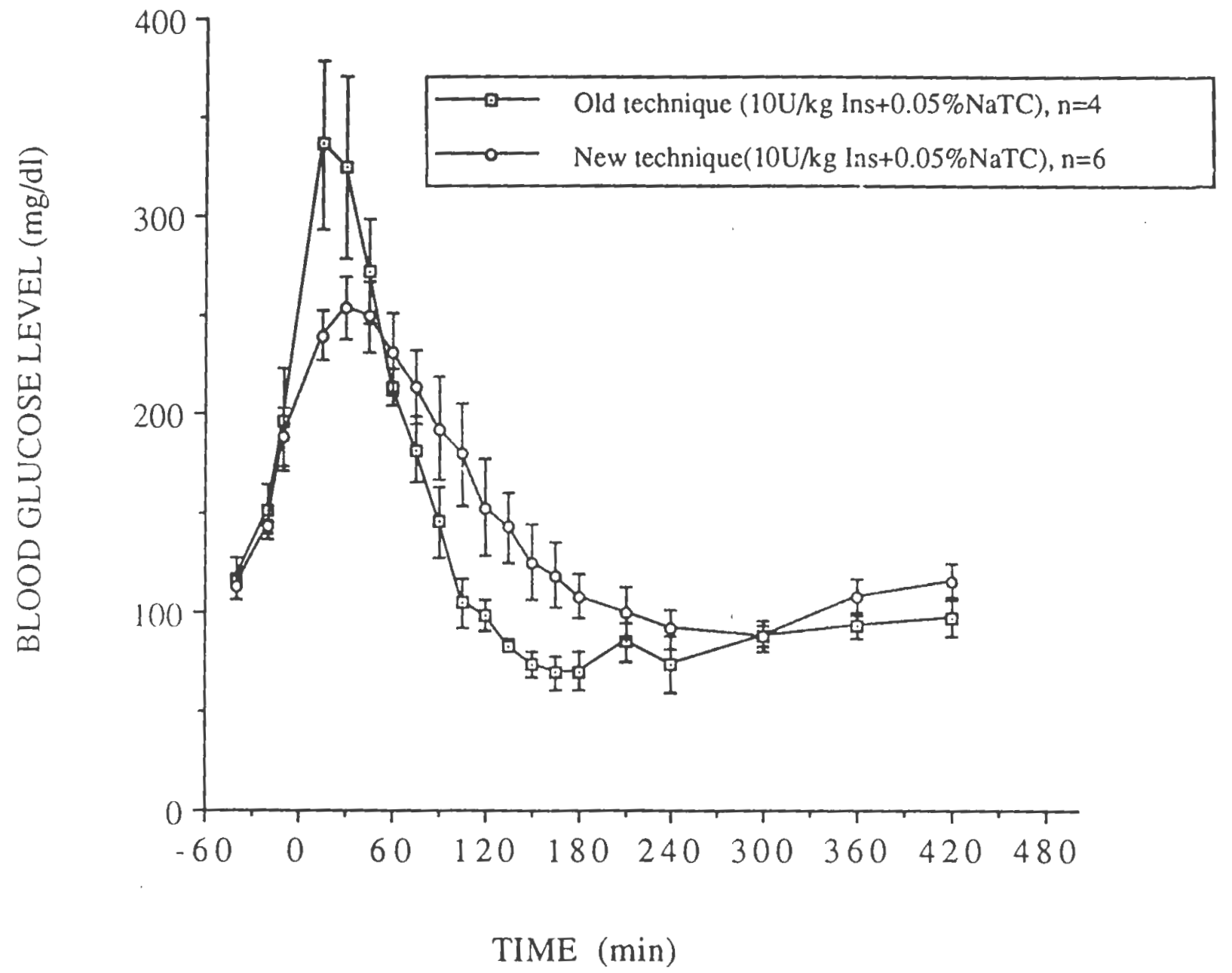

Figure 10. Comparison of the Reduction in Blood Glucose Using the Two Non-Surgical Perfusion Techniques 
Compared to the surgical technique (Hirai et al., 1981a), the new non-surgical perfusion technique offers many advantages. The obvious advantage is the simplicity of technique which does not require surgery. A second advantage is the reusability of animals after each experiment. In previous cases where surgery is involved, the animals had to be sacrificed resulting in not only increased cost but also the animals can not act as their own controls. Hence a crossover study is not feasible with the Hirai animal model. The present technique will enable the researchers to utilize the crossover studies to reduce inter-animal variability which often produces discrepencies in extrapolating data in animals to humans (Adjei, 1990; Baldwin et al., 1990; Deurloo, 1989). Although the rabbit was used as animal model in this study, it is expected that the new nonsurgical perfusion technique can be applied to other animals without modification.

\subsubsection{Physicochemical Parameters to be Considered During Perfusion Studies:}

(a) Effect of Anesthetics:

During these studies, a significant increase in glucose levels was observed after administration of the anesthetics. To better define this observation, a control experiment was carried using two different anesthetic combinations. Table 6 shows the effect of anesthetics on blood glucose levels in rabbits. Sodium pentobarbital did not exhibit any increase in blood glucose levels as evident from Figure 11. The combination of anesthetics used in the perfusion studies i.e. ketamine hydrochloride, acepromazine maleate and 
Table 6. Effect of Anesthetics on Blood Glucose Levels in Rabbits

\begin{tabular}{llc}
\hline $\begin{array}{l}\text { TIME } \\
(\mathrm{min})\end{array}$ & $\begin{array}{c}\text { BLOOD GLUCOSE LEUELS } \begin{array}{c}\text { (mg/dI) } \\
\text { Controlsa } \\
\text { Mean+S.E }\end{array} \\
\text { Mean+S.E }\end{array}$ \\
\hline-40 & $\begin{array}{l}\text { 112.3 } \\
\text { adminis tration of anesthe tics }\end{array}$ \\
-30 & $132.8 \pm 10.9$ & $102.7 \pm 9.6$ \\
-20 & $171.1 \pm 17.3$ & $90.7 \pm 8.2$ \\
-10 & $221.1 \pm 22.6$ & $89.7 \pm 5.7$ \\
15 & $226.6 \pm 23.4$ & $89.0 \pm 4.0$ \\
30 & $225.1 \pm 23.6$ & $90.3 \pm 4.4$ \\
45 & $229.6 \pm 22.7$ & $88.0 \pm 2.6$ \\
60 & $227.5 \pm 22.4$ & $89.7 \pm 3.3$ \\
75 & $230.5 \pm 21.7$ & $88.7 \pm 4.2$ \\
90 & $219.5 \pm 21.6$ & - \\
105 & $216.4 \pm 19.4$ & $84.7 \pm 4.7$ \\
120 & $205.6 \pm 17.5$ & - \\
135 & & \\
\hline
\end{tabular}


Table 6. (Continued)

\begin{tabular}{lcc}
$\begin{array}{l}\text { TIME } \\
(\mathrm{min})\end{array}$ & $\begin{array}{c}\text { BLOOD GLUCOSE LEUELS } \\
\text { Controls } \\
\text { Mean+S.E }\end{array}$ & $\begin{array}{c}\text { (mi) } \\
\text { Controlsb } \\
\text { Mean+S.E }\end{array}$ \\
\hline 150 & $186.9 \pm 15.4$ & $95.7 \pm 12.7$ \\
165 & $178.6 \pm 16.3$ & - \\
180 & $170.3 \pm 16.0$ & $90.7 \pm 8.3$ \\
210 & $153.1 \pm 13.3$ & $92.0 \pm 7.2$ \\
240 & $142.9 \pm 11.1$ & $94.7 \pm 7.2$ \\
300 & $128.5 \pm 12.2$ & $89.3 \pm 3.2$ \\
360 & $114.5 \pm 8.0$ & $90.7 \pm 4.9$ \\
420 & $117.6 \pm 11.5$ & $90.0 \pm 4.6$ \\
\hline
\end{tabular}

a Anesthetics used: Ketamine Hydrochloride, Acepromazine Maleate, and Bylazine Hydrochloride, $n=8$

b Anesthetics used: Pentobarbital Sodium, $n=3$ 


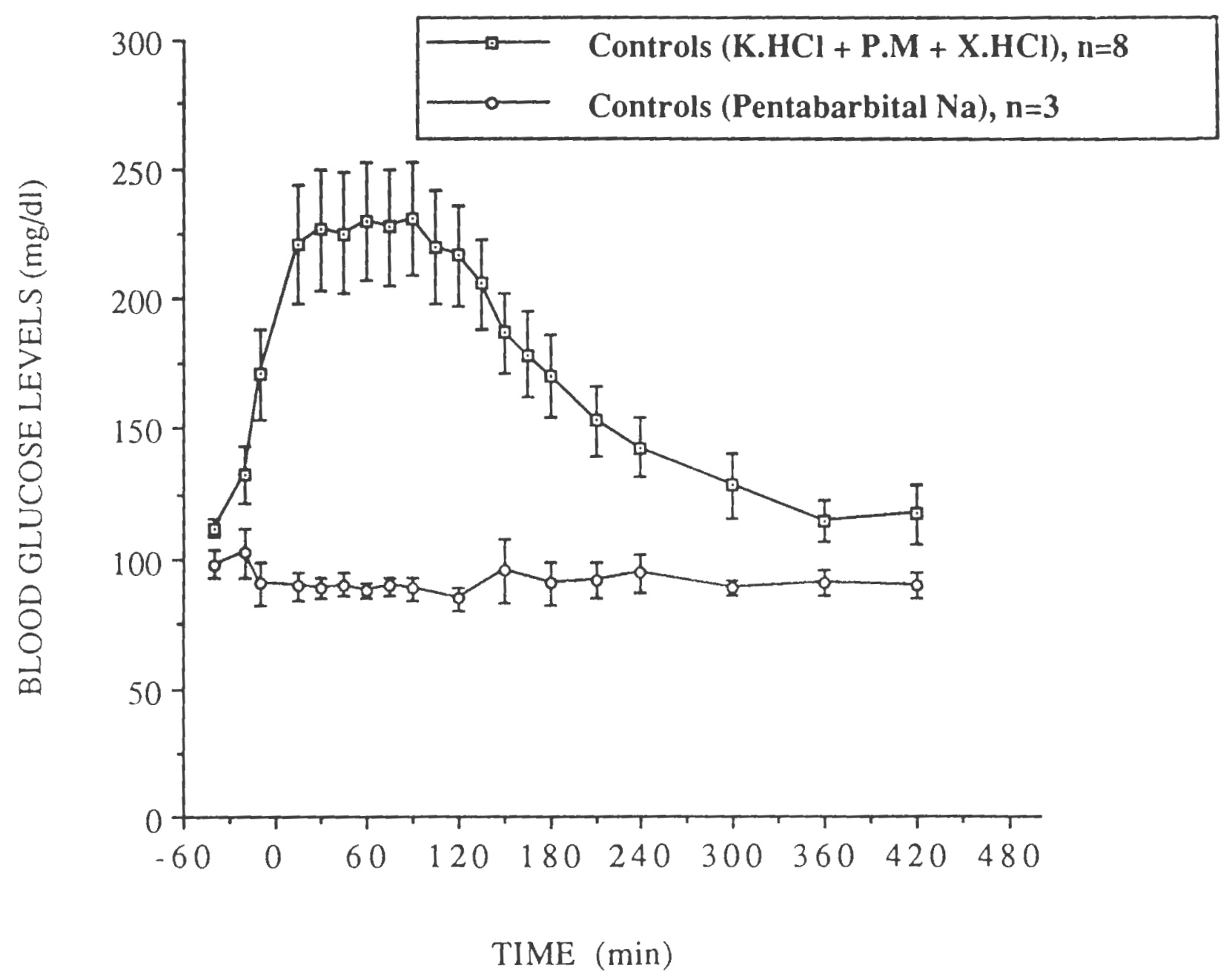

Figure 11. Effect of Anesthetics on Rabbit Blood Glucose Levels 
xylazine hydrochloride caused a rapid rise in blood glucose levels within 10 minutes after administration. Maximum glucose levels $(230.5 \pm 21.7 \mathrm{mg} / \mathrm{dl})$ were observed at $90-120$ minutes after administration. The glucose levels returned to normal after approximately 7.0 hours. These results were found to be very consistent and reproducible throughout the study in all the rabbits. Sodium pentobarbital did not cause any change in blood glucose levels, but could not be used in this study as it provides anesthesia for only 45 minutes and subsequent doses may cause death to the rabbits. For these perfusion studies, anesthesia of 4 to 4.5 hours was required and the above mentioned combination of drugs provided constant deep and safe anesthesia. Since the change in blood glucose levels was consistent and predictable, the same combination of anesthetics was used throughout the study to maintain the uniform conditions.

The mechanism for the increase in blood glucose levels by anesthetics is not very clear. Ketamine may be increasing plasma epinephrine and norepinephrine levels upon injection which may cause glycogenesis in liver cells (Katzung, 1989; Kahn et al., 1991). Glycogenesis is the conversion of glycogen to glucose, which might be the reason for the high glucose levels observed after injection of anesthetics.

(b) Positioning of The Rabbit Head: The nasal cavity is like a bowl. When perfusion is initiated, this cavity is filled with perfusate water and the excess solution starts flowing from the left nostril. The placement angle of the rabbit head is very critical. If the angle is too 
high, the head will be inclined too low, the cavity will not be filled and lower absorption will result. If the angle is above the horizontal plane, solution will be lost down the throat resulting an ever decreasing volume of perfusate. In this study, the rabbit head was placed at an angle of $14^{0}-15^{0}$ from the horizontal plane. The amount of perfusate collected was a constant 18 to $19 \mathrm{ml}$ out of $20 \mathrm{ml}$ throughout the testing which confirmed proper placement of head to achieve maximum and reproducible absorption for each formulation.

(c) Other Factors: Other factors which would influence the absorption of insulin from the nasal cavity are: the rate at which insulin solution was perfused, volume of the perfusate, the time of perfusion (Huang et al., 1985, 1985a) and the $\mathrm{pH}$ of the perfusate (Hirai et al., 1978). In this study all of these parameters were held constant to minimize the affect on the aborption of insulin. Further studies are required to define the specific effect of each parameter.

\subsection{Evaluation of Nasal Formulations:}

After establishing the experimental conditions for the new perfusion technique and validating the rabbit as the animal model, the second phase of this project was to evaluate the comparative bioavailability of various nasal formulations of insulin using this model. The formulations to be compared with the perfusion technique were sprays containing different doses of insulin, polyacrylic acid microparticles loaded with insulin, as well as a subcutaneous injection of insulin to establish baseline parenteral bioavailability. 


\subsubsection{Spray formulations:}

Spraying a formulation into the nasal cavity is the most popular and convenient means of delivering nasal products. For most of the drugs designated for nasal administration, the final dosage form will be a spray formulation. The reasons are obvious: spraying of drugs results in rapid absorption and in high plasma levels similar to those observed after an i.v. injection. Sprays result in the deposition of material on the nonciliated regions and hence the clearance of sprays is slower compared to drops. This results in increased absorption rates when as compared to nasal drops. Sprays are easy to administer and very convenient thus giving increased patient compliance. Sprays provide consistent dosing as compared to powders and drops.

Spray formulations containing a series of increasing doses of insulin were evaluated $(1.25,2.5,5.0,10.0 \mathrm{U} / \mathrm{kg})$ using the rabbit model. All the sprays contained $1 \% \mathrm{w} / \mathrm{v}$ of sodium taurocholate as an enhancer. The results are summarized in Table 7 and shown in Figure 12. Spray $3(10 \mathrm{U} / \mathrm{kg})$ resulted in lowest glucose levels of $38.3 \pm 1.15 \mathrm{mg} / \mathrm{dl}$ at 60 minutes. It was possible to replicate this $10 \mathrm{U} / \mathrm{kg}$ dose in only three rabbits because $10 \mathrm{U} / \mathrm{kg}$ was found to be fatal dose for some rabbits due to the rapid absorption of this large amount of insulin. Spray $4(5 \mathrm{U} / \mathrm{kg})$ gave minimum glucose levels $(47.4 \pm 9.9 \mathrm{mg} / \mathrm{dl})$ at 60 minutes. In case the of Spray $5(2.5 \mathrm{U} / \mathrm{kg})$, the lowest glucose levels $87.4 \pm 11.1 \mathrm{mg} / \mathrm{dl}$ were observed at 45 minutes. The spray 6 formulation containing $1.25 \mathrm{U} / \mathrm{kg}$ of insulin resulted in minimum levels of $102.7 \pm 14.4 \mathrm{mg} / \mathrm{dl}$ at 90 minutes after administration of the spray into the nasal cavity. When compared to 
Table 7. Effect of Insulin Spray Formulations on Rabbit Blood Glucose Levels

\begin{tabular}{|c|c|c|c|c|}
\hline \multirow{2}{*}{$\begin{array}{l}\text { rime } \\
\text { (min) }\end{array}$} & \multicolumn{4}{|c|}{ MEAN BLOOD GLUCOSE LEUELS (mg/dI) } \\
\hline & Sprayza & Spray $4^{b}$ & Spray $5 \mathrm{C}$ & Sproy6 $6^{d}$ \\
\hline-40 & $107.7 \pm 6.4$ & $106.0 \pm 2.9$ & $103.0 \pm 6.7$ & $99.6 \pm 4.1$ \\
\hline-30 & \multicolumn{4}{|c|}{ administration of anesthetics } \\
\hline-20 & $125.7 \pm 0.3$ & $125.6 \pm 4.6$ & $120.2 \pm 4.2$ & $117.4 \pm 3.7$ \\
\hline-10 & $145 \pm 13.4$ & $143.4 \pm 4.2$ & $152.0 \pm 11.3$ & $165.2 \pm 13.0$ \\
\hline 0 & \multicolumn{4}{|c|}{ nasal administration of insulin spray } \\
\hline 15 & $92.1 \pm 9.5$ & $105.4 \pm 6.7$ & $144.4 \pm 12.9$ & $152.2 \pm 15.9$ \\
\hline 30 & $70.7 \pm 12.8$ & $70.6 \pm 8.6$ & $98.7 \pm 9.8$ & $127.3 \pm 14.9$ \\
\hline 45 & $58.0 \pm 14.6$ & $53.4 \pm 8.4$ & $87.4 \pm 11.1$ & $110.0 \pm 16.1$ \\
\hline 60 & $38.3 \pm 1.15$ & $47.4 \pm 9.9$ & $89.3 \pm 14.8$ & $112.4 \pm 18.4$ \\
\hline 75 & $59.9 \pm 17.7$ & $52.9 \pm 9.6$ & $88.5 \pm 13.3$ & $105.9+18.3$ \\
\hline 90 & $77.2 \pm 31.5$ & $58.4 \pm 7.8$ & $94.3 \pm 13.4$ & $102.7 \pm 14.4$ \\
\hline 105 & $72.9 \pm 17.1$ & - & - & - \\
\hline 120 & $74.2 \pm 16.5$ & $65.4 \pm 7.9$ & $98.4 \pm 15.3$ & $107.0 \pm 14.3$ \\
\hline 135 & $60.1 \pm 2.2$ & - & - & - \\
\hline
\end{tabular}


Table 7. (Continued)

\begin{tabular}{lllll}
\hline $\begin{array}{l}\text { Time } \\
(\mathrm{min})\end{array}$ & Spray3 & $\begin{array}{c}\text { MEAN BLO0D GLUCOSE LEUELS }(\mathrm{mg} / \mathrm{d} I) \\
\text { Spray4b }\end{array}$ & Spray5c & Spray6d \\
\hline 150 & & & & \\
165 & $75.0 \pm 16.1$ & $71.6 \pm 5.4$ & $103.2 \pm 15.6$ & $105.8 \pm 11.5$ \\
180 & $60.4 \pm 4.5$ & - & - & - \\
210 & $75.7 \pm 14.4$ & $74.1 \pm 6.2$ & $99.1 \pm 12.1$ & $109.0 \pm 13.1$ \\
240 & $75.4 \pm 15.2$ & $71.6 \pm 6.3$ & $101.5 \pm 12.0$ & $105.4 \pm 10.2$ \\
300 & $64.7 \pm 10.8$ & $4.7 \pm 8.3$ & $98.5 \pm 11.9$ & $105.3 \pm 10.0$ \\
360 & $77.3 \pm 13.5$ & $81.3 \pm 8.4$ & $106.5 \pm 5.5$ & $98.6 \pm 6.8$ \\
420 & $85.7 \pm 14.9$ & $82.3 \pm 5.4$ & $99.9 \pm 5.6$ & $101.2 \pm 11.1$ \\
& $85.3 \pm 12.2$ & $84.5 \pm 5.1$ & $111.5 \pm 7.9$ & $108.8 \pm 17.6$ \\
\hline
\end{tabular}

a Dose $-10 \mathrm{U} / \mathrm{kg}$ insulin $+1 \% \mathrm{w} / \mathrm{v}$ sodium taurocholate, $n=3$

b Dose $-5 \mathrm{U} / \mathrm{kg}$ insulin $+1 \% \mathrm{w} / \mathrm{v}$ sodium taurocholate, $n=5$

c Dose $-2.5 \mathrm{U} / \mathrm{kg}$ insulin $+1 \% \mathrm{w} / \nu$ sodium taurocholate, $n=5$

d Dose $-1.25 \mathrm{U} / \mathrm{kg}$ insulin $+1 \% \mathrm{w} / \mathrm{v}$ sodium taurocholate, $n=5$ 


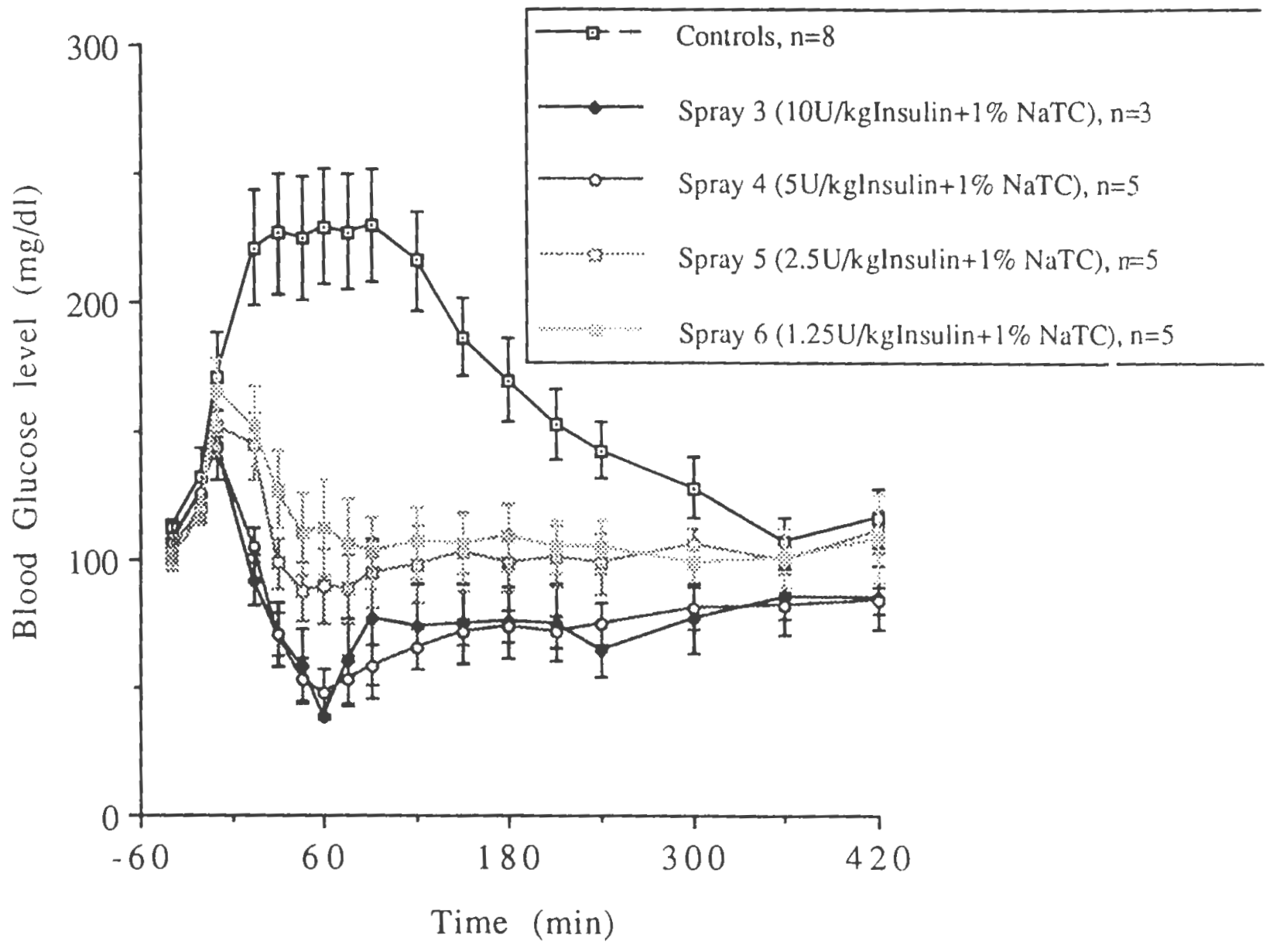

Figure 12. Blood Glucose Concentration as a Function of Time After Administration of Insulin Nasal Spray 
the controls, as the insulin dose was lowered from $10 \mathrm{U} / \mathrm{kg}$ to 1.25 $\mathrm{U} / \mathrm{kg}$, the insulin effect in terms of glucose reduction was reduced gradually.

\subsubsection{Comparison of spray and perfusion:}

Figure 13 compares the results obtained using the new perfusion technique and a comparable nasal spray. Spray 3 containing $10 \mathrm{U} / \mathrm{kg}$ of insulin resulted in an immediate reduction in glucose levels. Minimum levels were observed at 60 minutes. The perfusion method resulted in a gradual reduction in glucose levels. The lowest levels were observed after 240-300 minutes. The absorption of insulin from the nasal spray was faster compared to the perfused insulin solution. The reasons for this may be the higher concentration of enhancer present in the spray $(1 \mathrm{mg} / 100 \mu \mathrm{l})$ compared to the perfusion solution $(10 \mathrm{mg} / 20 \mathrm{ml})$. It has been reported that as the concentration of enhancer increases, drug absorption will increase (Lee, 1990). Another reason may be that, for the spray all the insulin $(10 \mathrm{U} / \mathrm{kg})$ was in $100 \mu \mathrm{l}$ and administered at one time. Whereas in the case of perfusion, the same amount of insulin $(10 \mathrm{U} / \mathrm{kg})$ was supplied to the nasal cavity in $20 \mathrm{ml}$ of solution and over a 3.5 hour period.

The exact mechanism of action of sodium taurocholate is not known. However, it is thought to involve both solubilization of insulin, and the direct effect of the surfactant on cell membranes perhaps involving reverse micelle formation (Gordon et al., 1985). The addition of bile salt is thought to result in formation of mixed micelles of bile salt and insulin as insulin monomers (Gordon et al., 1985). When sprayed into the nasal passages, a high transmembrane 


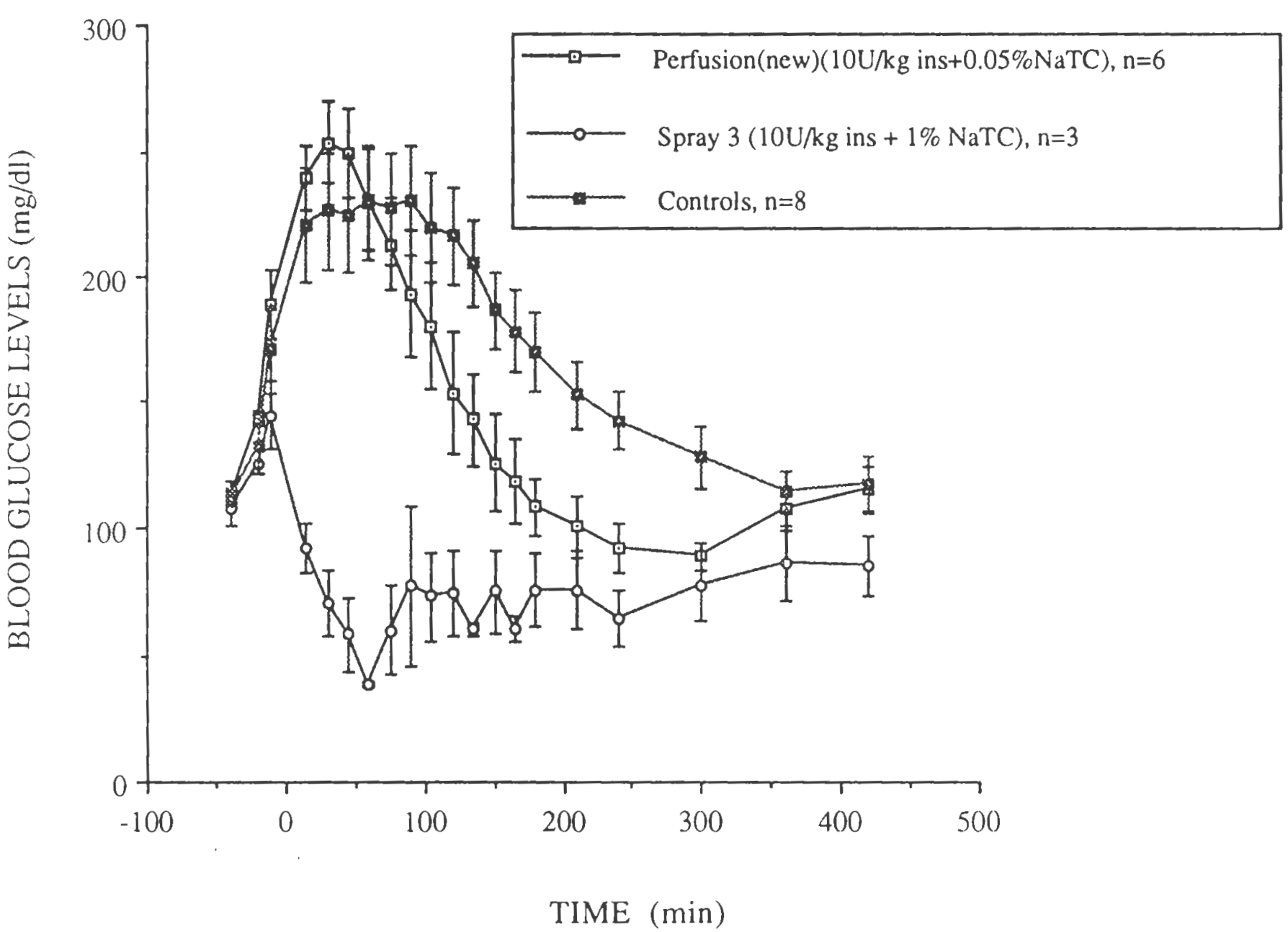

Figure 13. Comparison of Blood Glucose Levels After Administration of Insulin by Nasal Spray and Perfusion methods 
concentration gradient of solubilized insulin monomers would serve to drive insulin transport across the mucosal barrier. Sodium taurocholate may also increase the membrane permeability by loosening the intercellular junctions and/or by increasing the number of pores in the cell membrane (Birkett et al., 1974). It is well known that a polypeptide such as insulin is subjected to degradation by proteolytic enzymes during passage through the mucosal membrane. However, it has also been reported that the addition of bile salts resulted in inhibition of the enzymatic degradation of insulin and of the enzymatic activity of leucine aminopeptidase, which rapidly breaks down the B-chain of insulin from the hydrophobic N-terminal end (Hirai et al., 1981b). Never the less additional studies are required to determine the relationship between the enhancer concentration used in perfusion formulations and that utilized in spray formulations as well as the different mechanism of providing increased absorption shown by the different enhancers.

The bioavailability realized when testing formulations administered by different routes should be compared to a baseline level to evaluate the relative success of these efforts. Usually the amount of drug absorbed nasally is quantified by comparing the plasma levels of the drug or the biologic response after nasal administration to those levels observed after i.v. injection. Since insulin is usually given subcutaneously, the baseline response in this project was obtained by injecting insulin subcutaneously and the nasal formulations were evaluated relative to this baseline response. Table 8 summarizes the results obtained following subcutaneous 
Table 8. Observed Blood Glucose Levels After Administration of Insulin by Subcutaneous Route

\begin{tabular}{|c|c|}
\hline $\begin{array}{l}\text { TIME } \\
(\min )\end{array}$ & $\begin{array}{l}\text { BLOOD GLUCOSE LEUELS (mg/dI) } \\
\text { Subcutaneousa }\end{array}$ \\
\hline-40 & $104.0 \pm 5.1$ \\
\hline-30 & administration of anesthetics \\
\hline-20 & $117.0 \pm 2.2$ \\
\hline-10 & $142.8 \pm 3.7$ \\
\hline $\mathbf{0}$ & administration of insulin \\
\hline 15 & $205.6 \pm 8.2$ \\
\hline 30 & $199.6 \pm 7.5$ \\
\hline 60 & $149.4 \pm 12.3$ \\
\hline 75 & $125.4 \pm 13.2$ \\
\hline 90 & $106.8 \pm 9.3$ \\
\hline 120 & $77.4 \pm 6.5$ \\
\hline 150 & $68.0 \pm 1.2$ \\
\hline 180 & $62.0 \pm 2.9$ \\
\hline 210 & $21.6 \pm 2.6$ \\
\hline 240 & $71.2 \pm 2.1$ \\
\hline 300 & $74.0 \pm 2.7$ \\
\hline 360 & $87.8 \pm 6.1$ \\
\hline 420 & $101.2 \pm 6.2$ \\
\hline
\end{tabular}

a Dose $-0.25 \mathrm{U} / \mathrm{kg}$ of insulin, $n=5$ 


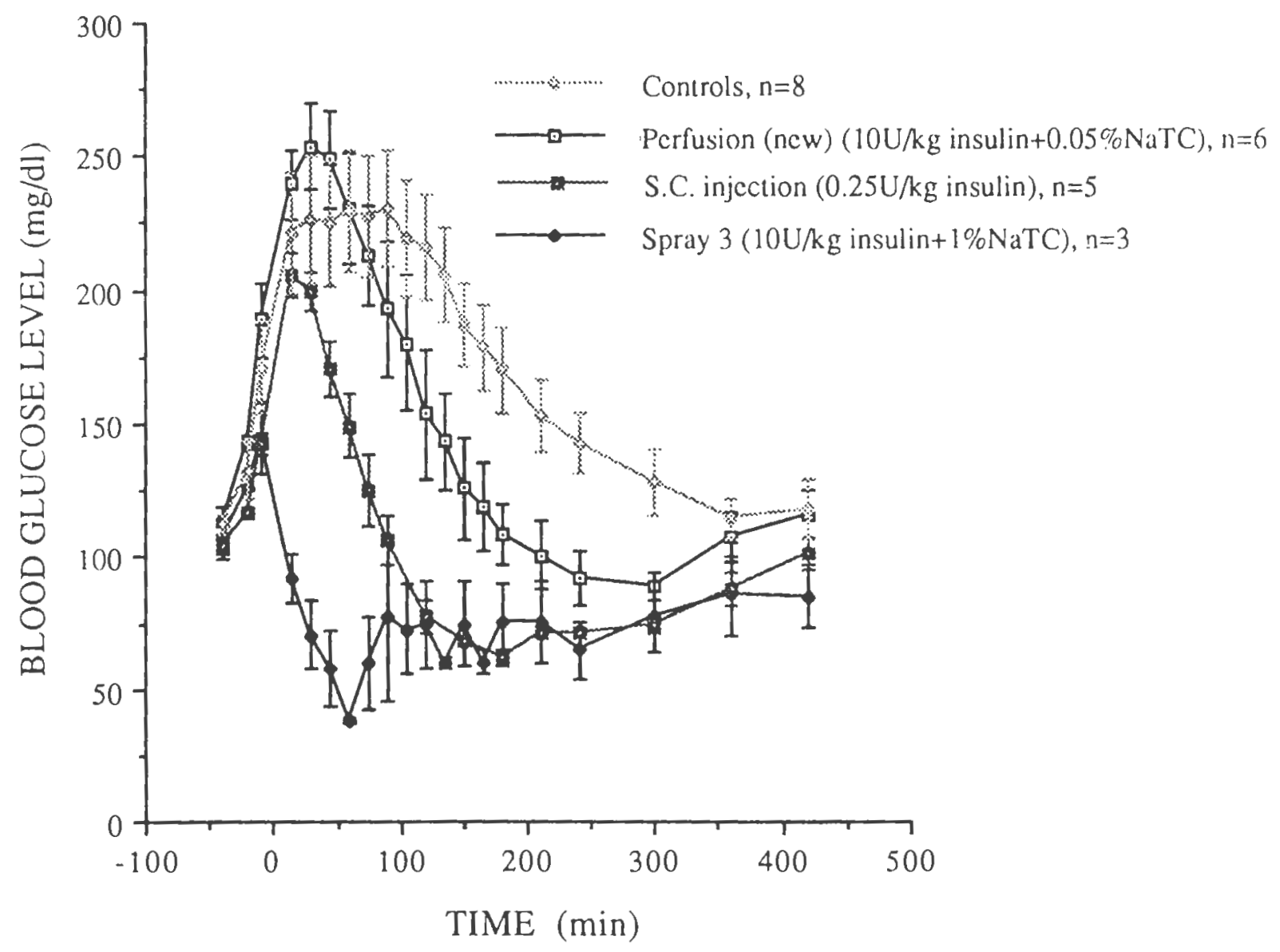

Figure 14. Comparison of Blood Glucose Reduction After Administration of Insulin by Nasal and S.C. Routes 
injection. The subcutaneous injection of $0.25 \mathrm{U} / \mathrm{kg}$ of insulin, as expected, resulted in slower absorption of drug from the injection site. As evident from Figure 14, the reduction in glucose levels after s.c. injection, started after 15 minutes with the lowest levels of $62 \pm 2.9 \mathrm{mg} / \mathrm{dl}$ observed approximately 180 minutes after injection. The pattern of glucose reduction was quite different from $10 \mathrm{U} / \mathrm{kg}$ spray. The nasal spray resulted in immediate drop in glucose levels with minimum levels of $38.3 \pm 1.15 \mathrm{mg} / \mathrm{dl}$ at 60 minutes after administration. Approximately 180 minutes after administration of s.c injection, the glucose levels returned to normal in a profile similar to that seen in the case of the spray formulations.

\subsubsection{Gel Formulation Containing Insulin Microparticles:}

Although, the inclusion of bile salts in formulations could provide a reasonable increase in the efficacy of transport and reproducibility of dosing (Pontiroli et al., 1982; Moses et al., 1983), there are serious concerns regarding the local toxic effects and irritation of the biological membranes by these compounds. There are reports in the literature indicating that cholic acid derivatives cause a breakdown of the mucous membrane structure (Martin et al., 1976); accelerate phospholipid and protein release from membranes; and damage intestinal mucosa, liposomal membranes and isolated hepatocytes (Duchateau et al., 1986). Another problem faced in nasal drug delivery is that all solution formulations are cleared rapidly from the nasal cavity by the mucociliary clearance mechanism. The mucous blanket is replaced every 10-15 minutes thereby giving minimal contact time for absorption of the drug molecules. It is hypothesized that by increasing the contact time or residence time, 
increased absorption of drugs should result from the nasal membrane. Previous researchers have used bioadhesive polymers such as polyacrylic acid (PAA) and methyl cellulose to enhance the absorption of drugs from nasal cavity. Polyacrylic acid has also been used as an alternative enhancer to promote the absorption of insulin (Nagai et al., 1984; Morimoto et al., 1985) and was preferred to bile salts as it is less irritating and less toxic to the nasal membrane. In this study, polyacrylic acid was cross-linked with maltose to obtain microspheres. The microspheres were loaded with insulin and freeze-dried to remove water from the system. The free flowing microparticles thus obtained were administered nasally in al\% w/v poyacrylic acid gel at pH-6.0.

Polyacrylic acid microparticles loaded with insulin, when administered nasally in a gel base to the rabbits, resulted in lower glucose levels as compared to the controls. As evident from Figure 15, initially there was an increase in the glucose levels due to the effect of anesthetics and then there was a gradual reduction in the glucose levels over a period of 5.0 hours. Maximum glucose levels of $186.0 \pm 19.3 \mathrm{mg} / \mathrm{dl}$ were observed approximately 75 minutes after administration of gel formulation (Table 9). The observed glucose levels throughout 7.0 hours were lower than those of the controls indicating that the formulation was providing controlled release of insulin.

As evident in Figure 15, the spray provides a quicker response and a greater reduction in glucose levels. Polyacrylic acid is bioadhesive in nature and increases the residence time of 
Table 9. Observed Blood Glucose Levels After Administration of Insulin by Nasal Route

\begin{tabular}{lc}
\hline $\begin{array}{l}\text { TIME } \\
(\mathrm{min})\end{array}$ & $\begin{array}{c}\text { BLOOD GLUCOSE LEUELS }(\mathrm{mg} / \mathrm{dl}) \\
\text { Nasal Gel formulation }\end{array}$ \\
\hline-40 & $114.6 \pm 3.9$ \\
-30 & administration of anesthetics \\
-20 & $131.6 \pm 3.2$ \\
-10 & $152.8 \pm 7.3$ \\
0 & administration of insulin \\
15 & $177.4 \pm 18.8$ \\
30 & $170.4 \pm 16.4$ \\
45 & $184.2+22.3$ \\
60 & $181.4 \pm 21.1$ \\
75 & $186.0 \pm 19.3$ \\
90 & $182.4 \pm 22.2$ \\
120 & $162.2 \pm 21.2$ \\
150 & $148.6 \pm 22.9$ \\
180 & $141.2 \pm 23.3$ \\
210 & $131.6 \pm 16.5$ \\
240 & $118.2 \pm 15.2$ \\
300 & $94.2 \pm 8.3$ \\
360 & $81.0 \pm 4.0$ \\
420 & $88.2 \pm 7.4$
\end{tabular}

a Polyacrylic microparticles were loaded with insulin $(100 / \mathrm{kg})$ and administered with $1 \%$ $w / v$ polyacrylic acid gel at $\mathrm{pH}=6.0, \mathrm{n}=5$ 


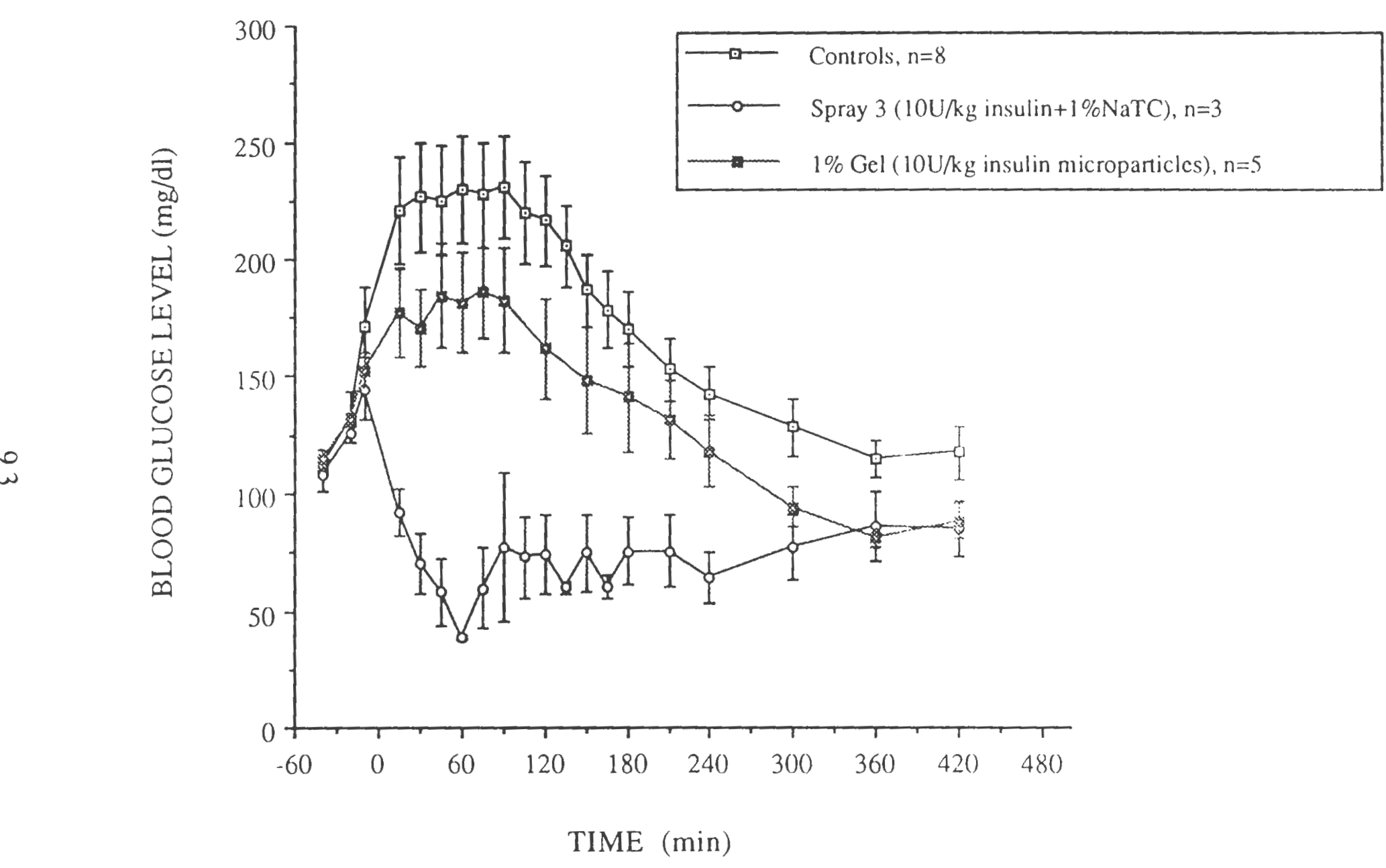

Figure 15. Comparison of Blood Glucose Reduction After Administration of Insulin by Spray and Gel Formulation 
formulation in the nasal cavity and thus provides a prolonged effect for a relatively less absorbed drug.

\subsection{Statistical analysis:}

A split-plot design was as used to evaluate the drug treatment effects on five rabbits over a time period of seven hours. Rabbit, type of treatment (formulation/administration) and time were the three factors used in the ANOVA procedure.

The $\mathrm{p}$ value obtained from the ANOVA table for the rabbit, treatment and time factors is same, and is equal to 0.0001 . There are significant interaction effects between treatment and time and treatment and rabbits $(p=0.0001)$. No significant interaction effects were observed between time and rabbits.

Least Significant Difference (LSD) test was used for pairwise comparisons between means of treatments, time and rabbits. All the determinations of significance were made at the $95 \%$ confidence level.

Controls were significantly different from perfusion (new), spray $4(5 \mathrm{U} / \mathrm{kg})$, spray $5(2.5 \mathrm{U} / \mathrm{kg})$, spray $6(1.25 \mathrm{U} / \mathrm{kg})$, s.c. and PAA microparticles (LSD=7.9931). Perfusion of insulin $(10 \mathrm{U} / \mathrm{kg})$ solution using the new technique resulted in reduction in glucose that was significantly different from spray $4(5 \mathrm{U} / \mathrm{kg})$, spray $5(2.5$ $\mathrm{U} / \mathrm{kg}$ ), spray $6(1.25 \mathrm{U} / \mathrm{kg})$, s.c. and PAA microparticles ( $\mathrm{LSD}=7.9931$ ). Spray $4(5 \mathrm{U} / \mathrm{kg})$ resulted in significant glucose reduction in rabbits compared to spray $5(2.5 \mathrm{U} / \mathrm{kg})$, spray $6(1.25 \mathrm{U} / \mathrm{kg})$, s.c. and PAA microparticles $(\mathrm{LSD}=7.9931)$. Spray $5(2.5 \mathrm{U} / \mathrm{kg})$ was found to be significantly different from spray $6(2.5 \mathrm{U} / \mathrm{kg})$, s.c. and PAA 
microparticles. No significant differences were observed between spray $6(1.25 \mathrm{U} / \mathrm{kg})$ and s.c. injection. Glucose levels observed after administration of PAA microparticles $(10 \mathrm{U} / \mathrm{kg}$ ) were found to be significantly different from those observed after administration of spray $6(1.25 \mathrm{U} / \mathrm{kg})$ and s.c. injection $(0.25 \mathrm{U} / \mathrm{kg})$.

Significant differences were observed between three rabbits (LSD=6.7554). No significant differences were observed between the two remaining rabbits.

\subsection{Comparison of Apparent Pharmacokinetic Parameters:}

The mean differences in glucose levels for rabbits receiving the various formulations and those of the controls were used to assess the apparent pharmacokinetic parameters. The results are summarized in Tables $10 \& 11$ and shown visually in Figures $16 \& 17$. $\mathrm{C}_{\max }$ is the maximum difference in glucose level from that of control. The time at which maximum difference was observed is $t_{\max }$. The observed values for $C_{\max }$ and $t_{\max }$ are given in Table 12 .

The time at which the maximum effect observed was relatively same for all the spray formulations. The $t_{\max }$ values are $70 \pm 10$, $63 \pm 7.3,69 \pm 9$ and $75 \pm 7.5$ minutes for spray $3(10 \mathrm{U} / \mathrm{kg})$, spray 4 (5 $\mathrm{U} / \mathrm{kg}$ ), spray $5(2.5 \mathrm{U} / \mathrm{kg})$, spray $6(1.25 \mathrm{U} / \mathrm{kg})$ respectively. No significant differences in $\mathrm{t}_{\mathrm{max}}$ values were observed for spray 4 ( 5 $\mathrm{U} / \mathrm{kg})$, spray $5(2.5 \mathrm{U} / \mathrm{kg})$ and spray $6(1.25 \mathrm{U} / \mathrm{kg})$. Subcutaneous injection of insulin and nasal gel formulation resulted in $t_{\max }$ values of $120 \pm 18.4$ and $222 \pm 62.6$ minutes respectively. The $t_{\max }$ value for s.c. injection differed significantly from those values for the spray formulations. The perfusion studies resulted in $t_{\max }$ values of $147 \pm 20.3$ minutes for the new technique and $180 \pm 60.9$ minutes for 
Table 10. Comparison of Mean Deviations in Blood Glucose Levels Compared to Controls After Adminitration of Insulin Spray Formulations

\begin{tabular}{|c|c|c|c|c|c|}
\hline \multirow{2}{*}{$\begin{array}{l}\text { TIME } \\
\text { (min) }\end{array}$} & \multicolumn{4}{|c|}{ Mean Deviations from Controlsa $(\mathrm{mg} / \mathrm{dl})$} & \multirow{3}{*}{-} \\
\hline & Spray 3b & Spray $4 c$ & spray 50 & Soray $6 \mathrm{e}$ & \\
\hline-40 & $17.5 \pm 14.5$ & $9.2 \pm 3.8$ & $12.2 \pm 5.3$ & $11.2 \pm 8.2$ & \\
\hline-30 & \multicolumn{4}{|c|}{ administration of anesthetics } & \\
\hline-20 & 67.0 & 73.0 & $28.3 \pm 21.3$ & $22.0 \pm 13.5$ & \\
\hline-10 & $63.7 \pm 15.0$ & $63.0 \pm 22.3$ & $49 \pm 2.1$ & $41.0 \pm 4.0$ & \\
\hline 0 & \multicolumn{4}{|c|}{ administration of insulin } & \\
\hline 15 & $176.0 \pm 32.7$ & $128.2 \pm 34.1$ & $89.2 \pm 20.5$ & $81.4 \pm 29.7$ & \\
\hline 30 & $200.5 \pm 21.6$ & $171.2 \pm 24.2$ & $143.1 \pm 19.8$ & $114.5 \pm 29.8$ & \\
\hline 45 & $218.4 \pm 14.5$ & $191.2 \pm 24.0$ & $157.2 \pm 18.0$ & $134.6 \pm 36.9$ & \\
\hline 60 & $219.1 \pm 23.3$ & $199.2 \pm 17.8$ & $157.3 \pm 12.1$ & $134.2 \pm 39.7$ & \\
\hline 75 & $209.2 \pm 13.8$ & $188.3 \pm 18.3$ & $152.7 \pm 14.8$ & $135.3 \pm 40.3$ & \\
\hline 90 & $214.1 \pm 20.8$ & $187.4 \pm 23.3$ & $151.5 \pm 21.1$ & $143.1 \pm 39.4$ & \\
\hline 120 & $171.1 \pm 20.1$ & $164.0 \pm 19.9$ & $131.0 \pm 22.7$ & $122.4 \pm 36.4$ & \\
\hline
\end{tabular}


Table 10. (Continued)

\begin{tabular}{|c|c|c|c|c|c|}
\hline \multirow{2}{*}{$\begin{array}{l}\text { TIME } \\
\text { (min) }\end{array}$} & \multicolumn{4}{|c|}{ Mean Deviations from Controlsa (mg/dl) } & \\
\hline & Spray 3b & Spray $4^{C}$ & Spray $5^{d}$ & Spray $6^{e}$ & \\
\hline 150 & $128.3 \pm 22.5$ & $129.3 \pm 18.8$ & $1) 5.2 \pm 23 .\{1$ & $9 / 6 \pm 31.3$ & \\
\hline 180 & $111.2 \pm 35.5$ & $110.7 \pm 22.7$ & $107.5 \pm 13.2$ & $99.3 \pm 31.9$ & \\
\hline 210 & $91.1 \pm 39.9$ & $92.8 \pm 21.7$ & $62.9 \pm 20.8$ & $78.4 \pm 26.6$ & \\
\hline 240 & $106.3 \pm 50.8$ & $77.9 \pm 21.8$ & $70.4 \pm 19.5$ & $47.3 \pm 20.3$ & \\
\hline 300 & $82.8 \pm 56.6$ & $63.2 \pm 24.6$ & $46.9 \pm 17.1$ & $36.8 \pm 23.9$ & \\
\hline 360 & $47.4 \pm 37.7$ & $33.5 \pm 14.8$ & $14.2 \pm 7.7$ & $28.4 \pm 16.4$ & \\
\hline 420 & $31.4 \pm 14.7$ & $21.1 \pm 6.0$ & 21.0 & $23.2 \pm 0.9$ & \\
\hline
\end{tabular}

a Negative values were not included while determining mean values

b Dose $-10 \mathrm{U} / \mathrm{kg}$ insulin $+1 \% \mathrm{w} / \mathrm{v}$ sodium taurocholate, $\mathrm{n}=3$

c Dose $-5 \mathrm{U} / \mathrm{kg}$ insulin $+1 \% w / v$ sodium taurocholate, $n=5$

d Dose $-2.5 \mathrm{U} / \mathrm{kg}$ insulin $+1 \% \mathrm{w} / \mathrm{v}$ sodium taurocholate, $\mathrm{n}=5$

e Dose $-1.25 \mathrm{U} / \mathrm{kg}$ insulin $+1 \% \mathrm{w} / \mathrm{v}$ sodium taurocholate, $\mathrm{n}=5$ 


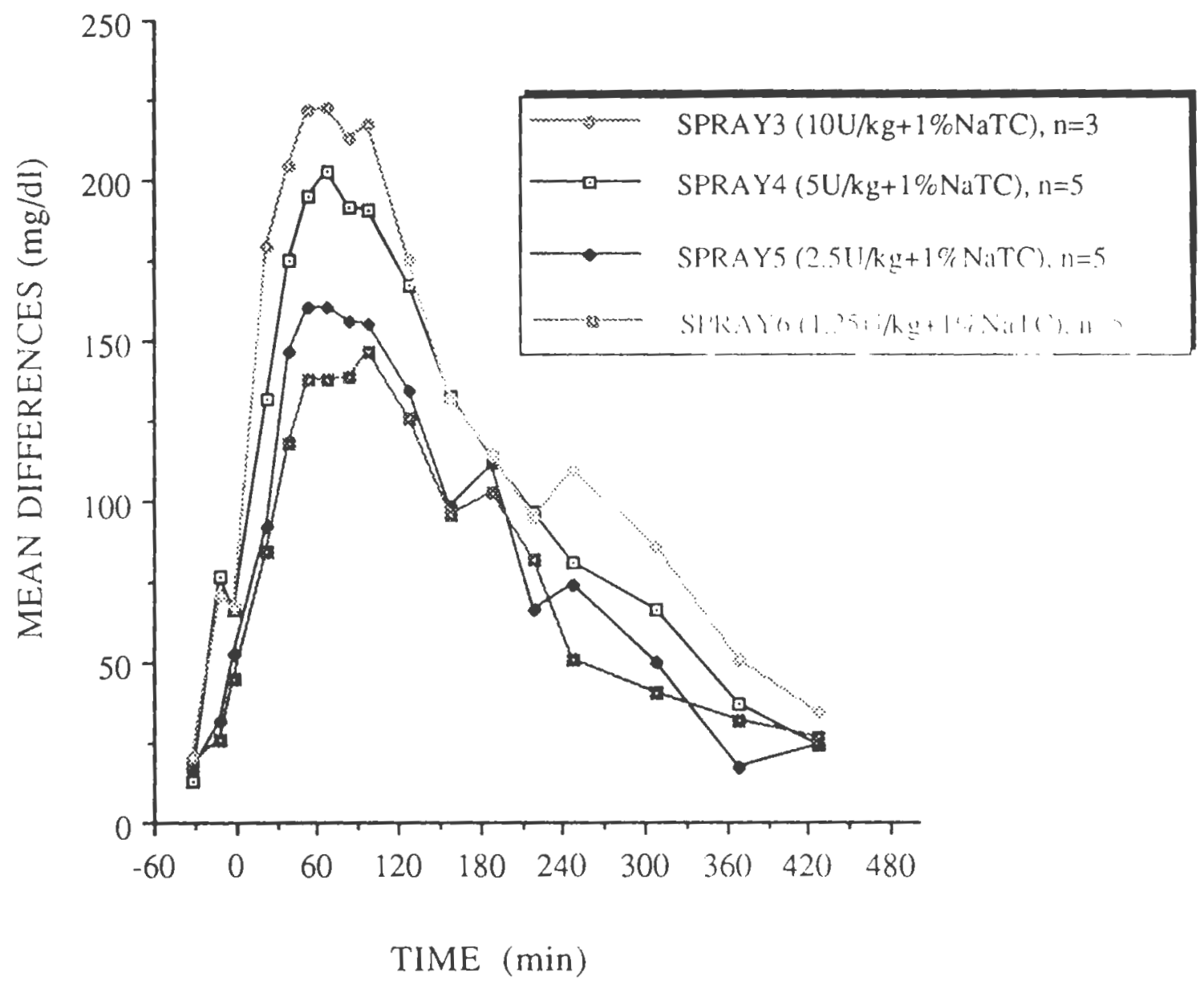

Figure 16. Comparison of Mean Deviations in Glucose Levels From Controls After Administration of Insulin Nasal Spray 
Table 11. Comparison of Mean Deviations in Blood Glucose Levels Compared to Contrals After Adminitration of Insulin

\begin{tabular}{|c|c|c|c|c|}
\hline \multirow{2}{*}{$\begin{array}{l}\text { TIME } \\
\text { (min) }\end{array}$} & \multicolumn{4}{|c|}{ Mean deviations from Controls $(\mathrm{mg} / \mathrm{dl})^{a}$} \\
\hline & subcutaneousb & $\mathrm{Gelc}$ & Perfusionfuenuld & lertusiunlu: \\
\hline-40 & $16.3 \pm 4.2$ & $15.5 \pm 6.5$ & $10.7 \pm 4.4$ & 10.5 \\
\hline-30 & \multicolumn{4}{|c|}{ administration of anesthetics } \\
\hline-20 & $20.5 \pm 18.5$ & 56.0 & $38 \pm 17.6$ & -. \\
\hline-10 & $62.7 \pm 25.5$ & $62.7 \pm 23.2$ & $18.5 \pm 4.5$ & $49.7 \pm 35.6$ \\
\hline 0 & \multicolumn{4}{|c|}{ administration of insulin formulation } \\
\hline 15 & $103.5 \pm 25.5$ & $119.7 \pm 47.4$ & $54 \pm 1.0$ & 13.0 \\
\hline 30 & $76.0 \pm 40.1$ & $128.0 \pm 48.1$ & $47.7 \pm 33.5$ & 34.0 \\
\hline 45 & $92.5 \pm 32.9$ & $127.3 \pm 36.8$ & $39.0 \pm 10.5$ & $50.3 \pm 33.6$ \\
\hline 60 & $97.2 \pm 31.9$ & $124.0 \pm 39.1$ & $75.7 \pm 26.2$ & $48.0 \pm 12.8$ \\
\hline 75 & $115.8 \pm 32.5$ & $112.7 \pm 42.7$ & $100.7 \pm 6.2$ & $79.8 \pm 11.8$ \\
\hline 90 & $139.0 \pm 34.0$ & $116.3 \pm 60.2$ & $112.7 \pm 16.6$ & $112.2 \pm 11.5$ \\
\hline 120 & $152.0 \pm 29.5$ & $116.7 \pm 62.7$ & $81.8 \pm 31.9$ & $137.7 \pm 5.8$ \\
\hline
\end{tabular}




\section{Table $11 . \quad$ (Continued)}

\begin{tabular}{|c|c|c|c|c|}
\hline \multirow{2}{*}{$\begin{array}{l}\text { TIME } \\
\text { (min) }\end{array}$} & \multicolumn{4}{|c|}{ Mean deviations from Controls ${ }^{a}(\mathrm{mg} / \mathrm{dl})$} \\
\hline & Subcutaneous & Gelc & Perfusion(newu)d & Perfusionlul: ie \\
\hline 150 & $130.4 \pm 22.2$ & $83.7 \pm 64.1$ & $91.0 \pm 18.1$ & $163.0 \pm 32.8$ \\
\hline 180 & $122.8 \pm 24.5$ & $116.5 \pm 69.5$ & $85.6 \pm 9.3$ & $147.7 \pm 15.8$ \\
\hline 210 & $92.8 \pm 21.1$ & $84.0 \pm 31.0$ & $56.6 \pm 8.9$ & $127.7 \pm 35.5$ \\
\hline 240 & $81.4 \pm 17.5$ & $47.7 \pm 18.2$ & $62.8 \pm 7.7$ & $138.7 \pm 43.6$ \\
\hline 300 & $51.8 \pm 19.1$ & $36.7 \pm 17.6$ & $11.8 \pm 7.2$ & $131.3 \pm 53.5$ \\
\hline 360 & $19.2 \pm 7.0$ & $27.0 \pm 11.1$ & $19.2 \pm 8.0$ & $140.7 \pm 67.0$ \\
\hline 420 & $6.5 \pm 2.6$ & $26.5 \pm 2.5$ & $18.0 \pm 13.0$ & $115.3 \pm 61.6$ \\
\hline
\end{tabular}

a Negative values were not included while determining mean values

b Dose $-0.25 \mathrm{U} / \mathrm{kg}$ insulin, $n=5$

c Insulin microparticles (10U/kg) in $1 \% w / v$ PAA gel at $\mathrm{pH}-6.0, \mathrm{n}=5$

d Perfusate $(20 \mathrm{ml})$ contained $10 \mathrm{U} / \mathrm{kg}$ insulin and $0.05 \% \mathrm{w} / \mathrm{v}$ NaTC in buffer $(\rho \mathrm{H}-7.4), n=6$

e Perfusate $(20 \mathrm{ml})$ contained $10 \mathrm{U} / \mathrm{kg}$ insulin and $0.05 \% \mathrm{w} / \mathrm{u} \mathrm{NaTC}$ in buffer $(\mathrm{pH}-7.4), n=3$ 


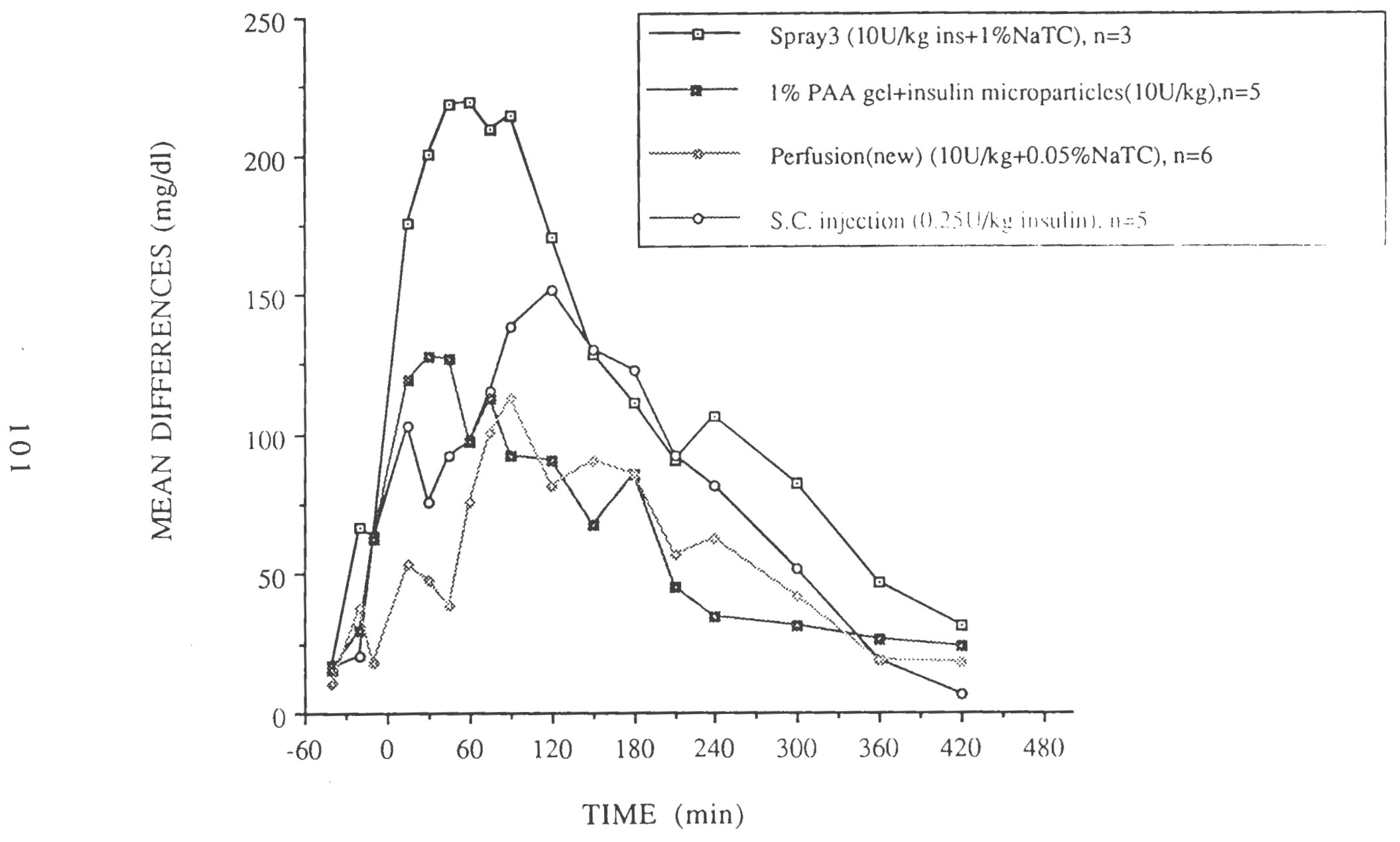

Figure 17. Comparison of Mean Deviations in Glucose Levels From Controls After Administration of Insulin 
Table 12. Comparison of Apparent Pharmacokinetic Parameters After Intranasal Administration of Various Insulin Formulations

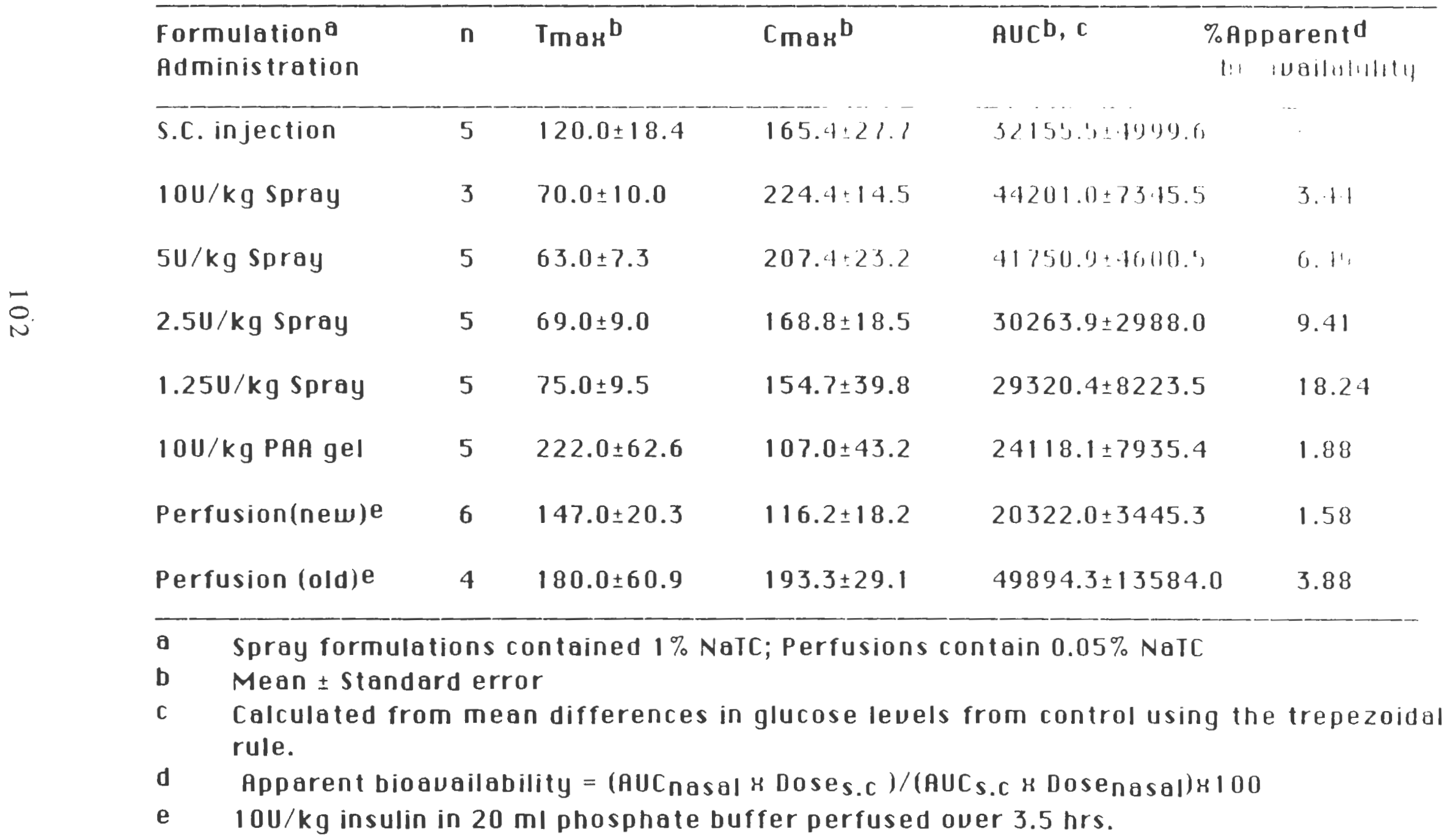


the old method. No significant difference was observed between $t_{\max }$ values observed between the two perfusion techniques. Howver the $t_{\max }$ value for new perfusion technique was significantly different from that obtained for spray formulations.

The values for $\mathrm{C}_{\max }$ showed a gradual decrease as the dose was lowered from $10 \mathrm{U} / \mathrm{kg}$ to $1.25 \mathrm{U} / \mathrm{kg}$. The observed values for $C_{\max }$ for spray $3(10 \mathrm{U} / \mathrm{kg})$, spray $4(5 \mathrm{U} / \mathrm{kg})$, spray $5(2.5 \mathrm{U} / \mathrm{kg})$, spray 6 $(1.25 \mathrm{U} / \mathrm{kg})$ were $224.4 \pm 14.5,207.4 \pm 23.2,168.8 \pm 18.5$ and $154.7 \pm 39.8$ $\mathrm{mg} / \mathrm{dl}$ respectively. No significant differences were observed in $\mathrm{C}_{\mathrm{max}}$ values for the spray formulations. The observed $\mathrm{C}_{\max }$ values for the s.c. injection, gel formulation, the new and old perfusion techniques were found to bel65.4 $\pm 27.7,107.3 \pm 43.2,116.2 \pm 18.2$ and $193.3 \pm 29.1$ $\mathrm{mg} / \mathrm{dl}$ respectively. The $\mathrm{C}_{\max }$ value for spray $4(5 \mathrm{U} / \mathrm{kg})$ was found to be significantly different from that observed for new perfusion technique. No significant differences were observed in $C_{\max }$ values for other formulations.

The area under the curve (AUC) was calculated based on the blood glucose levels as a function of time using trepezoidal rule. The s.c. injection of $0.25 \mathrm{U} / \mathrm{kg}$ of insulin resulted in AUC of $32155.5 \pm 4999.6 \mathrm{mg} / \mathrm{dl}$ minute. For the spray formulations, the AUC gradually increased from $29320.4 \pm 8223.5$ to $44201 \pm 7345.5 \mathrm{mg} / \mathrm{dl}$ minute as the dose was increased from $1.25 \mathrm{U} / \mathrm{kg}$ to $10 \mathrm{U} / \mathrm{kg}$. A plot of AUC vs dose following nasal administration of the spray formulations is given in Figure 18. The graph shows the dose to AUC relationship after intranasal administration of insulin from spray formulations. However, there was no proportional increase in the AUC values when compared to the dose administered. The 


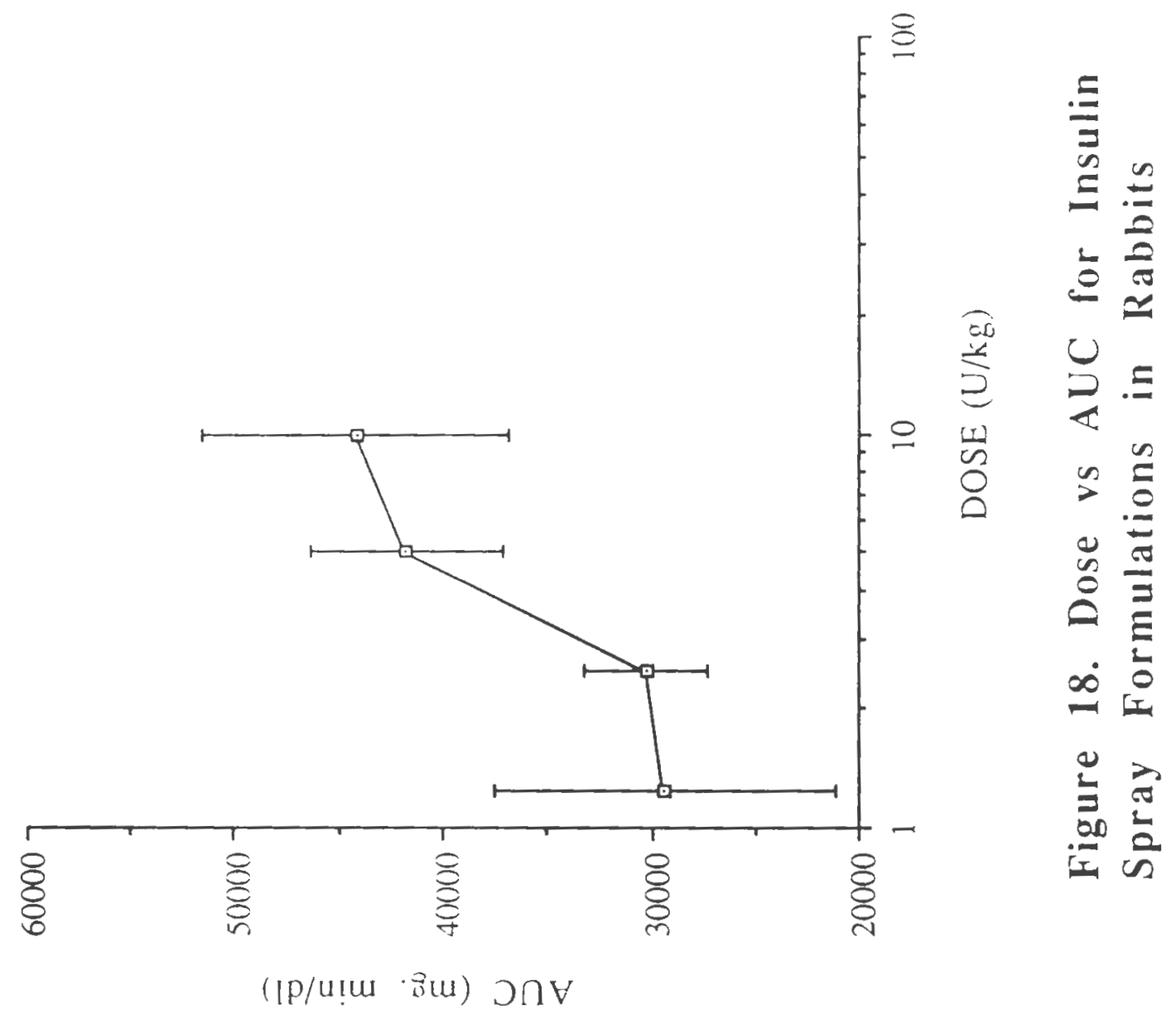


explanations for the nonlinearity observed include a saturable binding and/or metabolism with membrane or enzyme systems. The new perfusion technique resulted in AUC values of 20322.0 23445.3 $\mathrm{mg} / \mathrm{dl}$ minute. The AUC for Spray $4(5 \mathrm{U} / \mathrm{kg})$ was significantly different from that observed for Spray $6(1.25 \mathrm{U} / \mathrm{kg})$ and new perfusion technique. No statistically significant difference was observed between the AUC values for Spray $4(5 \mathrm{U} / \mathrm{kg})$ and s.c. injection $(0.25 \mathrm{U} / \mathrm{kg})$. The gel formulation $(10 \mathrm{U} / \mathrm{kg})$ resulted in lower AUC values as compared to spray $6(1.25 \mathrm{U} / \mathrm{kg})$ and in higher values as compared to that found using the newperfusion

We have compared s.c. and nasal route of insulin administration using response measurements (relative efficacy or apparent bioavailability), rather than plasma insulin concentrations (bioavailability). The merits of using this method are in the simplicity of the plasma glucose determinations and that efficacy (apparent bioavailability) is the parameter most relative to therapeutics. Although relative efficacy could be expected to be similar to bioavailability, this can not be assumed. Table 12 summarizes the apparent pharmacokinetic parameters obtained for the different modes of administration. The apparent bioavailability was calculated assuming that the effect observed for s.c. injection of insulin was $100 \%$. The apparent bioavailabilities observed for spray $3(10 \mathrm{U} / \mathrm{kg})$, spray $4(5 \mathrm{U} / \mathrm{kg})$, spray $5(2.5 \mathrm{U} / \mathrm{kg})$ and spray 6 $(1.25 \mathrm{U} / \mathrm{kg})$ were $3.44,6.49,9.41$ and $18.24 \%$ respectively. The apparent bioavailability increased gradually from spray $3(3.44 \%)$ to spray $6(18.24 \%)$. The relative absorption of insulin was higher for $1.25 \mathrm{U} / \mathrm{kg}$ spray when compared to $10 \mathrm{U} / \mathrm{kg}$ spray. The probable 
reasons for this nonlinearity may be due to the fact that the transport of insulin across the nasal membrane is following saturation kinetics (Anik et al., 1984). In other words, the amount of insulin that could be absorbed across the mucosal membrane is limited and hence an increase in insulin dose did not result in proportional increase in AUC. Insulin loaded PAA microparticles resulted in lower bioavailability $(1.88 \%)$ compared to spray formulations, but a higher bioavailability when compared to the perfusion studies using new technique (1.58\%). 


\section{CONCLUSIONS}

The rabbit was used as an animal model to develop a nonsurgical perfusion technique. Insulin was utilized as a model polypeptide drug. The results of this study indicated that the new non-surgical perfusion technique can be used to evaluate the nasal absorption potential of insulin in rabbits. The new non-surgical perfusion technique was compared with that developed by Mehta et al. (1990). The absorption of insulin was measured by the changes observed in blood glucose levels. Various nasal formulations were also evaluated using the rabbit as an animal model. The apparent bioavailabilities for the various formulations/dosage forms were determined based on the effect observed after subcutaneous injection of insulin. The results of this investigation can be summarized as follows:

(1) A new non-surgical perfusion technique was developed and established using the rabbit as animal model.

(2) The new non-surgical perfusion technique was comparable to the existing non-surgical perfusion technique. The new technique was found to offer certain advantages compared to the old one. These include reusability of the animal, simplicity of the technique and reproducibility of the results. Further studies are required to completely characterize this new technique.

(3) The study conditions needed to characterize the rabbit model during the perfusion studies were identified. These include the angle 
at which rabbit head is placed, the perfusion rate, the volume of the perfusate, the amount of the enhancer present in the perfusion solution and the $\mathrm{pH}$ of the solution.

(4) Spray formulations containing different levels of insulin were evaluated in the same animal model. The nasal sprays administered by spray pump resulted in immediate reduction of glucose levels. The maximum hypoglycemic effect was observed approximately 60 minutes after administration. As the dose was increased from 1.5 $\mathrm{U} / \mathrm{kg}$ to $10 \mathrm{U} / \mathrm{kg}$, there was an increased reduction in blood glucose levels. However, the glucose reduction was not proportional to the insulin dose. The PAA gel formulation containing insulin loaded microparticles resulted in a hypoglycemic effect but the overall effect was less compared to the spray formulations. As expected the subcutaneous injection of insulin $(0.25 \mathrm{U} / \mathrm{kg})$ resulted in slower absorption of insulin when compared to nasal sprays.

(5) The spray formulations tested caused a higher hypoglycemic effect when compared to perfusion solutions most probably due to higher amount of enhancer present in the spray formulations.

(6) The apparent bioavailability was calculated based on the AUC values obtained from the mean differences in glucose levels from those of the controls. The apparent bioavailability increased for spray formulations as the dose of insulin was decreased. A maximum apparent bioavailability of $18.8 \%$ was observed at a dose of 1.25 
$\mathrm{U} / \mathrm{kg}$. The lowest values were observed for the perfusion study carried out by the new technique.

(7) A split-plot design was used to evaluate the treatment effects.

When compared to the controls, sprays, insulin loaded PAA microparticles, s.c. and perfusion experiments resulted in significant reductions in blood glucose levels at $95 \%$ confidence level. 


\section{BIBLIOGRAPHY}

Adjei, A., Bioavailability of leuprolide acetate following nasal delivery to healthy humans. Abstract. Pharmaceutical Research, 7(9 Suppl): S115 (1990).

Anand Kumar, T. C., David, G. F., Sankarnarayanan, A., Puri, V., and Sundram, K. R., Pharmacokinetics of progesterone after its administration to overiectomized rhesus monkeys by injection, infusion, or nasal spraying. Proceedings of National Academy of Sciences USA, 79: 4185-4189 (1982).

Anik, S.T., McRae, G., Nerenberg, C., Worden, A., Foreman, J., Hwang, J. Y., Kushinsky, S., Jones, R. E., and Vickery, B., Nasal absorption of Nafarelin acetate, the decapeptide [D-Nal $\left.(2)^{6}\right]$ LHRH, in rhesus monkeys 1. Journal of Pharmaceutical Sciences, 73(5): 684-685 (1984).

Aoki, F. Y., and Crawley, J. C. W., Distribution and removal of human albumin-technitium $99 \mathrm{~m}$ instilled intranasally. British Journal of Clinical Pharmacy, 3: 869-878 (1976).

Audhya, T., and Goldstein, G., Comparative efficacy of various routes of administration of thymopentin (TP-5) with consideration of degradative mechanisms. International Journal of Peptide Protein Research, 22: 187-193 (1983). 
Aungst, B. J., Rogers, N. J., and Shefter, E., Comparison of nasal, rectal, buccal, sublingual and intramascular insulin efficay and the effects of a bile salt absorption promoter. Journal of Pharmacy and Experimental Therapeutics, 244(1): 23-27 (1987).

Baldwin, P. A., Klinbeil, C. K., Grimm, C. J., and Longenecker, J. P., The effect of sodium tauro-24,25-dihydrofusidate on the nasal absorption of human growth hormone in three animal models. Pharmaceutical Research, 7(5): 547-552 (1990).

Banga, A. K., and Chien, Y. W., Systemic delivery of therapeutic peptides and proteins. International Journal of Pharmaceutics, 48: $15-50$ (1988).

Birket, D., and Silen, W., Alteration of the physical pathways through the gastric mucosa by sodium taurocholate. Gastroenterology, 67: $1131-1138(1974)$.

Bjork, E., and Edman, P., Degradable starch microspheres as a nasal delivery system for insulin. International Journal of Pharmaceutics, 47: 233-238 (1988).

Bond, S. W., Hardy, J. G., and Wilson, C. G., Deposition and clearance of nasal sprays. Proceedings of 2 nd European Congress of Biopharmaceutics and Pharmacokinetics, Salamanca, 1: 93-98 (1984). 
Borchardt, R. T., Mazer, N. A., Rytting, J. H., Shek, E., Ziv, E., and Touitou, E., The delivery of peptides. Journal of Pharmaceutical Sciences, 78(11): 883-892 (1989).

Brown, S. A., Nelson, R. W., and Bottoms, G. D., Models for the pharmacokinetics and pharmacodynamics of insulin in alloxaninduced diabetic dogs. Journal of Pharmaceutical Sciences, 76(4): 295-299 (1987).

Chien, Y. W., and Chang, S. F., 'Historic development of transnasal systemic medications' In Transnasal Systemic Medications, Chien, Y.W. (Ed.), Elsevier, New York,1-100 (1985).

Chien, Y. W., and Su, K. S. E., Intranasal drug delivery for systemic medications, CRC Critical Reviews of Therapeutic Drug Carrier Systems, 4(2): 83-85 (1987).

Chien, Y. W., Su, K. S. E., and Chang, S. F. (Eds.), Nasal systemic drug delivery, Marcel Dekker, Newyork (1989).

Chien, Y. W., and Banga, A. K., Potential developments in systemic delivery of insulin. Drug Development and Industrial Pharmacy, 15(10): 1601-1634 (1989a).

Chiou, G. C. Y., and Chuang, C. Y., Improvement of systemic absorption of insulin through eyes with absorption enhancers. Journal of Pharmaceutical Sciences, 78(10) : 815-818 (1989). 
Colaizzi, J. L., 'Pharmacokinetics of intranasal drug administrations' In Transnasal Systemic Medications, Chien, Y.W. (Ed.), Elsevier, New York, p107-118 (1985).

Corbo, D. C., Huang, Y. C, and Chien, Y. W., Nasal delivery of progestational steroids in ovariectomized rabbits. I. Progesterone Comparison of pharmacokinetics with intravenous and oral administration. International Journal of Pharmaceutics, 46: 133-140 (1988).

Corbo, D. C., Liu, J. C., and Chien, Y. W., Characterization of the barrier properties of mucosal membranes. Journal of Pharmaceutical Sciences, 79(3): 202-206 (1990).

Crane, C. W., Path, M. C., and Luntz, G. R. W. N., Absorption of insulin from the human small intestine. Diabetes 17: 625-627 (1968).

Damge, C., Michel, C., Aprahamian, M., Couvreur, P., and Devissaguet, J. P., Nanocapsules as carriers for oral peptide delivery. Journal of Controlled Release, 13: 233-239 (1990).

David, G. F. X., Puri, C. P., and Anand Kumar, T. C., Bioavailability of progesterone enhanced by intranasal spraying. Experientia 37: 533534 (1981). 
Davis, S. S., 'Advanced delivery systems for peptides and proteinspharmaceutical considerations' in Delivery Systems for Peptide Drugs, Davis, S. S., Illum, L., and Tomlinson, E. (Eds.), Plenum Press, New York, 1-2l (1989).

Deurloo, M. L, Hermens, W. A., and Romeyn, S. G., Absorption enhancement of intranasly administered insulin by sodium taurodihydrofusidate (STDHF) in rabbits and rats. Pharmaceutical Research, 6: 853-856 (1989).

De Boer, A. G., van Hoogdalem, E. J., Heijligers-Feijen, C. D., Verhoef, J., and Breimer, D. D., Rectal absorption enhancement of peptide drugs. Journal of Controlled Release, 13: 241-246 (1990).

Duchateau, G. S. M. J. E., Zuidema, J., and Merkus, F. W. H. M., Bile salts and intranasal drug absorption. International Journal of Pharmaceutics, 31: 193-199 (1986).

Faraj, J. A., Hussain, A. A., Aramaki, Y., Iseki, K., Kagoshima, M., and Dittert, L. W., Mechanism of nasal absorption of drugs. III: Nasal absorption of leucine enkephalin. Journal of Pharmaceutical Sciences, 79(8): 698-702 (1990a).

Faraj, J. A., Hussain, A. A., Aramaki, Y., Iseki, K., Kagoshima, M., and Dittert, L. W., Mechanism of nasal absorption of drugs IV: Plasma levels of radioactivity following intranasal administration of leucine 
enkephalin. Journal of Pharmaceutical Sciences, 79(8): 698-702 (1990b).

Farraj, N. F., Johansen, B. R., Davis, S. S., and Illum, L., Nasal administration of insulin using bioadhesive microspheres as a delivery system. Journal of Controlled Release, 13: 253-261 (1990).

Fink, G., Gennser, G., Liedholm, P., Thorell, J. and Mulders, J., Comparison of plasma levels of luteinizing hormone releasing hormone in men after intravenous or intranasal administration. Journal of Endocrinology, 63: 351-360 (1974).

Geurkink, N., Nasal anatomy, physiology, and function. Journal of Allergy Clinical Immunology, 72: 123-128 (1983).

Gibaldi, M., Role of surface-active agents in drug absorption. Federation Proceedings, 29(4): 1343-1349 (1970).

Gibaldi, M., and Feldman, S., Mechanisms of surfactant effects on drug absorption. Journal of Pharmaceutical Sciences, 59(5): 579-589 (1970).

Gonda, I., and Gipps, E., Model of disposition of drugs administered into the human nasal cavity. Pharmaceutical Research, 7(1): 69-75 (1990). 
Gopinath, P. G., Gopinath, G., and Anand Kumar, T. C., Target site of intranasally sprayed substances and their transport across the nasal mucosa: A new insight into the intranasal route of drug delivery. Current Therapeutic Research, 23(5): 596-607 (1978).

Gordon, G. S., Moses, A. C., Silver, R. D., Flier, J. S., and Carey, M. C., Nasal absorption of insulin : Enhancement by hydrophobic bile salts. Proceedings of National Academy of Sciences USA, 82 : 7419-7423 (1985).

Hardy, J. G., Lee, S. W., and Wilson, C. G., Intranasal drug delivery by spray and drops. Journal of Pharmacy and Phrmacology, 37: 294-297 (1985).

Harris, A. S., Ohlin, M., Svensson, E., Lethagen, S., and Nilsson, I. M., Effects of concentration and volume on bioavailability and biological response to intranasal desmopressin. Journal of Pharmaceutical Sciences, 77: 337-339 (1988).

Harris, A. S., Ohlin, M., Svensson, E., Lethagen S., and Nilsson, I. M., Effect of viscosity on the pharmacokinetics and biological response to intranasal desmopressin. Journal of Pharmaceutical Sciences, 78(6): 470-471 (1989).

Harris, A. S., 'Biopharmaceutical aspects on the intranasal administration of peptides' in Delivery Systems for Peptide Drugs, 
Davis, S. S., Illum, L., and Tomlinson, E. (Eds.), Plenum Press, New York, 191-204 (1989).

Hayashi, M., Hirasawa, T., Muraoka, T., Shiga, M., and Awazu, S., Comparison of water influx and sieving coefficient in rat jejunal, rectal and nasal absorptions of antipyrine. Chemical Pharmaceutical Bulletin, 33(5): 2149-2152 (1985).

Hermens, W. A. J. J, Deurloo, M. J. M., Romeyn, S. G., Verhoeh, J. C., and Merkus, F. W. H. M., Nasal absorption enhancement of 17Bestradiol by dimethyl- $B$-cyclodextrin in rabbits and rats. Pharmaceutical Research, 7(5): 500-503 (1990).

Hermens, W. A., Hooymans, P. M., and Verhoef, J. C., Effects of absorption enhancers on human nasal tissue ciliary movement in vitro. Pharmaceutical Research, 7(2):144-146 (1990).

Hicks, C. R., (Editor) Fundamental Concepts in the Design of Experiments, Holt, Rinehart and Winston, New York, 3rd edition (1982).

Hirai, S., Ikenaga, T., and Matsuzawa, T., Nasal absorption of insulin in dogs. Diabetes, 27(3): 296-299 (1978).

Hirai, S., Yashiki, T., Matsuzawa, T., and Mima, H., Absorption of drugs from the nasal mucosa of rat. International Journal of Pharmaceutics, 7: 317-325 (1981). 
Hirai, S., Yashiki, T amd Mima, T., Effect of surfactants on the nasal absorption of insulin in rats. International Journal of Pharmaceutics, 9:165-172 (1981a).

Hirai, S., Yashiki, T., and Mima, H., Mechanisms for the enhancement of the nasal absorption of insulin by surfactants. International Journal of Pharmaceutics, 9: 173-184 (1981b).

Hori, R., Komada, F., Okumura, K., Pharmaceutical approach to subcutaneous dosageforms of insulin. Journal of Pharmaceutical Sciences, 72(4) : $435-439$ (1983).

Huang, C. H., Kimura, R., Bawarshi-Nassar, R., and Hussain, A., Mechanism of nasal absorption of drugs I: Physicochemical parameters influencing the rate of in situ nasal absorption of drugs in rats. Journal of Pharmaceutical Sciences, 74(6): 608-611 (1985).

Huang, C. H., Kimura, R., Bawarshi-Nassar, R., and Hussain, A., Mechanism of nasal absorption of drugs II: Absorption of tyrosine and the effect of structural modification on its absorption. Journal of Pharmaceutical Sciences, 74(12): 1298-1300 (1985a).

Hussain, A., Hirai, S., and Bawarshi, R., Nasal absorption of propranolol in rats. Journal of Pharmaceutical Sciences, 68(9):1196 (1979). 
Hussain, A., Hirai, S., and Bawarshi, R., Nasal Absorption of Propranolol from different dosage forms by rats and dogs. Journal of Pharmaceutical Sciences, 69(12): 1411-1413 (1980).

Hussain, A., Foster, T., Hirai, S., and Kashiara, T., Nasal absorption of propranolol in humans. Journal of Pharmaceutical Sciences, 70: 466467 (1981).

Hussain, A., Kimura, R., Huang, C. H., and Kashihara, T., Nasal absorption of naloxone and buprenorphine in rats. International Journal of Pharmaceutics, 21: 233-237 (1984).

Hussain, A., Faraj, J., Aramaki, Y., and Truelove, J. E., Hydrolysis of leucine enkephalin in the nasal cavity of the rat - a possible factor in the low availability of nasally administered peptides. Biochemical and Biophysical Research Communications, 133(3): 923-928 (1985).

Hussain, A., 'Mechanism of nasal absorption of drugs' In Biological and synthetic membranes. Alan R. Liss Inc. (1989).

Hussain, A., Rakestraw, D., Rowe, S., and Aungst, B.J., Nasal administration of a cognition enhancer provides improved bioavailability but not enhanced brain delivery.Journal of Pharmaceutical Sciences, 79(9): 771-772 (1990).

Igawa, T., Maitani, Y., Machida, Y., Nagai, T., Effect of absorption promoters in intranasal administration of human fibroblast 
interferon as a powder dosage form in rabbits. Chemical Pharmaceutical Bulletin, 37(2): 418-421 (1989).

Illum, I., Jorgensen, H., Bisgaard, H., Krogsgaard, O., and Rossing, N., Bioadhesive microspheres as a potential nasal drug delivery system. International Journal of Pharmaceutics, 39: 189-199 (1987).

Illum, L., Farraj, N., Critchley, H., and Davis, S. S., Nasal administration of gentamicin using a novel microsphere delivery system, International Journal of Pharmaceutics, 46: 261-265 (1988).

Ishida, M., Machida, Y., Nambu, N., and Nagai, T., New mucosal dosage form of insulin. Chemical Pharmaceutical Bulletin, 29(3): 810-816 (1981).

Jafek, B. W., Ultrastructure of human nasal mucosa. Laryngoscope, 93: 1576-1599(1983).

Jagannadha Rao, A., Moudal, N. R., and Li, C. H., ß-Endorphin: Intranasal administration increases the serum prolactin level in monkey. International Journal of Peptide Protein Research, 28: 546548 (1986).

Kahn, C. R., and Shechter, Y., 'Insulin, oral hypoglycemic agents, and the pharmacology of the endocrine pancreas' In Goodman and Gilman's The Pharmacological Basis of Therapeutics, Pergamon Press, New York, 8th Edition, Chapter 61 (1990). 
Karnes, H. T., Shiu, G., and Shah, V. P., Validation of bioanalytical methods. Pharmaceutical Research, 8(4): $421-426$ (1991).

Katzung, B. G., (Ed.) Basic and clinical pharmacology, 4th edition, Appleton\&Lange, California. Chapter 24: 312-314 (1989).

Lau, S. W. J., and Slattery, T., Absorption of diazepam and lorazepam following intranasal administration. International Journal of Pharmaceutics, 54: 171-174 (1989).

Lee, V. H. L., Petide and protein drug delivery systems. BioPharm, 1(3): 24-31 (1988).

Lee, V. H. L., Trends in peptide and protein drug delivery. BioPharm, 4(3): $22-25$ (1991).

Lee, W. A., Permeation enhancers for the nasal delivery of protein and peptide therapeutics. BioPharm 3(10): 22-25 (1990).

Lee, W. A., and Longenecker, J. P., Intranasal delivery of proteins and peptides. BioPharm, 1(4): 30-37 (1988).

Lewis, H. J., and Kellaway, I. W., In-vitro investigation of the potential of mucoadhesive microspheres for the controlled nasal delivery of oxytocin. Journal of Pharmacy and Pharmacology, 42(Suppl.): 142P (1990). 
Lewis, H. J., and Kellaway, I. W., Nasal delivery of mucoadhesive polymers. Proceedings of the International Symposium on Controlled Release of Bioactive Materials, Controlled Release Society, Inc., 17: 289-290 (1990).

Longenecker, J. P., Moses, A. C., Flier, J. S., Silver, R. D., Carey, M. C., and Dubovi, E. J., Effects of sodium taurodihydrofusidate on nasal absorption of insulin in sheep. Journal of Pharmaceutical Sciences, 76(5): $351-355$ (1987).

Longenecker, J. P., 'Nazlin R - Transnasal systemic delivery of insulin' In Peptide drug delivery' in Delivery Systems for Peptide Drugs, Davis, S. S., Illum, L., and Tomlinson, E. (Eds.), Plenum Press, New York, 211-220 (1989).

Maitani, Y., Igawa, T., Machida, Y., and Nagai, T., Plasma levels following intranasal and intravenous administration of human interferon- $B$ to rabbits. Drug Design Delivery, 4(2): 109-119 (1989).

Maitani, Y., Machida, Y., and Nagai, T., Influence of molecular weight and charge on nasal absorption of dextran and DEAE-dextran in rabbits, International Journal of Pharmaceutics, 49: 23-27 (1989).

Martin, G. P., Marriott, C., and Kellaway, I. W., Direct effect of bile salts and phospholipids on the physical properties of mucus. Gut 19: 103-107 (1978). 
Martin, G. P., and Marriott, C., Membrane damage by bile salts: the protective function of phospholipids. Journal of Pharmacy and Pharmacology, 31: 754-759 (1981).

McMartin, C., Hutchinson, L. E. F., Hyde, R., and Peters, G. E., Analysis of structural requirements for the absorption of drugs and macromolecules from the nasal cavity, Journal of Pharmaceutical Sciences, 76(7): 535-540 (1987).

Mehta, R. C., Gokhale, R. D., Farhadieh, B., and Needham, T. E., A novel non-surgical technique for intranasal perfusion in rabbits.

Pharmaceutical Research, 7(9 Suppl.): S115 (1990).

Michel, C., Aprahamian, M., Defontaine, L., Couvreur, P., and Damge, C., The effect of site of administration in the gastrointestinal tract on the absorption of insulin from nanocapsules in diabetic rats. Journal of Pharmacy and Pharmacology, 43: 1-5 (1991).

Morimoto, K., Kamiya, E., Takeeda, T., Nakamoto, Y., and Morisaka, K., Enhancement of rectal absorption of insulin in polyacrylic acid aqueous gel bases containing long chain fatty acid in rats. International Journal of Pharmaceutics, 14: 149-157 (1983).

Morimoto, K., Morisaka, K., and Kamada, A., Enhancement of nasal absorption of insulin and calcitonin using polyacrylic acid gel. Journal of Pharmacy and Pharmacology, 37: 134-136 (1985). 
Morimoto, K., Akatsuchi, H., Aikawa, R., Morishita, M., and Morisaka, K., Enhanced rectal absorption of $\left[\mathrm{Asu}^{1,7}\right]$-eel calcitonin in rats using polyacrylic acid aqueous gel base. Journal of Pharmaceutical Sciences, 73(10): 1366-1368 (1984).

Moses, A. C., Gordon, G. S., Carey, M. C., and Flier, J. S., Insulin administered as an insulin-bile salt aerosol-Effectiveness and reproducibility in normal and diabetic subjects. Diabetes, 32: 10401047 (1983).

Nagai, T., Nishimoto, Y., Nambu, N., Suzuki, Y., and Sekine, K., Powder dosage form of insulin for nasal administration. Journal of Controlled Release, 1: 15-22 (1984).

Nagai, T., Topical mucosal adhesive dosage forms. Medical Research Reviews., 6(2): 227-242 (1986).

Olanoff, L. S., and Gibson, R., Method to Enhance Intranasal Peptide Delivery In Control Release Society, Americn Chemical Society, Chapter 22: 301-309 (1987).

Phillpotts, R. J., Davies, H. W., Willman, J., Tyrrell, D. A. J., and Higgins, P. G., Pharmacokinetics of intranasally applied medication during a cold. Antiviral Research, 4: 71-74 (1984). 
Pontiroli, A. E., Alberetto, M., Secchi, A., Dossi, G., Bosi, I., and Pozza, G., Insulin given intranasally induces hypoglycaemia in normal and diabetic subjects. British Medical Journal, 284: 303-306 (1982).

Pontiroli, A. E., Calderara, A., and Pozza, G., Intranasal drug deliverypotential advantages and limitations from a clinical pharmacokinetic perspective. Clinical Pharmacokinetics, 17(5): 299-307 (1989).

Pontiroli, A. E., Intranasal administration of calcitonin and of other peptides: Studies with different promoters. Journal of Controlled Release, 13: 247-251 (1990).

Pontiroli, A. E., and Pozza, G., Intranasal administration of peptide hormones: Factors affecting transmucosal absorption. Diabetes, 40: 770-774 (1991).

Raehs, S. C., Sandow, J. Wirth, K. and Merkle, H. P., The adjuvant effect of bacitracin on nasal delivery of gonadorelon and buserelin in rats. Pharmaceutical Research, 5(11): 689-693 (1988).

Sandow, J., Herling, A. W., Schmiedel, R., and Seidel, H., "Routes of peptide drug delivery" In 'Topics in Pharmaceutical Sciences', Breimer, D. D. and Speiser, P. Eds., Elsevier Science Publishers B. V. (1987).

Su, K. S. E., Campanale, K. M., Mendelsohn, L. G., Kerchner, G. A., and Gries, C. L., Nasal delivery of polypeptides I: Nasal absorption of 
enkephalins in rats. Journal of Pharmaceutical Sciences, 74(4): 394398 (1985).

Su, K. S .E., 'Nasal absorption of enkephalins in rats' in Delivery Systems for Peptide Drugs, Davis, S. S., Illum, L., and Tomlinson. E. (Eds.), Plenum Press, New York, 221-232 (1989).

Tengamnuay, P., and Mitra, A. K., Bile salt-fatty acid mixed micelles as nasal absorption promoters of peptides. Pharmaceutical Research, 7(2): $127-133$ (1990).

Tomlinson, E., Davis, S. S., and Illum, L., 'Key issues in the delivery of peptides and proteins' in Delivery Systems for Peptide Drugs, Davis, S. S., Illum, L., and Tomlinson. E. (Eds.), Plenum Press, New York, 191 204 (1989).

Touitou, E., Donbrow, M., and Rubinstein, A., Effective intestinal absorption of insulin in diabetic rats using a new formulation approach. Journal of Pharmacy and Pharmacology, 32: 108-110 (1980).

Tzagournis, M., and Skillman, T. G., Diabetes mellitus: An overview, The Upjohn Company, 1-36 (1989).

Verhoef, J., Deurloo, MJ., Hermens, W., and Merkus, F.W. H. M., Absorption enhancement of intrnasally administered insulin by STDHF in rabbits and rats. Proceedings of the International 
Symposium on Controlled Release Bioactive Materials, 30: 85-86 (1989).

Yamakawa, I., Kawahara, M., Watanabe, S., and Miyake, Y., Sustained release of insulin by double-layered implant using poly(D,L-lactic acid). Journal of Pharmaceutical Sciences, 79(6): 505-509 (1990).

Zhou, X. H., Po, A. L. W., Effects of cholic acid and other enhancers on the bioavailability of insulin from a subcutaneous site. International Journal of Pharmaceutics, 69: 29-41 (1991).

Zia, H., Dondeti, P., Greenly, H., and Luzzi, L. A., New approach for intranasal delivery of peptides I. Nasal absorption of insulin in rabbits. Abstract, Pharmaceutical Research, 6(9): S89 (1989). 